\title{
Multifunctional and smart Er203-ZnO nanocomposites for electronic ceramic varistors and visible light degradation of wastewater treatment
}

Thekrayat Hassan AlAbdulaal ( $\nabla$ talabdulaal@kku.edu.sa )

King Khalid University https://orcid.org/0000-0002-4478-9985

Manal AlShadidi

King Khalid University

Mai Hussien

Ain Shams University

Ganesh Vanga

King Khalid University

Abdel-Fatah Bouzidi

University of Sfax: Universite de Sfax

Saqib Rafique

Swansea University

Hamed Algarni

King Khalid University

Heba Zahran

King Khalid University

Mohamed Shaaban Abdel-wahab

King Abdulaziz University

Ibrahim Yahia

King Khalid University

\section{Research Article}

Keywords: Er2O3-doped ZnO Nanocomposites, combustion approach, optical energy bandgaps, electrical characteristics, diffused reflectance, photocatalytic.

Posted Date: May 3rd, 2021

DOI: https://doi.org/10.21203/rs.3.rs-320749/v1 
License: (c) (i) This work is licensed under a Creative Commons Attribution 4.0 International License. Read Full License

Version of Record: A version of this preprint was published at Environmental Science and Pollution Research on October 28th, 2021. See the published version at https://doi.org/10.1007/s11356-02116754-6. 


\title{
Multifunctional and smart $\mathrm{Er}_{2} \mathrm{O}_{3}-\mathrm{ZnO}$ nanocomposites for electronic ceramic varistors and visible light degradation of wastewater treatment
}

\author{
Thekrayat AlAbdulaal $^{1 *}$, Manal AlShadidi ${ }^{1,}$ Mai Hussien ${ }^{2,3}$, Ganesh Vanga ${ }^{1}$, Abdel-Fatah Bouzidi ${ }^{4}$, Saqib \\ Rafique $^{5}$, Hamed Algarni ${ }^{1}$, Heba Zahran ${ }^{1,3}$, Mohamed Abdel-wahab ${ }^{6}$, Ibrahim Yahia ${ }^{1,3,7}$ \\ ${ }^{1}$ Department of Physics, Faculty of Science, King Khalid University, P.O. Box 9004, Abha, Saudi Arabia \\ ${ }^{2}$ Department of Chemistry, Faculty of Education, Ain Shams University, Roxy, 11757 Cairo, Egypt. \\ ${ }^{3}$ Nanoscience Laboratory for Environmental and Bio-medical Applications (NLEBA), Semiconductor Lab., \\ Metallurgical Lab.1. Department of Physics, Faculty of Education, Ain Shams University, Roxy, 11757 Cairo, Egypt. \\ ${ }^{4}$ Research Unit, Physics of Insulating and Semi-insulating Materials, Faculty of Sciences, University of Sfax, \\ B.P.1171, 3000 Sfax, Tunisia. \\ ${ }^{5}$ Multidisciplinary Nanotechnology Centre, College of Engineering, Swansea University, Swansea SA1 8EN, United \\ Kingdom. \\ ${ }^{6}$ Center of Nanotechnology, King Abdulaziz University, Jeddah, 21589, Saudi Arabia. \\ ${ }^{7}$ Research Center for Advanced Materials Science (RCAMS), King Khalid University, Abha 61413, P.O. Box 9004, \\ Saudi Arabia.
}

\section{Abstract}

In this proposed study, Erbium $\left(\mathrm{Er}^{3+}\right)$-doped $\mathrm{ZnO}$ nanocomposites were prepared through the effective, basic, and green combustion method. The significant effects of Er-dopants on the structural, morphological features, dielectric and optical behaviors of the pure $\mathrm{ZnO}$ matrix as well as $\mathrm{Er}_{2} \mathrm{O}_{3}-\mathrm{ZnO}$ nanostructured materials were investigated applying X-ray diffraction (XRD), scanning electron microscopy (SEM), Fourier transformation Infrared spectroscopy (FTIR), and $\mathrm{UV}-\mathrm{Vis}$ spectrophotometer techniques. These results showed that the synthesized $\mathrm{Er}_{2} \mathrm{O}_{3}-\mathrm{ZnO}$

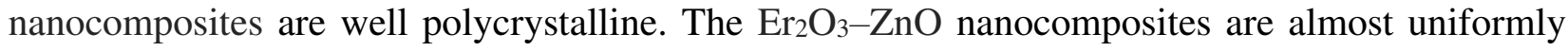
distributed on the surface morphologies. Furthermore, UV-Vis diffuse reflectance spectroscopy, AC electrical conductivity, and dielectric properties' current-voltage characteristics were utilized to examine the influence of erbium-doping on the optical properties, energy bandgaps of the proposed $\mathrm{Er}_{2} \mathrm{O}_{3}-\mathrm{ZnO}$ nanostructured powder. The tested nano-samples were applied for the visible light photodegradation of p-chlorophenol (4-CP) and p-nitrophenol (4-NP). The Er-doped $\mathrm{ZnO}$ ratio affects the photocatalytic activity of the $\mathrm{ZnO}$ matrix. This current research substantiated that more than $99.5 \%$ of $4-\mathrm{CP}$ and 4-NP were photodegraded through 30 min of irradiation. Four times, the Er: $\mathrm{ZnO}$ nanocatalysts were used and still displayed an efficiency of more than $96.5 \%$ for $4-\mathrm{CP}$ and 4-NP degradations in the specified period $=30 \mathrm{~min}$. The as-prepared $\mathrm{Er}_{2} \mathrm{O}_{3}-\mathrm{ZnO}$ nanostructured are 
considered novel potential candidates in broad nano-applications from visible photocatalytic degradation of waste pollutants to the electronic varistor devices.

\section{Keywords:}

$\mathrm{Er}_{2} \mathrm{O}_{3}$-doped $\mathrm{ZnO}$ Nanocomposites, combustion approach, optical energy bandgaps, electrical characteristics, diffused reflectance, photocatalytic.

*Corresponding author: Thekrayat Hassan AlAbdulaal*

Tel.: +966-54080-6213

Email Address: drthekra88888@gmail.com, talabdulaal@kku.edu.sa 


\section{Introduction}

The nanocrystals are promising candidates to be used as a technological material in different applications, such as bioimaging, solar cells, and tunable lasers, which eventually have a strong dependence on controlling the nanocrystals 'properties through adding impurities as a dopant (Michalet et al. 2005). It is reported that the impurities could potentially adjust structure morphology, magnetic, optical, and electronic properties of bulk semiconductor materials. Material science research mostly focuses on different types of semiconductors taking advantage of their exceptional optical and electronic characteristics. Last decades, the research of semiconductor materials with one-dimensional (1D) has engrossed extremely intense attention due to the electrical, physical, chemical, and magnetic characteristics with dimensionality-dependent in nanoscale. The different 1D nanoscale semiconductor has been produced and also investigated, including III-V group, carbon group, II-VI group, as well as oxide group materials (Calarco 2005; Iijima and Ichihashi 199; Vayssieres 2003; Mor et al. 215). Among those various unique 1D nanoscale oxides, zinc oxide $(\mathrm{ZnO})$ materials have been considered as a great potential candidate to own a structure of n-type wurtzite, considerable energy of exciton binding with $60 \mathrm{meV}$, and a broad-ranging optical energy bandgap of $3.37 \mathrm{eV}$ at ambient temperature. The outstanding transparent and piezoelectric properties of $\mathrm{ZnO}$ semiconductor materials have extended the range of high technology in various applications, including transparent electrodes and wave filters of surface acoustic ( Lee et al. 2004). Both zinc interstitials or oxygen vacancies perform significant roles in n-type semiconductor dopants, mainly affecting chemical and physical properties (Zeng et al. 2010; Djurisic et al. 2010; Unalan et al. 2008; Willander et al. 2009).

In recent decays, $\mathrm{ZnO} 1 \mathrm{D}$ nanostructures (NSs), including nanotubes, nanorods, nanowires (NWs), and nanobelts, are promising candidates to be applied widely in technological applications for nanoscale photoelectronic devices, such as light-emitting diodes (LEDs), piezoelectric nanogenerators, gas sensors, photovoltaic cells, photodetectors, biosensors, and field emission devices (Li et al. 2005; Pacholski et al. 2002; Law et al. 2005; Dalal et al. 2006; Hatch et al. 2013; Tseng et al.2003). The intentional ratios of dopants to $\mathrm{ZnO}$ materials as a host matrix encourages dramatic variations in the consistent morphological, transport, electrical, and optical properties. Mainly, the ionic radius and electronegativity of the doping component affect the composite growth process. For $\mathrm{ZnO}$ materials, effective doping is reached as $\mathrm{Zn}^{+2}$ - ions are substituted with higher valence elements. 
Lately, air and water pollutions have been considered as the main environmental issues that required more intensive efforts to motivate the continuous essential practical environmental research. $\mathrm{ZnO}$ semiconductors have been recognized to be attractive photocatalysts due to the large efficiency of catalytic, environmental sustainability, and reasonable price (Kamat 1993; Pelizzetti and Serpone 1986). $\mathrm{ZnO}$ nanomaterials have been developed as effective catalysts for water detoxification due to the efficient generation of $\mathrm{H}_{2} \mathrm{O}_{2}$, as well as high mineralization and reaction rates. Also, $\mathrm{ZnO}$ has a larger amount of dynamic positions with large surface reactivity (Carraway et al. 2004). Although chlorophenols have been utilized in pesticide and antiseptics manufacture, formed in the chlorinebleaching procedure throughout papermaking, shaped throughout the chlorination of drinking water, and manufactured in chemical, textile, and pharmaceutical engineering, they cause mouth burning, lung damage, headache, disturbs the digestive tract as well as the immune system according to the type and dose of exposure (Michalowicz and Duda 2007). Meanwhile, nitrophenols were produced using the phenol reaction and nitrite ions in water with solar light, formed throughout pesticide production and degradation, generated via the electronic and metallurgic manufacturing utilized in solvents, plastic, and dyes production (US EPA 2016).

Many research studies reports doping $\mathrm{ZnO}$ 1D-NSs have certainly enhanced its physical properties, including enlarged transparency, improved conductivity, amplified ferromagnetic behavior, and shortened work function (Wang et al. 2013; Yuan et al. 2008; Chu et al. 2007; Ruankham et al. 2011). It is well acknowledged that III group, such as boron (B-), gallium (Ga-), aluminum (Al-), and indium (In-), are considered as the furthermost appropriate dopants for the ntype of $\mathrm{ZnO}$ materials, that are found in transparent conducting oxides (TCO) which display great optical transparency and large conductivity (Kim et al. 2014; Xu et al. 2004; Chen et al. 2010; Lin et al. 2006; Bae et al. 2005). Several studies have stated n-type doping of ZnO 1D-NS materials through using titanium (Ti-), hydrogen $\left(\mathrm{H}_{-}\right)$, and as well as elements of group VII, like chlorine (Cl-), and fluorine (F-) (Chang et al. 2011; Huang et al. 2012; Luo et al. 2011). Nevertheless, it is challenging and unstable to produce p-type dopants of $\mathrm{ZnO}$ 1D nanostructured materials due to indefinite mechanisms. However, elements of Group V, such as arsenic (As-), nitrogen (N-), antimony (Sb-), and phosphorus (P-), are potentially promising p-type doping for $\mathrm{ZnO} 1 \mathrm{D}$ NSs, where p-type $\mathrm{ZnO}$ materials achieved via potentially replacing those elements with oxygen (Lee et al. 2004; Chavillon et al. 2012; Chen et al. 2010). In comparison, group IB atoms, including copper $(\mathrm{Cu}-)$, gold ( $\mathrm{Au}-)$, and silver ( $\mathrm{Ag}-)$ are used to get p-type $\mathrm{ZnO}$ materials, while group I atoms, such as lithium (Li-), potassium (K-), and sodium (Na-), have been reported to replace Zn-sites (Xing 
et al. 2008; Li et al. 2011; Jayakumar et al. 2006; Zhang et al. 2010). Recently, enhancing the luminescence properties of semiconductors has widely achieved via using rare-earth elements as dopants. It has been reported that ZnO1D-NSs materials as a matrix could be successfully doped with filler elements of rare-earth atoms, such as Erbium (Er-), europium (Eu-), lanthanum (La-), and dysprosium (Dy-) (Lo et al. 2011; Wang et al. 2011; Jia et al. 2009; Wu et al. 2006). During the last years, many photodetectors have been prepared using large bandgap semiconductors, like SiCN, diamond, SiC, II-VI compounds, and III-V compounds, where that UV-photodetectors have been fabricated with either $\mathrm{p}-\mathrm{n}$ junction structures or metal-semiconductor-metal (MSM) (Chang et al. 2003; Yang et al. 2010; Afsal et al. 2012; Hsu and Lu 2012; Nie et al. 2013).

Different researches on $\mathrm{ZnO}$ doping have been investigated in several available reports of Ce-, In, and Ga- dopants (Sofiani et al. 2006; Zironi et al. 1997; de L 2003). The ZnO microstructure changes have been considered in detail due to various dopant elements, including Sn-, In-, Al-, Fe-, and $\mathrm{Cu}$-(Paraguay et al. 2000). Dopants play significant roles in semiconductor devices, which have encouraged the study of semiconductors' properties and promising applications (Alivisatos 1996). Rare-earth elements-doped semiconductor nanocrystals have unique chemical and physical properties in addition to their special phosphors of high efficiency and low degradation (Rakov et al. 2003). It has been found that II-VI group semiconductors are exclusive host materials for optically energetic impurities doping at ambient temperature (Ishizumi and Kanemitsu 2005).

The rare-earth Er- ions doped $\mathrm{ZnO}$ nanostructures can be an extremely multifunctional nanomaterial with simultaneous semiconducting, optical, and electromechanical properties. Among various lanthanides, Erbium (Er-) elements gain enormous critical attention, taking advantage of its massive potential in different applications (Divya et al. 2015; Khataee et al. 2015).

Kai Sheng Yu et al. described the actual methyl blue (MB) photodegradation utilizing Er: $\mathrm{ZnO}$ photocatalyst below UV light (Yu et al. 2013). Also, below UV light, A Khataee et al. grow excellent crystalline of Er-doped $\mathrm{ZnO}$ nanocomposites using the sonochemical approach for the purpose of photocatalytic degradation of sensitive orange 29 dye (2015). J. Gao et al. synthesized Er-doped $\mathrm{ZnO}$ nanocomposites utilizing the liquid boiling approach, where Er: $\mathrm{ZnO}$ was considered as photocatalysts for acid red B dye's photodegradation below sunlight (2011). Up to the current reported scientific research, there are not much-reported studies incomplete clear portrayal regarding effects in morphological, structural, electrical, optical, dielectric, energy bandgaps, and nonlinear optical (NLO) properties of induced Er-ions as rare-earth-doped $\mathrm{ZnO}$ composited nanomaterials, because of the difficult doping growth processes (Julian et al. 2005; 
Falcony et al. 1988; Ortiz et al. 1987; Voort et al. 1992; Gu et al. 2004). Additionally, procedure optimization is required to develop a full understanding of doping mechanisms, which is considered one of the main scope of this current research.

In this proposed research, undoped zinc oxide $(\mathrm{ZnO})$ and Erbium-doped $\mathrm{ZnO}$ nanocomposites $\left(\mathrm{Er}_{2} \mathrm{O}_{3}-\mathrm{ZnO}\right)$ have been synthesized using an effective, low cost, easy, and ecofriendly combustion technique. The synthesized nano-ZnO's of different ratios as a matrix with different concentrations of erbium ions. The morphological, structural, and optical, electrical, as well as photocatalytic performances of the $\mathrm{Er}_{2} \mathrm{O}_{3}-\mathrm{ZnO}$ nanostructured materials were studied. The surface morphology and structure analysis of $\mathrm{Er}_{2} \mathrm{O}_{3}-\mathrm{ZnO}$ nanocomposites have been characterized by employing a scanning electron microscope (SEM), X-ray diffraction (XRD), and Fourier transformation infrared (FT-IR) spectroscopy technique. The optical diffused reflectance and their related parameters of the as-prepared $\mathrm{Er}_{2} \mathrm{O}_{3}-\mathrm{ZnO}$ nanocomposites were measured via Shimadzu UV-Vis-NIR spectrophotometer in a range of light wavelength between $200 \mathrm{~nm}$ to $1600 \mathrm{~nm}$. Besides, the AC electrical conductivity, dielectric constant, and current-voltage characteristics were investigated in detail. The photocatalytic efficiencies of Methylene Blue, phenol, and Rhodamine $\mathrm{B}$ degradations were examined for all synthesized $\mathrm{Er}_{2} \mathrm{O}_{3}-\mathrm{ZnO}$ nanostructured materials. The photocatalytic efficiency enlarged as the Erbium doping concentrations increased.

\section{Experimental Approaches}

\subsection{Growth of Er-Doped ZnO Nanomaterials.}

In the proposed work, the main target is to produce $\mathrm{ZnO}$ nanoparticles (NPs) doped with different Erbium (Er-ions) concentrations via the low-cost combustion method. Primary, five gram of $\mathrm{Zn}\left(\mathrm{NO}_{3}\right)_{2} \cdot 6 \mathrm{H}_{2} \mathrm{O}$ was mixed and crushing well in crucibles, made of ceramic, with one gram of gum acacia. Then, separately adding eight various Erbium concentrations, in the range of 0.001-5

$\mathrm{g}$ to the earlier mixture, which was labeled as So, S1, S2, S3, S4, S5, S6, and S7, respectively as shown in Table.1. After that, $5 \mathrm{~mL}$ of distilled (DI) water was used to dissolve the previous mixtures. For almost 2 hours, the combinations of $\mathrm{Er}_{2} \mathrm{O}_{3}-\mathrm{ZnO}$ nanocomposite were heated at a temperature of $600{ }^{\circ} \mathrm{C}$ and then left to be cooled down to the ambient temperature. In this preparation technique, gum acacia has been work as a fuel to support the $\mathrm{ZnO}$ structure's change from a highly crystalline structure to a nanoscale structure through increasing their constituents inside the matrix. A handheld hydraulic press was utilized to shape a pellet with a diameter of 13 
$\mathrm{mm}$ and a thickness of $1 \mathrm{~mm}$. The final product of $\mathrm{ZnO}$-nanoparticles doped with Erbium at several concentrations is presented in Fig. 1.

Table. 1. The sample code of $\mathrm{ZnO}$ - nanostructures with different doping concentrations of Praseodymium $\operatorname{Pr}^{3+}$-ions.

\begin{tabular}{|cc|c|}
\hline \multicolumn{2}{|c|}{ Samples } & Codes \\
\hline \multicolumn{2}{|l|}{ Pure ZnO } & So \\
\hline \multicolumn{2}{|l|}{ 0.001g Er-doped ZnO } & S1 \\
\hline 0.01g & Er-doped ZnO & S2 \\
\hline $0.1 g$ & Er-doped ZnO & S3 \\
\hline $0.5 g$ & Er-doped ZnO & S4 \\
\hline 19 & Er-doped ZnO & S5 \\
\hline $2.5 g$ & Er-doped ZnO & S6 \\
\hline $5 g$ & Er-doped ZnO & S7 \\
\hline
\end{tabular}

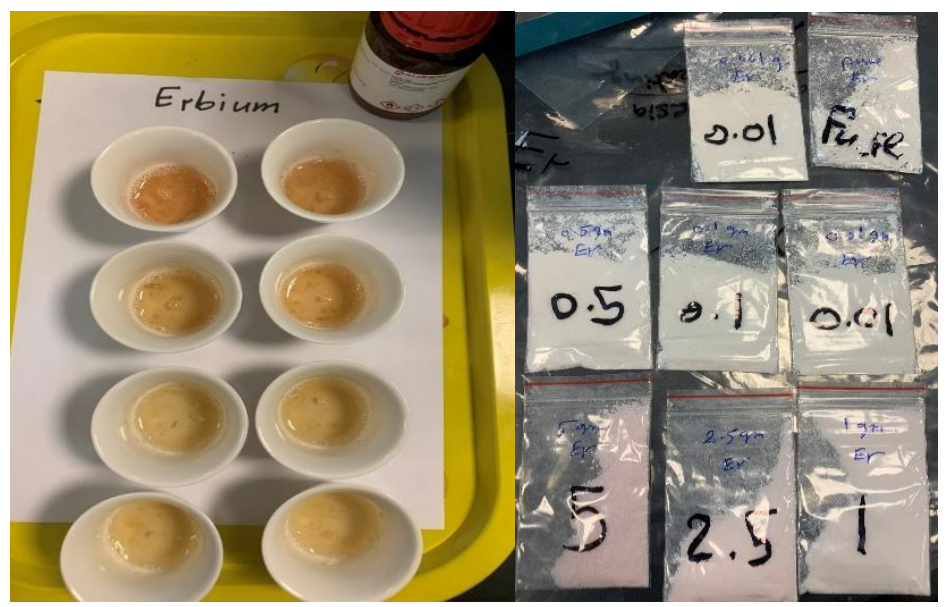

Fig. 1. The as-prepared $\mathrm{Er}_{2} \mathrm{O}_{3}-\mathrm{ZnO}$ nanocomposites with a different Erbium doping concentration.

\subsection{Devices \& Measurements}

$\mathrm{X}$-ray diffractometer (XRD) is an effective approach to study the prepared $\mathrm{ZnO}$ nanostructure's structural morphology with different Erbium doping ratios. In this work, XRD data was attained through Shimadzu LabX-XRD-6000, applying filtered radiation of $C u K_{\alpha}(\lambda=$ $1.5406 \AA ̊$ ) at room temperature. The attained XRD results were matched with the programmed software (pdf-2 library) in XRD Shimadzu, where the diffraction angle $(2 \theta)$ ranges between $5^{\circ}$ and 
$80^{\circ}$. In this research study, the SEM was JSM-6360 type with a $20 \mathrm{kV}$ operating voltage, which was utilized to examine the surface morphologies of all produced $\mathrm{Er}_{2} \mathrm{O}_{3}-\mathrm{ZnO}$ nanocomposites.

Additionally, the optical diffused reflectance spectra of the produced $\mathrm{Er}_{2} \mathrm{O}_{3}-\mathrm{ZnO}$ nanostructured materials were measured using a 3600 UV/Vis/NIR spectrophotometer (Shimadzu, Japan), the wavelength ranged from $200 \mathrm{~nm}$ to $1600 \mathrm{~nm}$, the step scan was $5 \mathrm{~nm}$, and the reference sample as barium sulfate. To measure the Furrier transform infrared (FT-IR) spectra of the prepared $\mathrm{Er}_{2} \mathrm{O}_{3}-\mathrm{ZnO}$ nanocomposites, DXR FT-IR Spectrometer, THERMO SCIENTIFIC, was applied within the wavenumber range from 400 to $4000 \mathrm{~cm}^{-1}$. The $\mathrm{Er}_{2} \mathrm{O}_{3}-\mathrm{ZnO}$ nano-samples were subjected to the FT-IR analysis through primarily preparing $100 \mathrm{mg}$ of potassium bromide with finely two percent $(2 \%)$ of the mixtures crushed the $\mathrm{Er}_{2} \mathrm{O}_{3}-\mathrm{ZnO}$ nano-powders.

At a constant temperature, the prepared $\mathrm{Er}_{2} \mathrm{O}_{3}-\mathrm{ZnO}$ nanocomposite samples' electrical measurements were accomplished utilizing a computerized digital Keithley 4200-SCS with a broad range of frequency between $3 \mathrm{kHz}$ and $10 \mathrm{MHz}$. The distinctive circuit of controllable PID was utilized to measure the current-voltage at ambient temperature. The electrical circuit comprises of a pico, digital ammeter that is DPM-111/SVS labs Inc model. USA, a power supply that operates at high voltage from the EHT-11/SVS labs Inc. USA model, and a PID controlled oven that has the PID-200 model. The operating system is connected to a distinct oven, where a holder with double probes is linked to it. In this current research, $\mathrm{ZnO}$ doped with various ratios of Erbium ions was pressed in 10 tons on a solid disc to have a disc dimension of $1 \mathrm{~mm}$ thickness and as well $13 \mathrm{~mm}$ diameter.

\subsection{Photodegradation Measurements.}

The photocatalytic performance and the degradation of typical pollutant p-chlorophenol and p-nitrophenol in various conditions were assessed as a type of colorless pollutant for the synthesized nanomaterials. The visible light irradiation performed using a wooden visible photocatalytic reactor planned by the group of I.S. Yahia in NLEBA at Ain Shams University (ASU) in Egypt. The irradiation source is 14 lamps (i.e., wavelength greater than $420 \mathrm{~nm}$ and power $=18$-watt (Mai et al. 2020). These photocatalytic experiments were used to test $\mathrm{Er}_{2} \mathrm{O}_{3}-\mathrm{ZnO}$ nanoparticles against phenol derivates. An aqueous solution of $100 \mathrm{ml}$ was formed in water containing $300 \mathrm{ppm} \mathrm{p}$ chlorophenol and p-nitrophenol, separated. The phenolic solution was applied for photodegradation using $0.01 \mathrm{~g}$ of pure $\mathrm{ZnO}$ and various $\mathrm{Er}_{2} \mathrm{O}_{3}-\mathrm{ZnO}$ loading. For the proper homogeneity of the photocatalyst and the equilibrium of adsorbent desorption, the resulting suspension was stirred for 
$30 \mathrm{~min}$ before light irradiation. At a standard period, $5 \mathrm{ml}$ of $\mathrm{Er}_{2} \mathrm{O}_{3}: \mathrm{ZnO}$ solution was taken from the photoreactor, followed by centrifugation for 10 minutes at $3000 \mathrm{rpm}$ to remove all powder suspension. After that, UV-Vis spectrophotometry has been applied to analyze the solution. Distilled water was utilized for baseline correction.

\section{Results and Discussion}

\subsection{Structural and Morphological Characterization of Er-doped ZnO Nanocomposites.}

\subsubsection{X-ray diffraction pattern (XRD).}

The XRD patterns of undoped $\mathrm{ZnO}$ and $\mathrm{Er}_{2} \mathrm{O}_{3}-\mathrm{ZnO}$ nanocomposite samples are illustrated in Fig. 2, which offer mostly diffraction bands due to the wurtzite ZnO phase (JSPDS 01- 0750576) with weak lines related to the carbon phase (JSPDS 01-072-2091) as reported by Yu et al. (2013). All obtained XRD peaks of undoped $\mathrm{ZnO}$ nanoparticles agreed very well with the typical card data for $\mathrm{ZnO}$ structure of hexagonal; the card number is JCPDS No01- 075-0576 (Zhang et al. 2011). The important peaks correspond to (101) and (100) planes have been observed in the investigated $\mathrm{Er}_{2} \mathrm{O}_{3}-\mathrm{ZnO}$ samples, which excellently matched with the reported XRD data of $\mathrm{ZnO}$ via K.-S. Yu et.al (2013). The typical, sharp, strong XRD bands of $\mathrm{ZnO}$ are located at $31.8^{\circ}, 34.4^{\circ}$, $36.3^{\circ}, 47.5^{\circ}, 56.6^{\circ}, 62.9^{\circ}$, and $66.4^{\circ}$ angles, which are consistent respectively with the (100), (002), (101), (102), (110), (103), and (201) plane indices (Yu et al. 2013). The $\mathrm{ZnO}$ structure is proved to be hexagonal wurtzite in nature.

In XRD patterns, a small shift in $2 \theta$ to the left diffraction angles for the (002) plane has been noticed for the undoped $\mathrm{ZnO}$ material. This angles' movement directs the effective integration of Erbium doping in the $\mathrm{ZnO}$ as well as the existence of the second phase in $\mathrm{Er}_{2} \mathrm{O}_{3}$-doped $\mathrm{ZnO}$ nanocomposites as increasing the Er concentrations. XRD analysis showed that the contents of Erbium dopant affected the crystalline structure of the combustion Er-doped $\mathrm{ZnO}$ nano-powder noticeably and affects the formation of $\mathrm{Er}_{2} \mathrm{O}_{3}$ phase, which was started to be found with increasing Erbium concentrations. A. Khataee et. al investigated the structural morphology of the Er-doped $\mathrm{ZnO}$ nano-powders with different ratios of Erbium dopants (Khataeeet al. 2015). In this current

study, the XRD approach was utilized for investigating both the chemical composition and structural morphology of the combustion synthesized $\mathrm{Er}_{2} \mathrm{O}_{3}$-doped $\mathrm{ZnO}$ nanostructures. The found XRD data effectively confirmed the substitution of Er-REE ions in the $\mathrm{ZnO}$ lattice. 


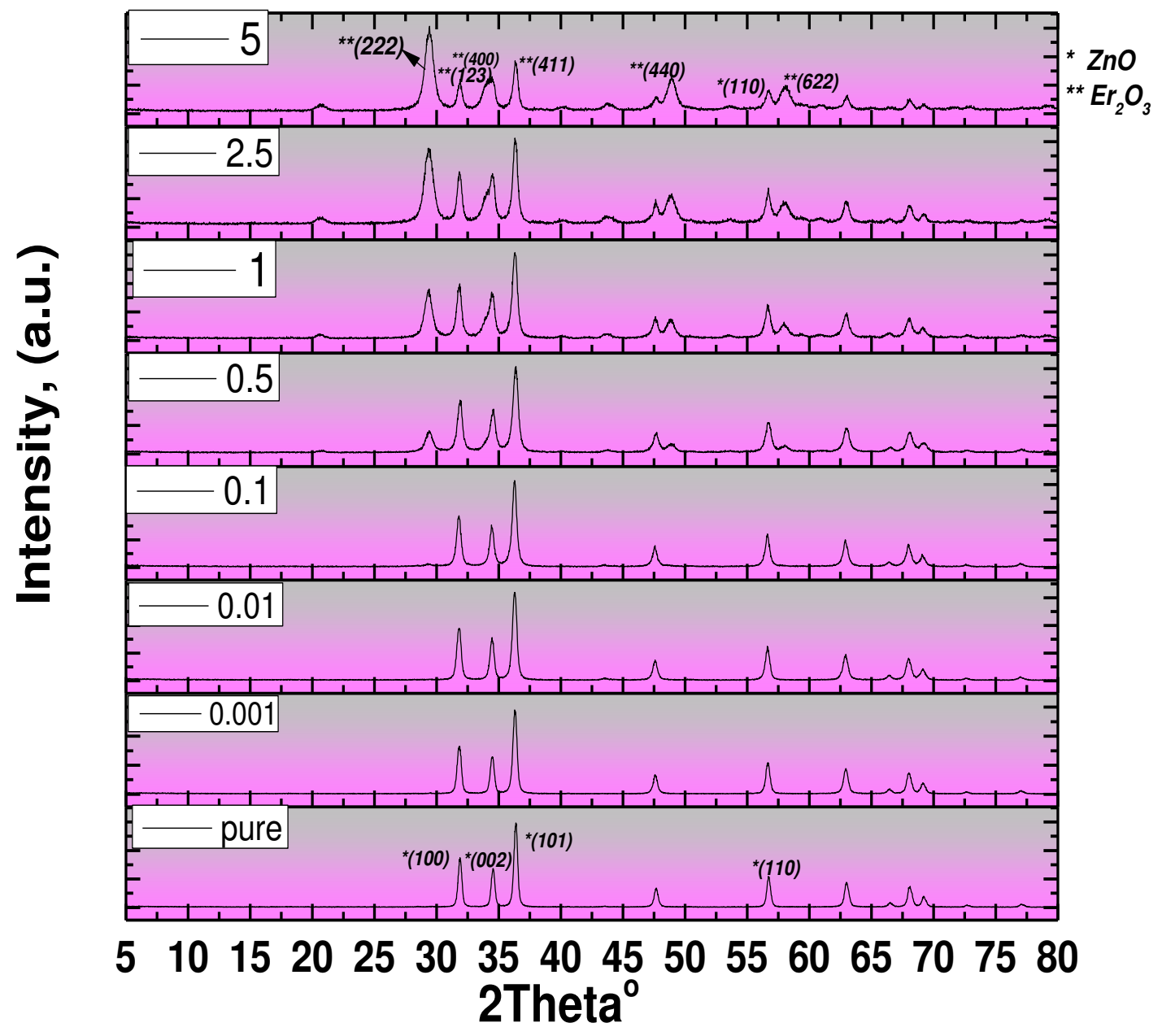

Fig.2. XRD patterns of the prepared $\mathrm{Er}_{2} \mathrm{O}_{3}-\mathrm{ZnO}$ nanostructures with various Erbium concentrations.

Table. 1 illustrates the calculated mean values of the grain size in the scale of nanometres, the dislocation density $(\eta)$ in $(\mathrm{nm})^{2}$, and the lattice strain $(\varepsilon)$ for all phases of the manufactured pure- $\mathrm{ZnO}$ with different Erbium doping levels on the $\mathrm{Er}_{2} \mathrm{O}_{3}-\mathrm{ZnO}$ nanocomposites. Here, Scherrer's equation was applied to investigate the XRD and determine the crystallinity size (D) of the-as prepared $\mathrm{Er}_{2} \mathrm{O}_{3}-\mathrm{ZnO}$ nanostructured samples as:

$$
D=0.9 \lambda / \beta \cos \theta
$$

Furthermore, with the doping difference, the average values of the crystallite size of all prepared $\mathrm{ZnO}-\mathrm{Er}_{2} \mathrm{O}_{3}$ nanocomposites are changed in the range of $(63 \mathrm{~nm}-26 \mathrm{~nm})$. Those obtained data is in 
a great match with the published grain size with $15 \mathrm{~nm}$ to $19 \mathrm{~nm}$ on average for Pr-doped $\mathrm{ZnO}$ nanoparticles, which were synthesized and investigated by D.Venkatesan et al. (2010).

Table. 2. Calculated values of the grain size, dislocation density, and the lattice strain from XRD analysis; associated with the obtained SEM results for studied $\mathrm{Er}_{2} \mathrm{O}_{3}-\mathrm{ZnO}$ nanostructured samples.

\begin{tabular}{|c|c|c|c|c|c|}
\hline \multirow[t]{2}{*}{ Samples } & \multirow[t]{2}{*}{ Phases } & \multicolumn{3}{|c|}{$\begin{array}{c}\text { Mean Values, } \\
\text { From XRD analysis }\end{array}$} & \multirow{2}{*}{$\begin{array}{l}\text { Mean grain sizes, } \\
\text { From SEM analysis, } \\
\qquad(\mathbf{n m})\end{array}$} \\
\hline & & $\begin{array}{c}\text { Grain size, } \\
(\mathbf{n m})\end{array}$ & $\begin{array}{c}\text { Dislocation } \\
\text { density, }(\mathrm{nm})^{-2}\end{array}$ & Lattice Strain & \\
\hline \multirow[b]{2}{*}{ So } & Phase $1 \mathrm{ZnO}$ & 53.322 & 0.00056 & 0.00077 & \multirow[b]{2}{*}{105.111} \\
\hline & Phase 2 carbon & 22.556 & 0.00223 & 0.00160 & \\
\hline \multirow[b]{2}{*}{ S1 } & Phase $1: \mathrm{ZnO}$ & 50.836 & 0.00081 & 0.000891 & 85.944 \\
\hline & Phase 2: $\mathrm{Er}_{2} \mathrm{O}_{3}$ & 11.617 & 0.00919 & 0.00321 & \\
\hline \multirow[b]{2}{*}{ S2 } & Phase 1: $\mathrm{ZnO}$ & 39.219 & 0.00130 & 0.00115 & 86.188 \\
\hline & Phase 2: $\mathrm{Er}_{2} \mathrm{O}_{3}$ & 37.803 & 0.00410 & 0.00192 & \\
\hline \multirow[b]{2}{*}{ S3 } & Phase $1: \mathrm{ZnO}$ & 63.248 & 0.00038 & 0.00063 & \multirow[t]{2}{*}{75.111} \\
\hline & Phase 2: $\mathrm{Er}_{2} \mathrm{O}_{3}$ & 37.441 & 0.00133 & 0.00116 & \\
\hline \multirow[b]{2}{*}{ S4 } & Phase $1: \mathrm{ZnO}$ & 25.043 & 0.00176 & 0.00143 & 70.389 \\
\hline & Phase 2: $\mathrm{Er}_{2} \mathrm{O}_{3}$ & 19.538 & 0.00318 & 0.00189 & \\
\hline \multirow[b]{2}{*}{ S5 } & Phase 1: $\mathrm{ZnO}$ & 32.983 & 0.00159 & 0.00128 & \multirow[t]{2}{*}{78.50} \\
\hline & Phase 2: $\mathrm{Er}_{2} \mathrm{O}_{3}$ & 19.643 & 0.00305 & 0.00191 & \\
\hline \multirow[b]{2}{*}{ S6 } & Phase 1: $\mathrm{ZnO}$ & 35.071 & 0.00136 & 0.00119 & \multirow[t]{2}{*}{84.333} \\
\hline & Phase 2: $\mathrm{Er}_{2} \mathrm{O}_{3}$ & 22.258 & 0.00383 & 0.00198 & \\
\hline \multirow[b]{2}{*}{ S7 } & Phase 1: $\mathrm{ZnO}$ & 26.659 & 0.00174 & 0.00139 & \multirow[t]{2}{*}{86.313} \\
\hline & Phase 2: $\mathrm{Er}_{2} \mathrm{O}_{3}$ & 19.042 & 0.00349 & 0.00197 & \\
\hline & & & & & \\
\hline
\end{tabular}


Individually, from the next equations 2 and 3, the average values of dislocation density $(\eta)$ and lattice strain $(\varepsilon)$ of pure- $\mathrm{ZnO}$ and $\mathrm{Er}_{2} \mathrm{O}_{3}$-doped $\mathrm{ZnO}$ nanocomposites were computed (Callister 1997, Pathinettam Padiyan et al. 2002):

$\eta=1 / D^{2}$

$\varepsilon=\beta \cos \theta / 4$

where the X-ray wavelength $(\lambda)$ is in the unit of $\mathrm{nm}$, the diffraction angle is $\theta$ in the degree unit, and $\beta$ is the full width at half maximum (FWHM) in the unit of a radian. From the data of both Table. 2 and Fig. 2, it is understandable that the $\mathrm{Er}_{2} \mathrm{O}_{3}-\mathrm{ZnO}$ phases do not occur in low doping, which was appeared as the dopant concentration was increased. The dislocation density in nanomaterials is an imperfection related to the lattice's misregister in one part of the crystal concerning another part.

\subsubsection{Scanning Electron Microscopy (SEM) images.}

Scanning electron microscopy (SEM) was employed to examine the as-prepared Erbiumdoped $\mathrm{ZnO}$ nanostructures' growth topographies. Fig. 3 demonstrates the SEM images to investigate the structure morphologies of the studied $\mathrm{Er}_{2} \mathrm{O}_{3}-\mathrm{ZnO}$ nanocomposites with different Erbium doping ratios ranging from $0.001 \mathrm{~g}$ to $5 \mathrm{~g}$ (i.e., So to $\mathrm{S} 7$, respectively). The variations in the structure morphology for the undoped $\mathrm{ZnO}$ and Erbium-doped $\mathrm{ZnO}$ nanostructures were noticeable. The SEM images of the $\mathrm{Er}_{2} \mathrm{O}_{3}-\mathrm{ZnO}$ nanocomposite powders generally displayed the uniform distribution of Er-ZnO spherical nanoparticles. The Erbium-ions create small-sized grains and promote the crystal nucleation rate, while Erbium grains' trapping stops grain development. The cause of this issue might be due to the variation in ionic radius between zinc and Erbium (Dong et al. 2012).

With the increase in Erbium doping concentrations, both the shape and the size of the $\mathrm{Er}_{2} \mathrm{O}_{3}-$ $\mathrm{ZnO}$ nanoparticles differed. As a result, the obtained SEM findings agreed very well with the XRD analysis. The morphology analysis illustrates the grain sizes' calculated mean values were ranging from $70 \mathrm{~nm}$ to $86 \mathrm{~nm}$ for Er-doped $\mathrm{ZnO}$ nanostructured materials and around $105 \mathrm{~nm}$ for pure $\mathrm{ZnO}$ nanoparticles. In this present research, the attained SEM data excellently matched with that published SEM results by K. Yu et. al (2013). The structural morphology of $\mathrm{ZnO}$ and Er: $\mathrm{ZnO}$ was investigated and the distribution of the grain size was evaluated through Manual Microstructure Distance Measurement software. On average the particle diameter was 
between 40 and $60 \mathrm{~nm}$ based on the Er ratios, where some of those particles had clearly a spherical shape. The SEM images concluded that the grain size partially declined with increasing the Erbium concentrations in $\mathrm{ZnO}$.

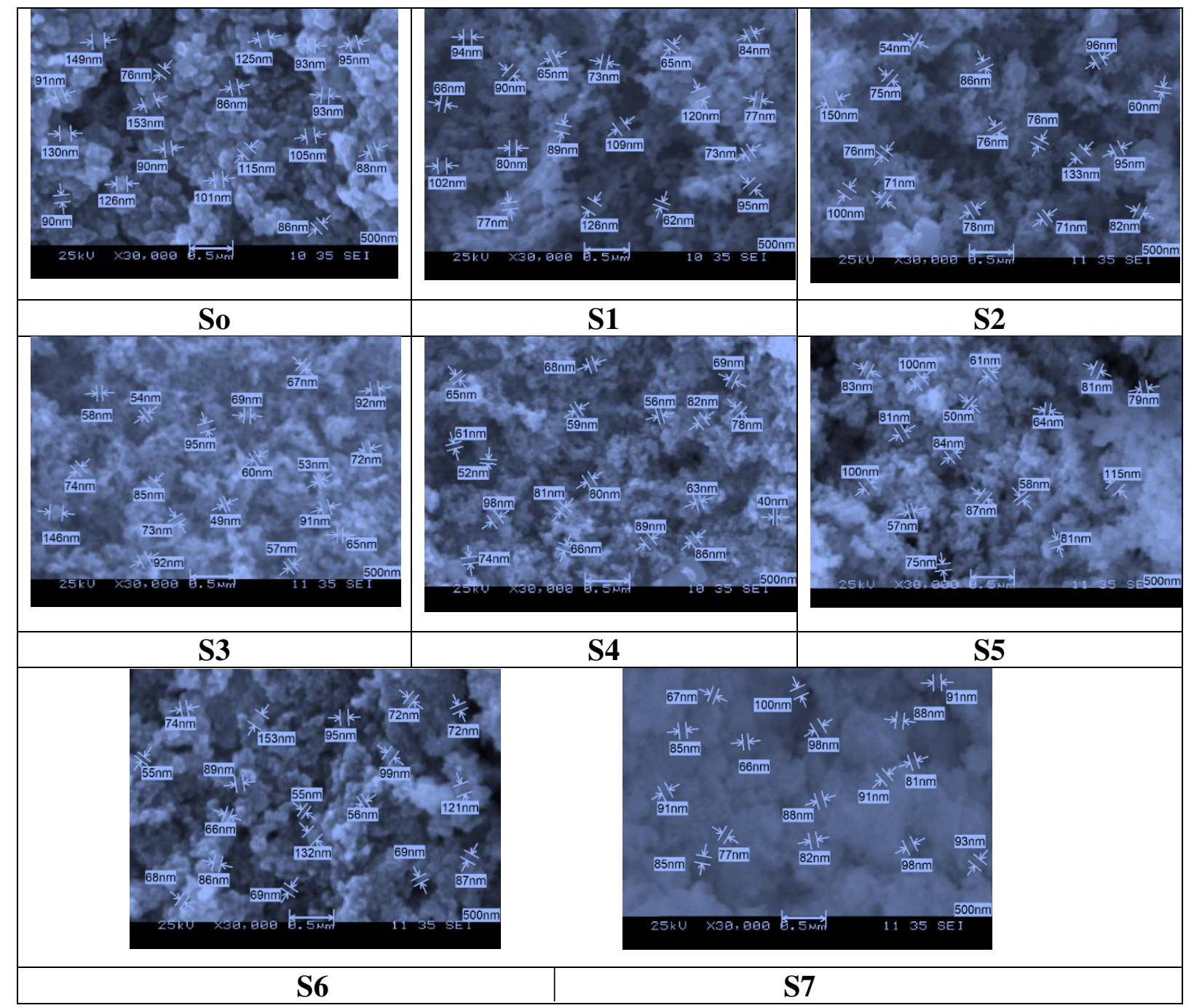

Fig. 3. SEM images of the as-prepared $\mathrm{Er}_{2} \mathrm{O}_{3}-\mathrm{ZnO}$ nanostructures, with different Erbium doping concentrations.

\subsection{Optical Characterization of Er-Doped ZnO Nanocomposites.}

\subsubsection{Fourier Transformation Infrared Spectroscopy (FT-IR).}

FT-IR spectroscopy was employed to examine the considered $\mathrm{Er}_{2} \mathrm{O}_{3}-\mathrm{ZnO}$ nanostructured samples' vibrational properties since it is an extremely sensitive characterization technique and can contribute to XRD findings. Fig. 4 presents the FT-IR spectra, which define the relation between the light absorbance and the wavenumber in the range $\left(400 \mathrm{~cm}^{-1}-7000 \mathrm{~cm}^{-1}\right)$ for the $\mathrm{Er}_{2} \mathrm{O}_{3}-\mathrm{ZnO}$ 
nanostructured at different Er-doping concentrations. It can be noticeable that the Erbium- doping affects both the shape and the intensity of the main absorption bands and that changes were more obvious in the $\mathrm{Er}_{2} \mathrm{O}_{3}-\mathrm{ZnO}$ curves than the undoped $\mathrm{ZnO}$. In the FT-IR spectral range, there is an overlapping of IR-lines, which contributions to the phases of both $\mathrm{ZnO}$ and $\mathrm{Er}_{2} \mathrm{O}_{3}$. There were small improvements in the optical transparency at the low doping concentrations respecting the undoped $\mathrm{ZnO}$ sample. With increasing the Erbium ratios, the transmittance of $\mathrm{ZnO}-\mathrm{Er}_{2} \mathrm{O}_{3}$ samples displayed lower values.

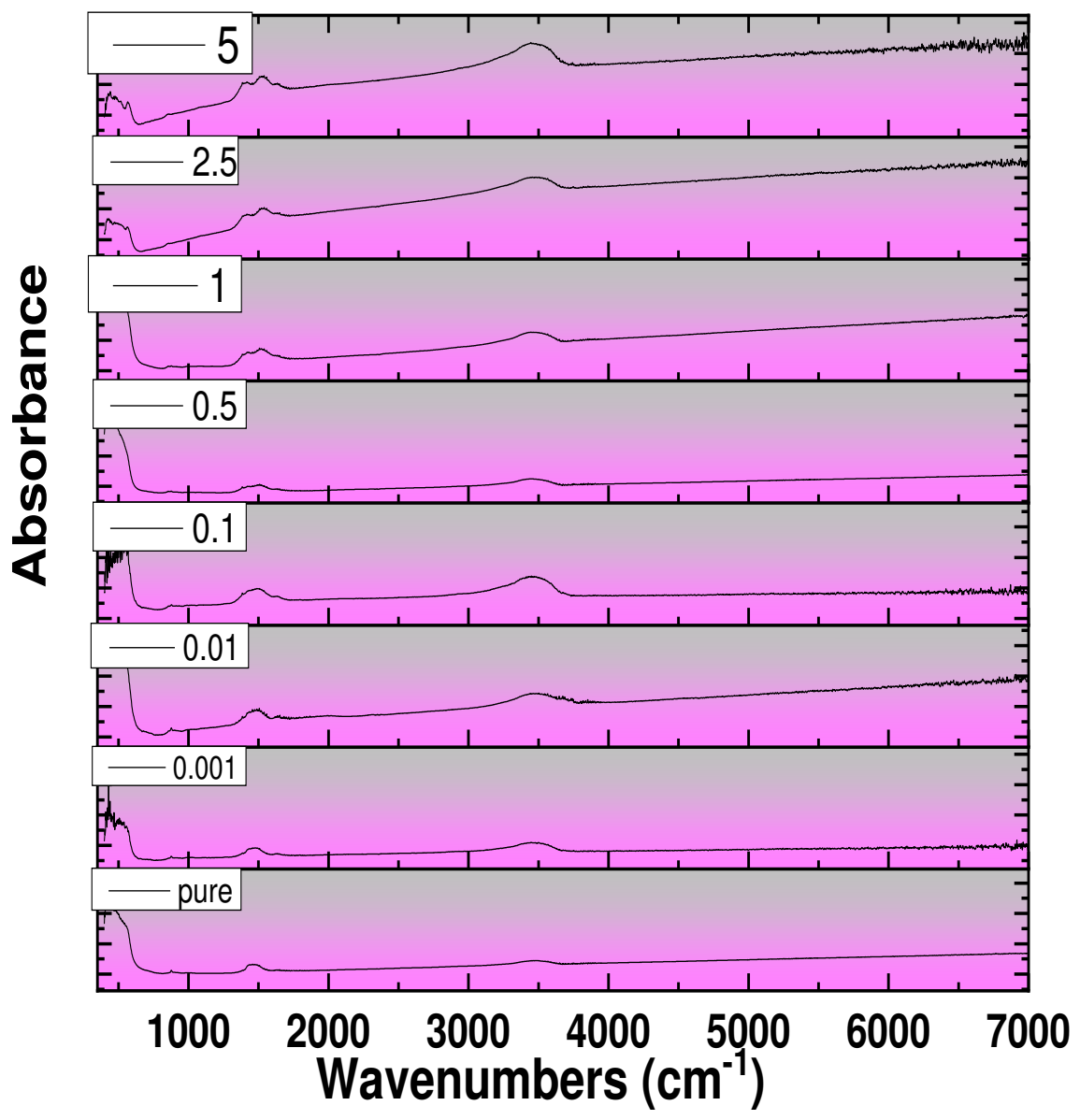

Fig. 4. FT-IR spectra of the synthesized $\mathrm{Er}_{2} \mathrm{O}_{3}-\mathrm{ZnO}$ nanostructures at various Erbium doping concentrations.

The highest doping ratios of $\mathrm{Er}_{2} \mathrm{O}_{3}$ (S7) have the maximum absorbance, which excellently agreed with the found results of the structure morphology from both XRD and SEM analysis. Optically, Sonik Bhatia et. al applied Fourier Transformation infrared spectroscopy (FT-IR) to 
investigate the chemical composition of Er: ZnO nanoparticles (2016). FT-IR spectra illustrated few peaks located at 501,1515, and $3621 \mathrm{~cm}^{-1}$, where the sharp strongest peak at $501 \mathrm{~cm}-1 \mathrm{confirm}$ the $\mathrm{ZnO}$ formation, and the wide peak at $1515 \mathrm{~cm}-1$ is related to $\mathrm{OH}$ bond (Sonik Bhatia et al. 2016). Also, there was small and sharp peak presented at $3621 \mathrm{~cm}^{-1}$, which was assigned to $\mathrm{OH}$ vibration stretching mode in $\mathrm{Er}$ : $\mathrm{ZnO}$ nanocomposites. To conclude, the absorption intensity increased as increasing the Er doping ratios, where that was perfectly matched with these current FT-IR data.

\subsubsection{Optical Diffused reflectance (ODR)}

The optical Diffused reflectance (ODR) measurement is considered a traditional technique used to collect optical data on the proposed $\mathrm{Er}_{2} \mathrm{O}_{3}-\mathrm{ZnO}$ nanostructured composite powder's through the reflectance characteristics. For semiconductor materials, the optical energy bandgaps and the absorption coefficient are two factors that can be achieved from ODR analysis. Individually, Fig. 5 and Fig. 6 illustrate the optical diffused reflectance (ODR) and the absorption index (k) of the $\mathrm{Er}_{2} \mathrm{O}_{3}-\mathrm{ZnO}$ versus the light wavelength from $200 \mathrm{~nm}$ to $700 \mathrm{~nm}$. From Fig. 5, it is obvious that there were no many differences between diffuse reflectance (ODR) of all studied samples in wavelength of the range from $200 \mathrm{~nm}$ to $370 \mathrm{~nm}$. After that, the ODR noticed a sharp increase in the wavelength ranges from $370 \mathrm{~nm}$ to $410 \mathrm{~nm}$, producing the optical bandgap.

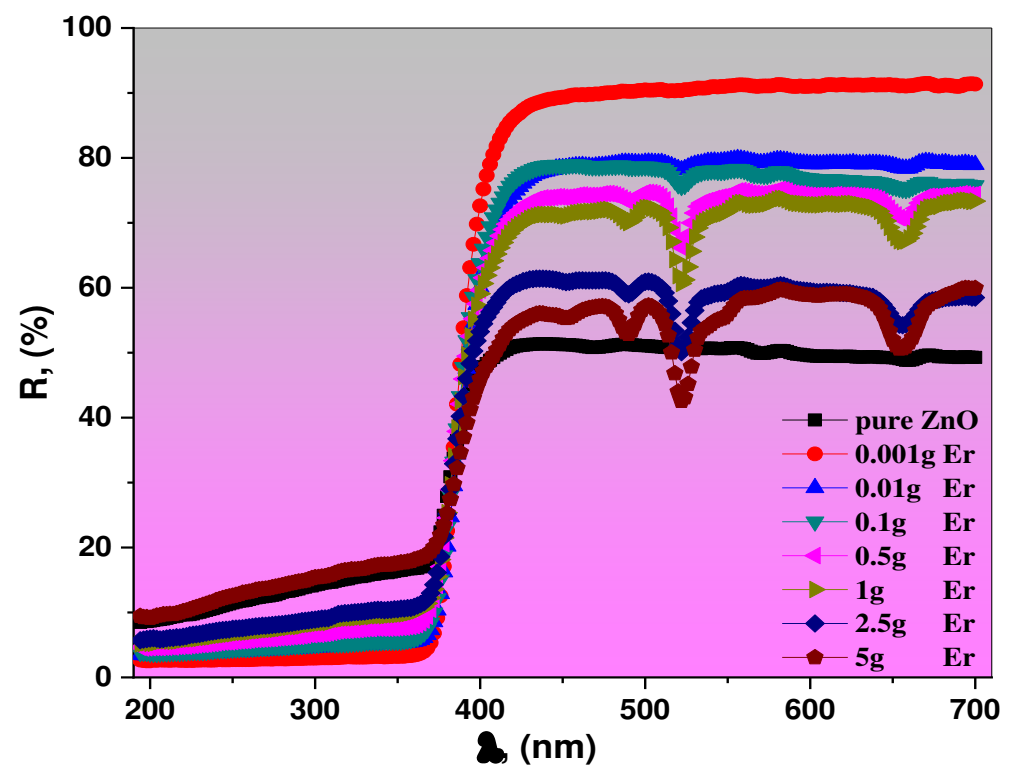

Fig. 5. Optical diffused reflectance (ODR) versus the light wavelength of the as-prepared $\mathrm{Er}_{2} \mathrm{O}_{3}-$ $\mathrm{ZnO}$ nanostructured with different Erbium doping concentrations. 
The diffuse optical reflectance (ODR) spectra demonstrated almost straight curves with no significant changes with the light wavelength among $410 \mathrm{~nm}$ and $700 \mathrm{~nm}$. It was clear that as increasing Er concentrations ion $\mathrm{ZnO}$ matrix, three valleys appeared at around $660 \mathrm{~nm}, 530 \mathrm{~nm}$, and $480 \mathrm{~nm}$ wavelength locations. The intensity of those reflection valleys increased and become sharper as the concentration ratios of Erbium increased. The obtained ODR results in this current study were in great agreement with the optical application of Er: $\mathrm{ZnO}$ nanoparticles by S. Bhatia et. al using UV -Vis spectrophotometer (UV Vis 2600/2700-Shimadzu) (Sonik Bhatia et al. 2016). The illustrated single peak at $537 \mathrm{~nm}$ in all Er: $\mathrm{ZnO}$ nanocomposites was corresponding to the phase of hexagonal wurtzite.

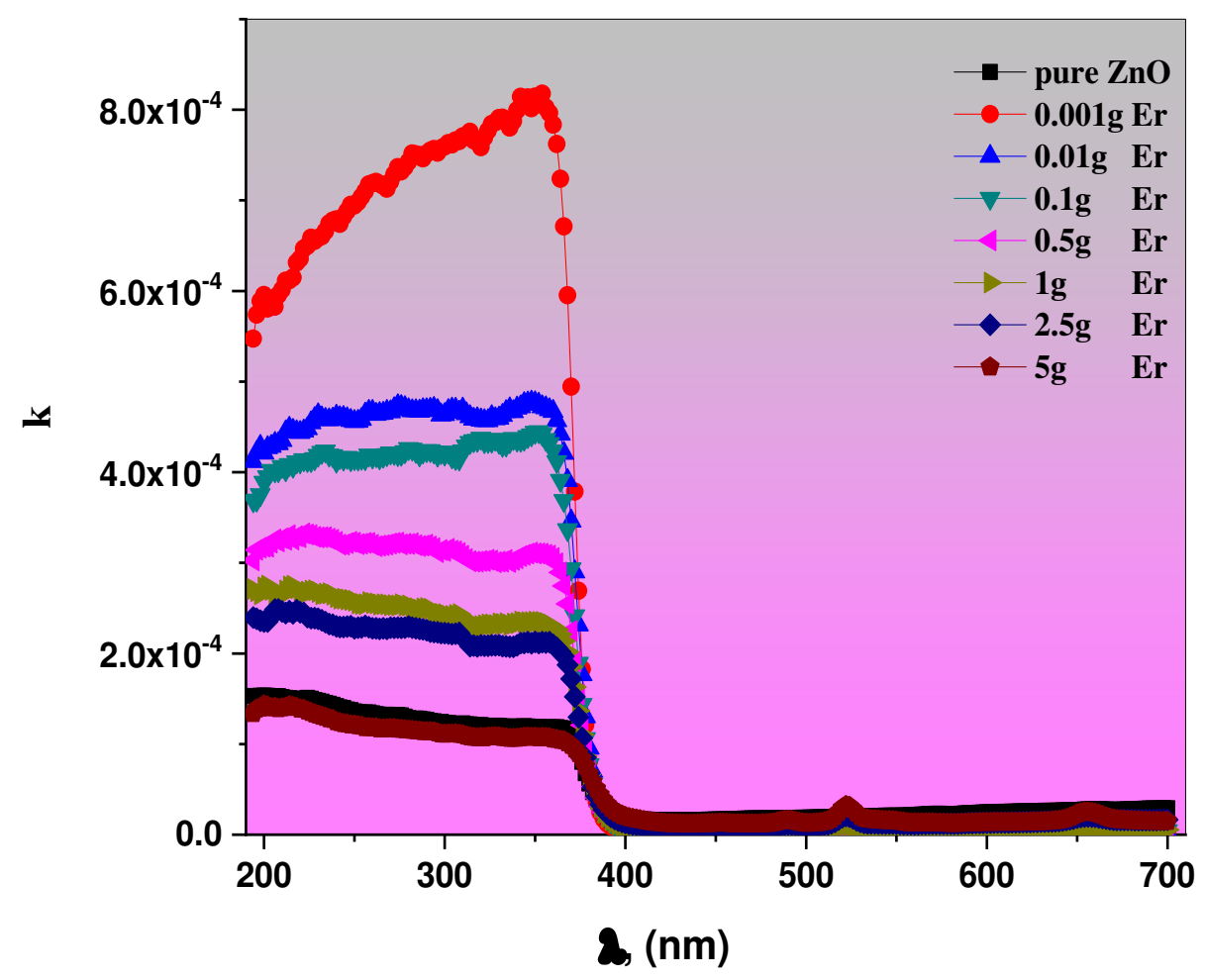

Fig. 6. Absorption coefficient (k) as a function of the wavelength of all prepared $\mathrm{Er}_{2} \mathrm{O}_{3}-\mathrm{ZnO}$ nanostructured with different Erbium doping concentrations.

In conclusion, the absorbed light via the deliberate samples produces the optical absorption bandgaps (SowriBabun et al. 2013; Zhang et al. 2008). Fig. 6 demonstrates that the studied $\mathrm{Er}_{2} \mathrm{O}_{3}-$ $\mathrm{ZnO}$ nanostructured samples have a little small absorption index values $(\mathrm{k})$, between $8.5 \times 10^{-4}$ and $1 \times 10^{-3}$, due to the non-absorbent surface area of the nanopowders, and the $\mathrm{Er}_{2} \mathrm{O}_{3}-\mathrm{ZnO}$ nano compounds are predisposed to the incident light. Similarly, this figure illustrates maximum 
absorption values at a light wavelength of about $380 \mathrm{~nm}$, characteristic for electronic transitions from band to the band $\left(\pi \rightarrow \pi^{*}\right)$ (El-Kabbany et al. 2014; Brütting 2006). Kai-sheng Yu et. al optically characterized $\mathrm{ZnO}$ and $\mathrm{Er} / \mathrm{ZnO}$ nanoparticles in the wavelength range of $200-800 \mathrm{~nm}$, where the strongest absorption peak for pure $\mathrm{ZnO}$ is located at $363 \mathrm{~nm}$ (2013). The light absorption in the visible region was less compared to the UV range, where the absorption band was because of the electron transition between VB and CB. The FT-IR spectra of Er-doped ZnO nanocomposites illustrated a somewhat redshifted at $375 \mathrm{~nm}$ band, indicating the ineffective impurity peak due to Er doping.

The following equations of Tauc's model were used to compute the optical bandgaps $E_{g}$ of the prepared $\mathrm{Er}_{2} \mathrm{O}_{3}-\mathrm{ZnO}$ nanopowders by (Kumaret al. 2013; Aydin et al. 2013) as:

$$
\begin{aligned}
& F(R)=\frac{(1-R)^{2}}{2 R}=\frac{K}{S}, \\
& \alpha=\frac{F(R)}{t}, \\
& (\alpha h v)^{1 / n}=A^{1 / n}\left(h v-E_{g}\right),
\end{aligned}
$$

where $F(R)$ represents the material reflectivity applying the model of Kubelka-Munk, $R$ is known that is immediately recorded using the UV-Vis spectrophotometer. The coefficient of molar absorption is known as $K$, and the scattering quantity is defined as $S$. In Eq. (6), $\alpha$ is known as the absorption index, $t$ is the material thickness inside the holder, and as well as in Eq. (7), hv is the photon energy, $v$ is the photon frequency of electromagnetic (EM) radiation, $h$ is Planck's constant, $A$ is the band tailing factor where its values ranged from $1 \times 10^{5} \mathrm{~cm}^{-1} \cdot \mathrm{eV}^{-1}$ to $1 \times 10^{6} \mathrm{~cm}^{-1} \cdot \mathrm{eV}^{-1}$ (Davis 1970), and $E_{g}$ is the optical energy bandgap of the studied nanomaterials. In the previous Eq. (7), the values are either $n=1 / 2$ for direct optical bandgaps or $n=2$ for indirect bandgaps transition. Then, the material direct and indirect bandgaps can be rewritten using the following formula (Kumaret al. 2013; Aydın et al. 2013):

$(\alpha h v)^{2}=A^{2}\left(h v-E_{g}\right), \quad(n=1 / 2$ for direct allowed transition $)$

while the following equation is expressed the material optical indirect bandgap as:

$$
(\alpha h v)^{1 / 2}=A^{1 / 2}\left(h v-E_{g}\right), \quad(n=2 \text { for indirect allowed transition })
$$




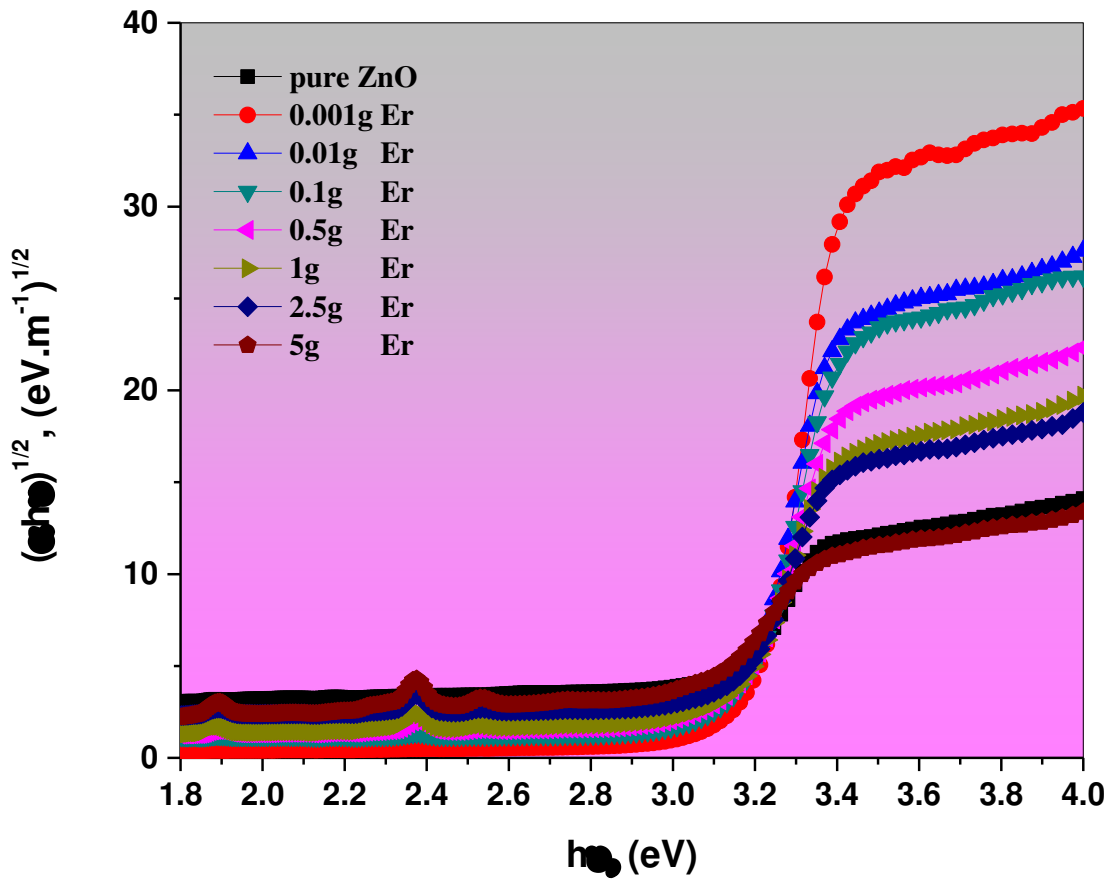

Fig. 7. Relationship between the optical allowed direct transition $(\alpha h v)^{1 / 2}$ and the photon energy $(h v)$ of all $\mathrm{Er}_{2} \mathrm{O}_{3}-\mathrm{ZnO}$ nanostructures with different doping ratios.

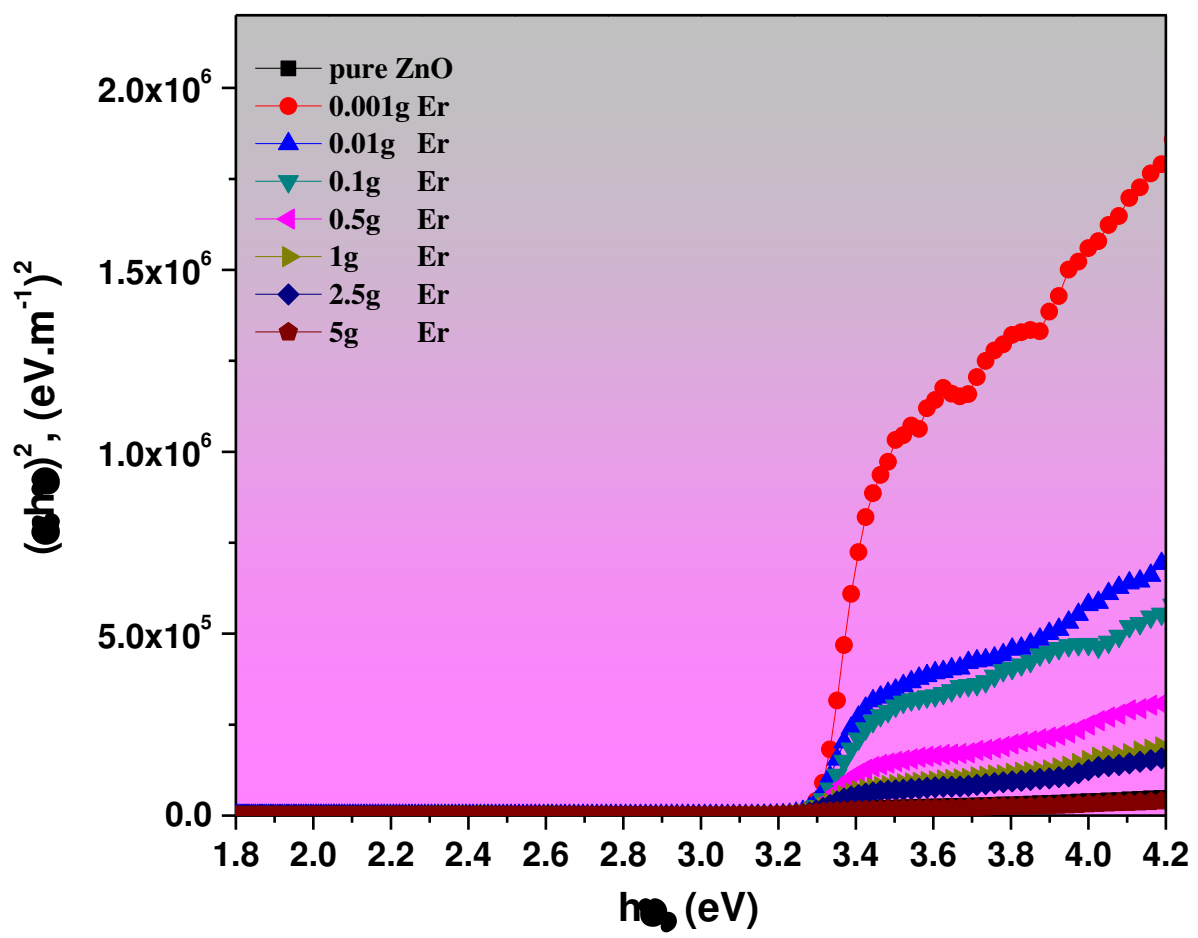

Fig. 8. Optical allowed indirect transition $(\alpha h v)^{2}$ versus the photon energy $(h v)$ of the as-prepared $\mathrm{Er}_{2} \mathrm{O}_{3}-\mathrm{ZnO}$ nanostructures at various doping ratios. 
Table. 3. The calculated Optical energy bandgaps (both direct and indirect transitions) of the asprepared $\mathrm{Er}_{2} \mathrm{O}_{3}-\mathrm{ZnO}$ nanostructured with different Erbium doping concentrations.

\begin{tabular}{|c|c|c|}
\hline Samples & $\mathbf{E}_{\mathbf{g} 1}(\mathbf{d}), \mathbf{e V}$ & $\mathbf{E}_{\mathbf{g} 1}(\mathbf{i n d}), \mathbf{e V}$ \\
\hline Pure & 3.19 & 3.35 \\
0.001 & 3.19 & 3.30 \\
0.01 & 3.16 & 3.28 \\
0.1 & 3.11 & 3.27 \\
0.5 & 3.10 & 3.25 \\
1 & 3.04 & 3.24 \\
2.5 & 2.98 & 3.23 \\
5 & 2.88 & 3.2 \\
\hline
\end{tabular}

Both Fig. 7 and Fig. 8 showed the individually plotting of $(\alpha h v)^{1 / 2}$ and $(\alpha h v)^{2}$ dependent on the photon energy $(h v)$ for $\mathrm{Er}_{2} \mathrm{O}_{3}-\mathrm{ZnO}$ nanopowder samples at several Erbium concentrations. The direct and indirect optical bandgaps have been respectively found through the intercept line for the curves, in Fig.7 \& Fig. 8, to the $x$-axis were $\alpha^{1 / 2}$ and $\alpha^{2}$ reaches to zero. As illustrated in Table.3, the direct optical bandgap's obtained values for the $\mathrm{Er}_{2} \mathrm{O}_{3}-\mathrm{ZnO}$ nanocomposites vary between 2.88 $\mathrm{eV}$ and $3.19 \mathrm{eV}$. On the other hand, the indirect allowed optical transition's evaluated values ranged from $3.2 \mathrm{eV}$ to $3.35 \mathrm{eV}$. The evaluated energy bandgaps of $\mathrm{Er}_{2} \mathrm{O}_{3}$-doped $\mathrm{ZnO}$ nanostructured samples were in excellent agreement with the published optical data for sol-gel synthesized Fedoped $\mathrm{ZnO}$ nanoparticles via C. Aydın et al. (2013). Approximately, the optical bandgap of pure $\mathrm{ZnO}$ nanoparticle was evaluated to be $3.19 \mathrm{eV}$, where the bandgap values decreased to reach $2.75 \mathrm{eV}$ as increasing the $\mathrm{Fe}$ doping ratios on $\mathrm{ZnO}$. Furthermore, $\mathrm{TiO}_{2}$-doped PMMA/FTO nanostructured films were optically linearly investigated by Thekrayat AlAbdulaal and Ibrahim Yahia using a VU-Vis spectrophotometer (2021). They detected a decrease in the bandgap values by increasing the doping concentrations on the matrix. In optical conclusion, both the direct and indirect determined values of the energy bandgaps of the proposed $\mathrm{Er}_{2} \mathrm{O}_{3}-\mathrm{ZnO}$ nanostructures are lower than those values of the pure $\mathrm{ZnO}$ nanoparticles. 


\subsubsection{Dielectric behavior and AC electrical conductivity of Er-doped ZnO nanocomposites.}

The complex dielectric function $\varepsilon^{*}(\omega)$ simplifies the material's direct response to electromagnetic radiation (EM) and also controls the propagation behavior of EM waves through the investigated media. As a result, it is critical to characterize the nature and the origin of the dielectric function for the as-proposed $\mathrm{Er}_{2} \mathrm{O}_{3}-\mathrm{ZnO}$ nanostructured by using the following equations (Mansour et al. 2010):

$\varepsilon^{*}(\omega)=\varepsilon_{1}(\omega)+i \varepsilon_{2}(\omega)$,

and

$\varepsilon_{1}(\omega)=\frac{C \times l}{\varepsilon_{0} \times A}, \quad$ and $\quad \varepsilon_{2}(\omega)=\tan \delta \times \varepsilon^{\prime}$

Here, the real component of the dielectric constant is $\varepsilon_{1}(\omega)$, whereas $\varepsilon_{2}(\omega)$ is the imaginary component. The variation of dielectric constant $\varepsilon_{1}(\omega)$ and dielectric loss $\varepsilon_{2}(\omega)$ versus the applied frequency ranging from $3 \times 10^{3} \mathrm{~Hz}$ to $10^{7} \mathrm{~Hz}$ are shown in Fig. 9 and Fig. 10.

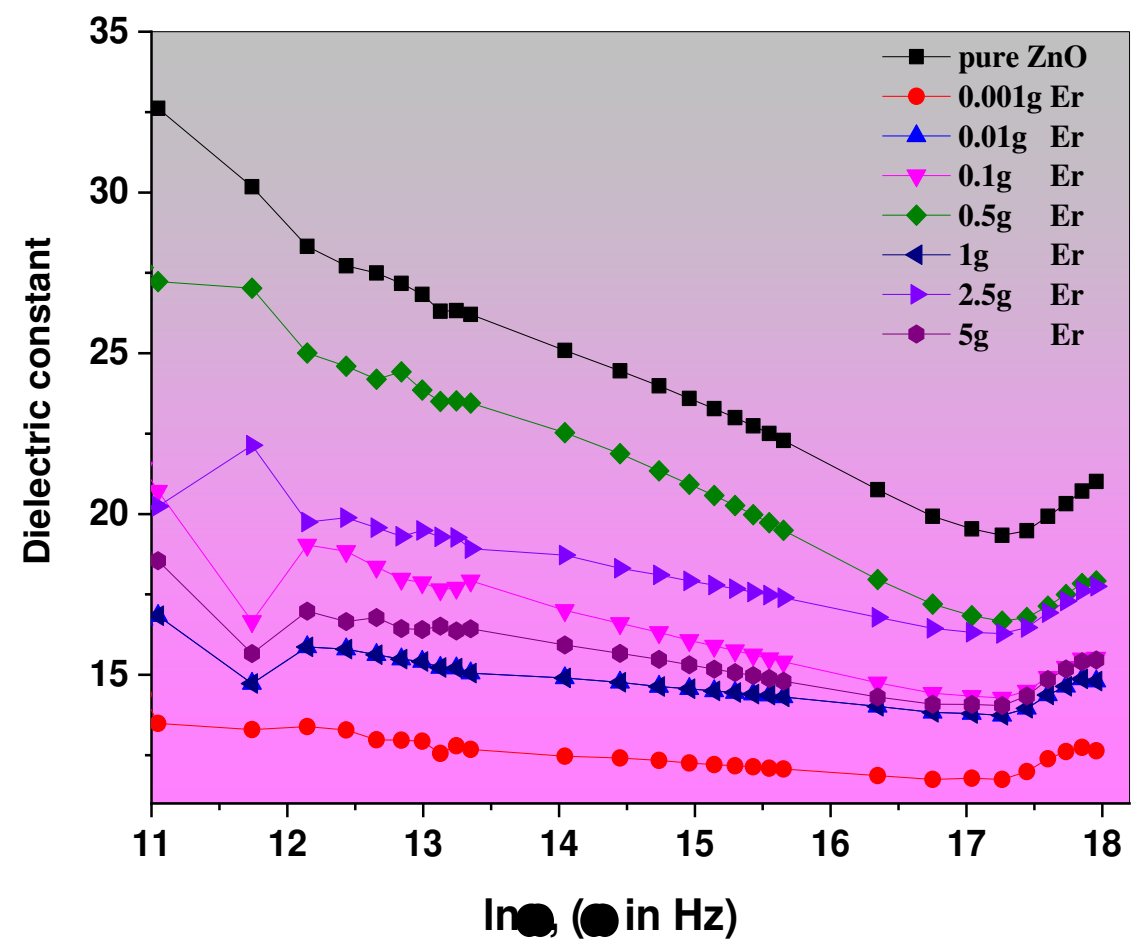

Fig. 9. Dielectric constant versus the applied frequency of the as-prepared $\mathrm{Er}_{2} \mathrm{O}_{3}-\mathrm{ZnO}$ nanostructured with different Erbium doping concentrations. 


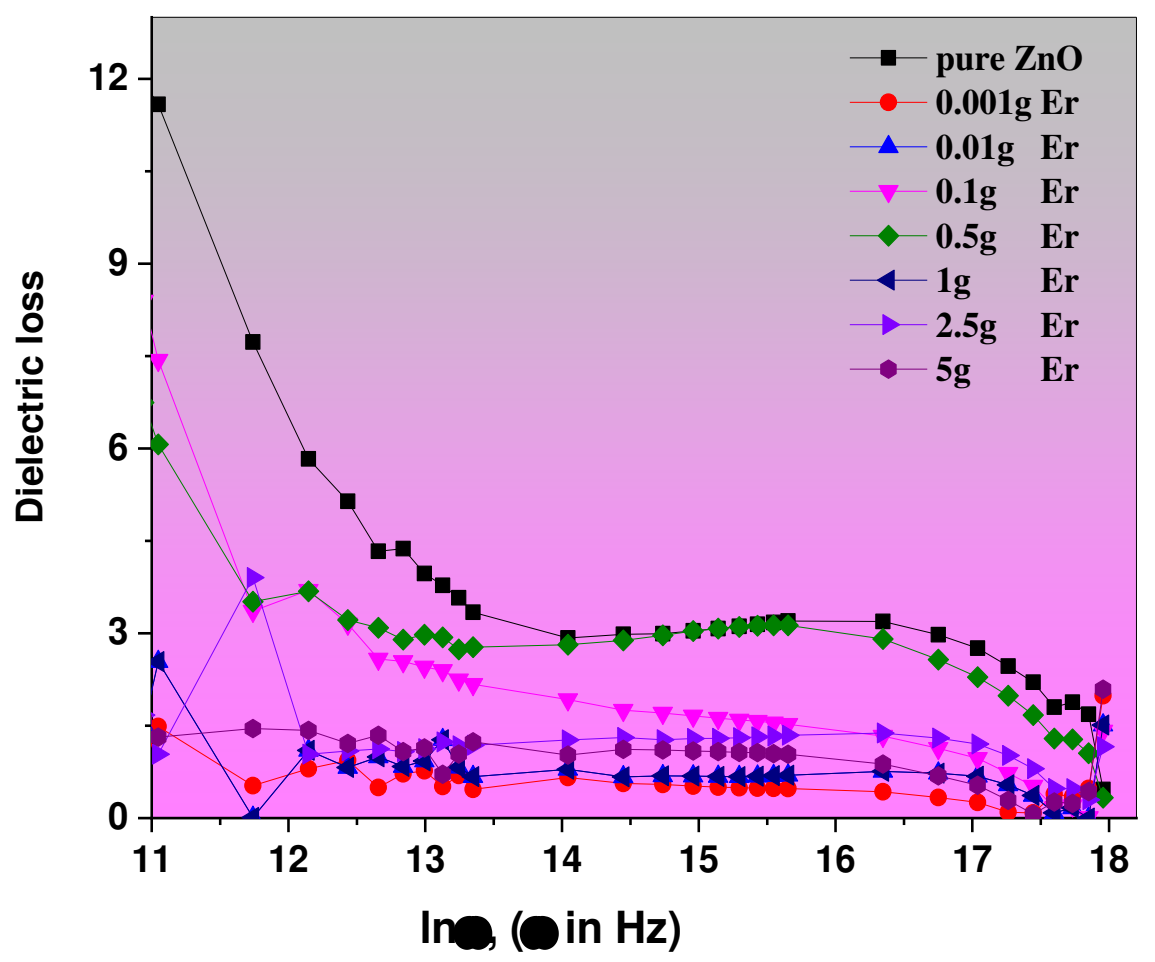

Fig. 10. Dielectric loss as a function of the applied frequency of the as-prepared $\mathrm{Er}_{2} \mathrm{O}_{3}-\mathrm{ZnO}$ nanostructured with different Erbium doping concentrations.

As shown in low-frequency regions from Fig. 9, the dielectric constants decline significantly as the incident frequency $(\ln \omega)$ increases up to around 14 . The dielectric constants decrease slightly with the rise of frequency. Enhancing the dielectric constants with a frequency reduction discloses that $\mathrm{Er}_{2} \mathrm{O}_{3}-\mathrm{ZnO}$ nanostructures determine large interfacial polarization in the region of low-frequency. At higher frequency values, the dielectric constant values increase and get the maximum value of approximately 35 as the $\ln \omega$ value reached 13 . Moreover, the dielectric constant values reduction is faster in the $\mathrm{Er}_{2} \mathrm{O}_{3}-\mathrm{ZnO}$ nanostructures with higher doping ratios of the Erbium-ions. To confirm, the values of both the dielectric constant and dielectric loss were larger in the region of low-frequency comparing to those values in the high-frequency region. Those found dielectric data in this current research greatly agreed with the available results by $\mathrm{P}$. Maji et. al (2015). The dielectric constants of $\mathrm{Zn}$ (NO3) 2 nanoparticles were observed to be declined with the polarization. In general, the reduction in the dielectric constant values for the investigated nanocomposites is assigned to the mechanism of dielectric polarization.

Also, the dielectric loss values reduce to the lowest possible point and then enlarge once more. Generally, reducing the values of the dielectric constant for the considered materials is linked to the 
polarization mechanism. To underline, dielectric polarization appears as ionic, dipolar, or interfacial electronic as an external electric field is practical to the $\mathrm{Er}_{2} \mathrm{O}_{3}-\mathrm{ZnO}$ nanomaterials. It can be concluded that ionic and electronic polarizations were dominant in the high range of frequency. In the region of low-frequency, the maximum value of the dielectric loss $\varepsilon_{2}(\omega)$ could be understood through the interfacial polarization mechanism due to charge carriers, which establish and limited by defects and grouped in the dielectric medium. When the frequency becomes higher, the $\varepsilon_{1}(\omega)$ starts to rise, getting the dipole oscillation's advantages, which can quickly rotate (Jonscher 1977).

It is significant to investigate the frequency influences on the AC electrical conductivity to describe the $\mathrm{Er}_{2} \mathrm{O}_{3}-\mathrm{ZnO}$ nanocomposite materials' conduction mechanism at different Erbium doping ratios. To compute the $\mathrm{AC}$ conductivity of the material under process, the next equations were applied (Murowski and Barczynski 1995; Bhattacharyya et al. 2001; Jali et al. 2007; Bobnar et al. 2004):

$$
\begin{aligned}
& \sigma_{\text {Total. } A C}(\omega)=\frac{t}{Z A}, \\
& \sigma_{\text {Total.AC }}(\omega)=\sigma_{D C}(\omega \rightarrow 0)+\sigma_{A C}(\omega), \\
& \sigma_{A C}(\omega)=A \omega^{S},
\end{aligned}
$$

Here, the total AC of electrical conductivity is noted as $\sigma_{\text {Total.AC }}(\omega), A$ is the effective area, and $Z$ is known as the impedance. Also, respectively, $\sigma_{D C}(\omega \rightarrow 0)$ and $\sigma_{A C}(\omega)$ are electrical conductivities of the DC and AC respectively, where $\omega$ is represented the angular frequency, and $s$ is donated the frequency exponent. The semiconductors showed AC values of the electrical conductivity between $10 \times 10^{-9}$ and $10 \times 10^{3} \Omega^{-1} \mathrm{~cm}^{-1}$ (Brütting 2006). Eq. 11 indicates that the AC electrical conductivity plays a major role in many-body interaction, explaining the power-laws universal behavior. The frequency exponent $(s)$ is a vital parameter that illustrates the multi interaction between the material impurities and charge carriers. The $s$ value depends on the frequency and the temperature, where its value varies from zero to one; it is equal to one for standard Debye type medium. Additionally, the frequency parameter is correlated to either charge carriers or inessential electrical dipoles caused by impurities. For disordered conductors, the frequency exponent range values between 0.6 to 0.8 , and it was around one for the highly disordered dielectric mediums (El-Mallah 2012; Tsonos 2019). C. Aydin et. al synthesized $\mathrm{ZnO}$ nanoparticles doped with iron metals (Fe) using a sol-gel calcination approach and investigated their electrical properties (2013). 


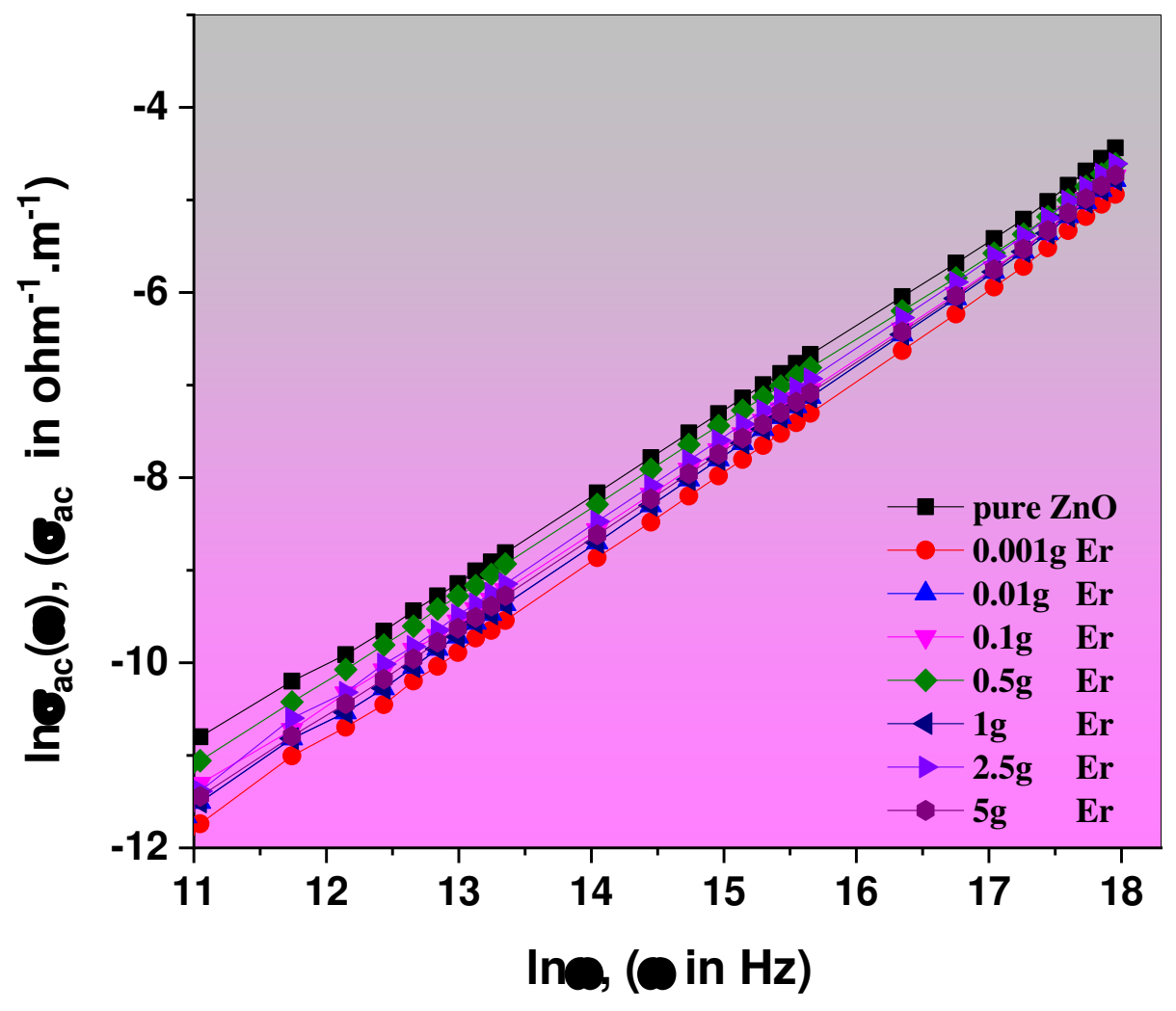

Fig. 11. AC electrical conductivities as a function of the as-prepared $\mathrm{Er}_{2} \mathrm{O}_{3}-\mathrm{ZnO}$ nanostructured with different Erbium doping concentrations.

The values of the $\mathrm{ZnO}$ electrical conductivity decreased as the concentrations of the $\mathrm{Fe}$ dopants increased. The attained values of activation energy were related to the optical energy levels of defects in the samples' bandgaps. The electrical conductivity of the Fe: $\mathrm{ZnO}$ nanoparticles were negatively affected by those defect levels.

\subsection{Varistor Applications of $\mathrm{Er}_{2} \mathrm{O}_{3}-\mathrm{ZnO}$ Nanocomposites.}

The voltage-current $(V-I)$ plots of undoped $\mathrm{ZnO}$ and doped with Erbium varistor nanoceramics at various Er contents are illustrated in Fig. 12(a-h). The studied materials demonstrate a nonlinear conductive property in the applied voltage range. All specimens displayed highly nonohmic behavior. This plot clearly showed that the conduction features could be separated into two zones: a linear range of high impedance below the knee-point voltage and a non-linear range of a low impedance above the knee point voltage. C.W. Nahm found that the knee-sharper of all plots among the two ranges is characterized as the improved nonlinear behavior (Nahm 2009). 

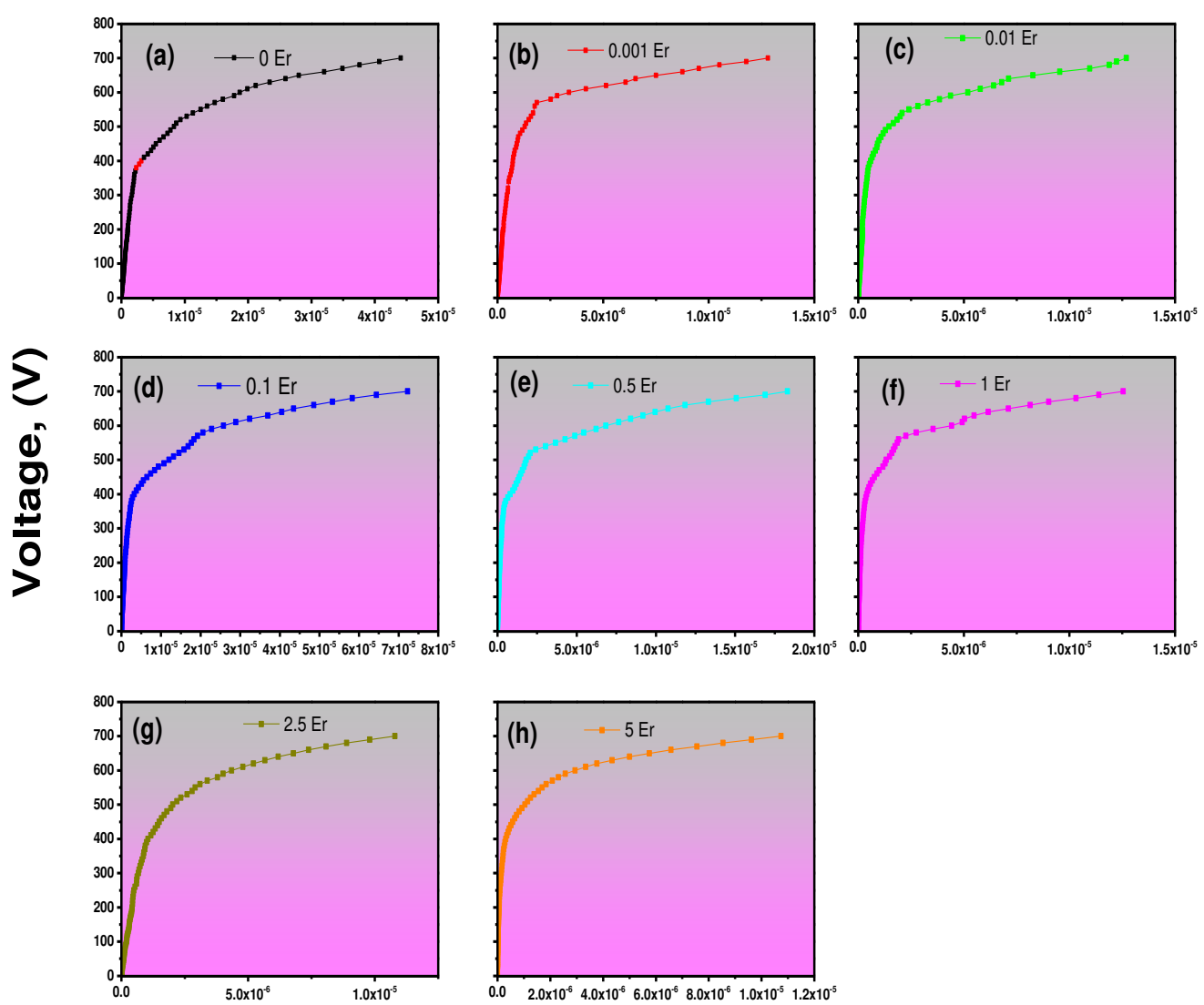

Current $\times 1 T^{-12},(1)$

Fig. 12 (a-h). $V-I$ characteristics of $\mathrm{ZnO}$ varistor ceramics versus the as-prepared $\mathrm{Er}_{2} \mathrm{O}_{3}-\mathrm{ZnO}$ nanostructured with different Erbium doping concentrations.

The $V$-I characteristics exhibited by all samples-based varistor ceramics consist predominantly of pre-breakdown, breakdown, and upturn regions (Knecht and Meith 1979). The varistor action takes place in the breakdown region. In this region, the applied voltage is a highly nonlinear function of the current and can be described by the empirical law as in (Kobayashi et al. 1978):

$I=K V^{\alpha}$,

where $V$ is the applied voltage, $I$ is current, $K$ is a constant depending on the geometry and manufacturing process, and $\alpha$ is the nonlinear coefficient. The nonlinear coefficient values $\alpha$ are obtained from the inverse slope of the $\ln V$ - $\ln I$ curves at any value of voltage as illustrated in Fig. 13. 


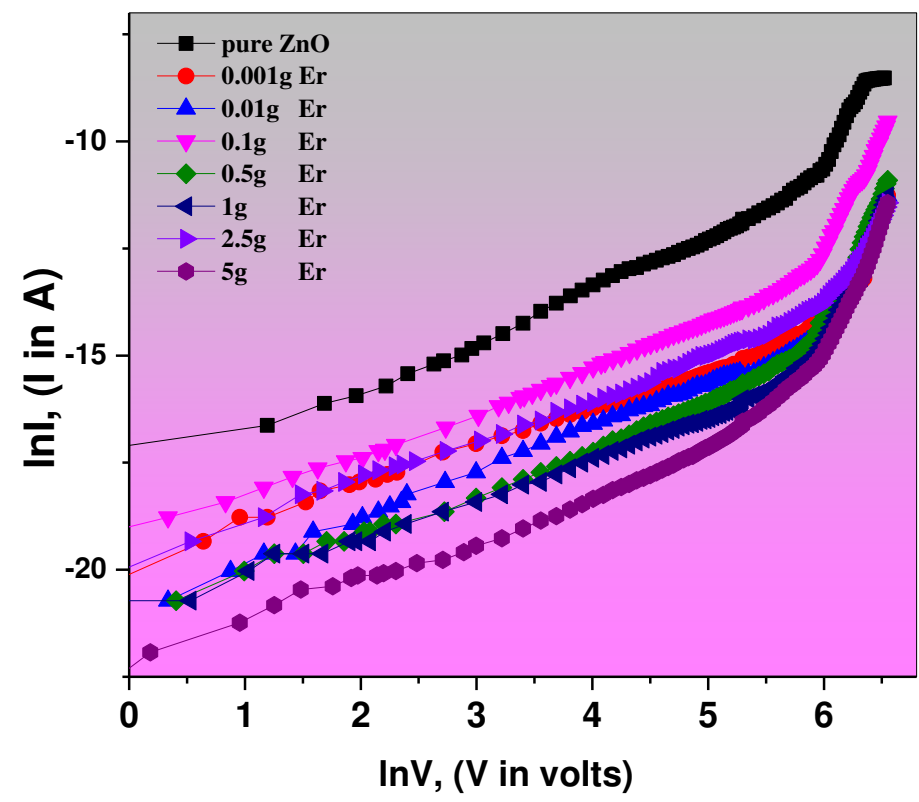

Fig. 13. The linear relation between $\ln I$ and $\ln V$ of the as-prepared $\mathrm{Er}_{2} \mathrm{O}_{3}-\mathrm{ZnO}$ nanostructured at various Erbium ratios.

It is recognized that the sharp knee-point among the linear region and the breakdown field is the better nonlinear properties, $V_{s s}$ is known as the threshold voltage, $\alpha$ is defined as the nonlinear coefficient, $R_{g b}$ is the grain boundary resistance that is calculated from the Cole-Cole plots of the impedance measurements. The leakage current $\left(I_{R}\right)$ is determined by the $V-I$ plots. The parameters of AC impedance have been used to analyze the complex impedance $\left(Z^{*}=Z^{\prime}+i Z^{\prime}\right)$ using the next expressions by Jonscher ( 1993):

$Z^{\prime}=\frac{1}{\omega c_{0}}\left[\frac{\varepsilon^{\prime \prime}}{\varepsilon^{\prime 2}+\varepsilon^{\prime \prime^{2}}}\right] ; Z^{\prime \prime}=\frac{1}{\omega c_{0}}\left[\frac{\varepsilon^{\prime}}{\varepsilon^{\prime 2}+\varepsilon^{\prime \prime^{\prime 2}}}\right]$,

where the selected angular frequency is written as $\omega$, the vacuum capacitance is defined as $c_{o}$, as well as both the real and imaginary components of the dielectric permittivity are defined as $\left(\omega^{\prime}, \omega^{\prime \prime}\right.$ $=\omega^{\prime} \tan \delta$ ), where they could be calculated via the following functions (Jonscher 1993):

$$
\begin{aligned}
& Z^{\prime}=\frac{R_{g b}^{2} Q \omega^{c} \cos \left(\frac{c \pi}{2}\right)+R_{g b}}{\left(1+R_{g b} Q \omega^{c} \cos \left(\frac{c \pi}{2}\right)\right)^{2}+\left(R_{g b} Q \omega^{c} \sin \left(\frac{c \pi}{2}\right)\right)^{2}}, \\
& -Z^{\prime \prime}=\frac{R_{g b}^{2} Q \omega^{c} \sin \left(\frac{c \pi}{2}\right)}{\left(1+R_{g b} Q \omega^{c} \cos \left(\frac{c \pi}{2}\right)\right)^{2}+\left(R_{g b} Q \omega^{c} \sin \left(\frac{c \pi}{2}\right)\right)^{2}},
\end{aligned}
$$


The resistance $\left(R_{b}\right)$ is simulated through the average square-technique, the CPE values are specified via $Q$, and the parameter $(c)$ is evaluated using the variance among the theoretical and experimental data. The CPE impedance is written as $Z_{C P E}=1 / A o(i \omega)^{c}$.
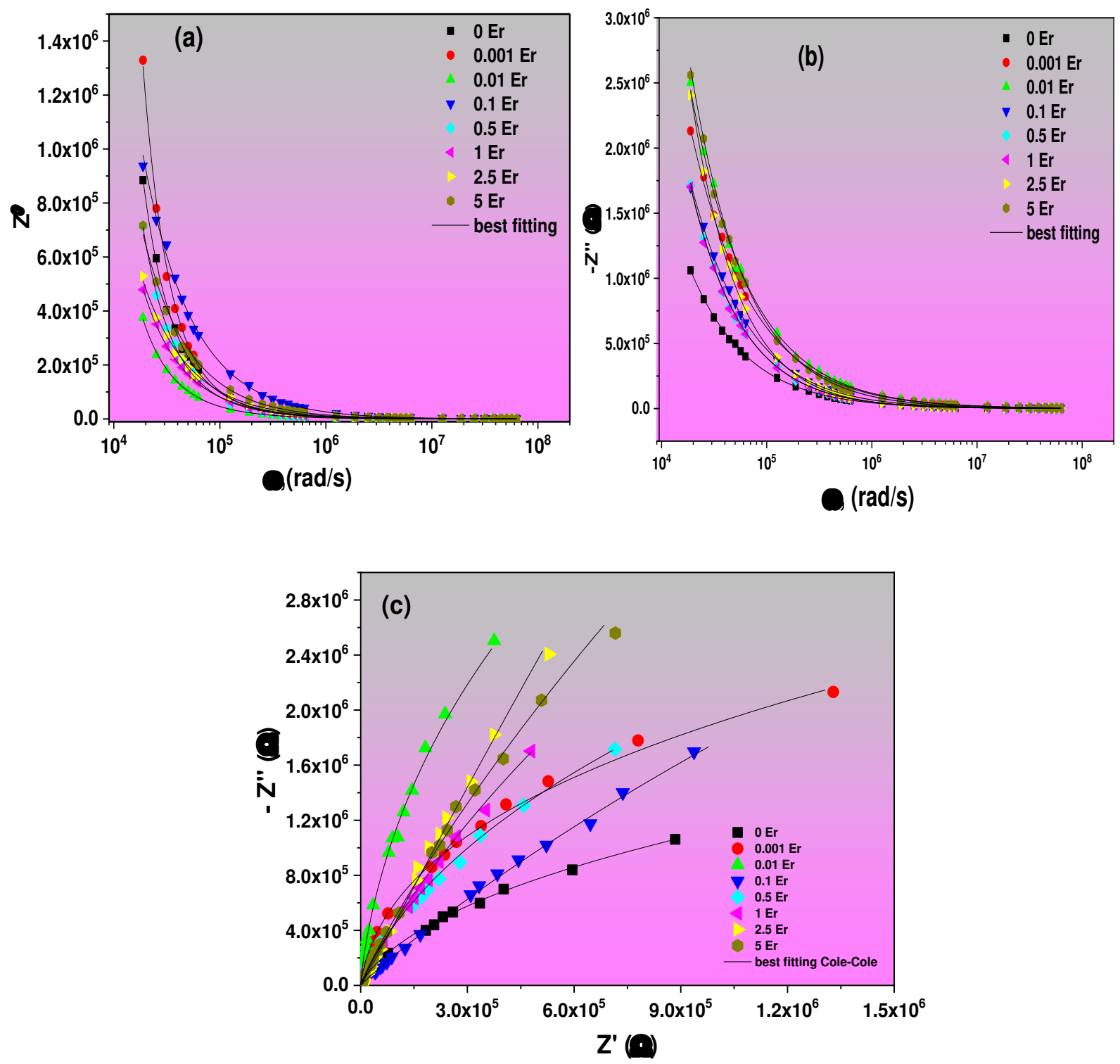

Fig. 14. (a) Real, (b) imaginary parts, and (c) Cole-Cole plots (the line represents the theoretical Cole-Cole fitting) of the as-prepared $\mathrm{Er}_{2} \mathrm{O}_{3}-\mathrm{ZnO}$ nanostructures with different Erbium doping concentrations.

The angular frequency is dependent on both real and imaginary components of different specimens' complex impedance is shown in Fig. 14 (a\&b). The observed values of the real portion of the complex impedance are large in the region of lower-frequency. It gradually decreases as 
increasing the angular frequency that is related to the increase of the AC electrical conductivity (see Fig. 14(a)) and keeps constant at the region with high-frequency. This is associated with the polarization of dielectric characteristics. Similar performance is found in the tendency of variation in the value of imaginary components of the complex impedance (see Fig. 14(b)). At the higherfrequency region, the experimental impedance data becomes frequency independent. To understand the illustrated results in Fig. 14(c), it is necessary to propose an equivalent circuit to extract grain boundary resistance and capacitance values for pure $\mathrm{ZnO}$ and the various Erbium contents-doped $\mathrm{ZnO}$-based ceramic varistor systems. It is noticed that all $\mathrm{ZnO}$ systems based ceramic varistor have a quasi-semicircle that are related to the contribution of the grain boundary. In this way, the equivalent model of the electrical circuit was utilized to determine the resistance of grain boundary $\left(R_{g b}\right)$ and capacitance $(Q)$ in parallel for various studied specimens.

The effect of doping Erbium doping levels on $\mathrm{ZnO}$-based ceramic varistors' nonlinear coefficient is very complex. Fig. 15(a) displays the difference between the leakage current and the grain boundary resistance for varistor samples with various Erbium contents. Obviously, the leakage current is decreased with increasing the Erbium contents. This is attributed to the increase in the homogeneous distribution and the activation energy of the imperfect quantity of varistor specimens. Based on the fitted impedance data and further investigating Erbium doping's effect, the variation of the capacitance values for different specimens was illustrated in Fig. 15(a). The variation of the capacitance showed an arrangement concerning the threshold voltage plots. The variation revealed an increase in the capacitance values.

Obtaining the grain boundary resistance $\left(R_{g b}\right)$ was possible for all the investigated varistors because the impedance spectroscopy approach tolerates the resistive separation for contribution among the grain boundary and the trap state. From the relevant impedance data, The obtained grain of boundary resistance $\left(R_{g b}\right)$ and the leakage current for the studied ceramic varistors as represented in Fig. 15 (b). Clearly, the leakage current declines and shows a little change. The increase of Erbium contents leads to an increase in the mean required energy for the homogeneous distribution in the ceramic varistor samples and for electrons overcoming the Schottky barrier. As a result, it is necessary to certify a large level of active barriers to the grain boundary and increase the resistance and avoid leakage currents to achieve higher values with a nonlinear coefficient. A graphical description of the nonlinear coefficient $\alpha$ and the threshold voltage $\left(V_{s s}\right)$ according to the Erbium contents in $\mathrm{ZnO}$-based varistors is illustrated in Fig. 15(c). 

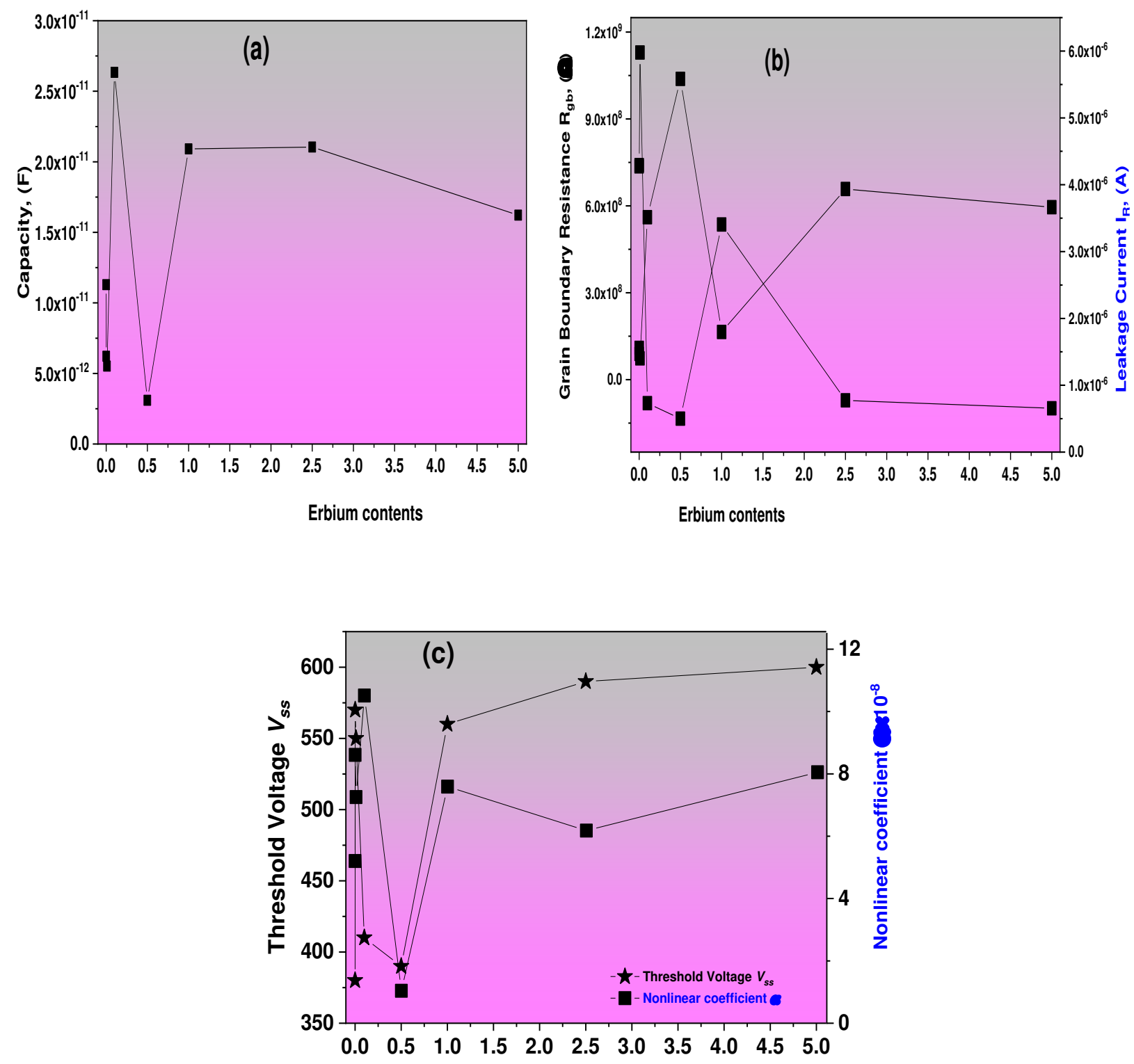

Erbium contents

Fig. 15 (a, b \& c). Influence of Erbium contents on $V-I$ fitted parameters of the as-prepared $\mathrm{Er}_{2} \mathrm{O}_{3}-\mathrm{ZnO}$ nanostructures with different Erbium doping concentrations.

It was clear that the variation in threshold voltage initially increased followed by a decrease, and lastly increased as the Erbium doping levels increased because of the reduction in the grain size of the $\mathrm{ZnO}$-based varistors. From Fig. 3(c), the nonlinear coefficients of Erbium-doped $\mathrm{ZnO}$ varistors firstly increased, then decreased, and lastly increased with various Erbium contents. With increasing the level doping of Erbium fillers, a similar variation of nonlinear coefficient $\alpha$ with the threshold voltage was observed. This was revealing an upside-down U-shaped curvature, 
which was considered an unsymmetrical behavior. Comparable published results were conveyed by X. Dong et al. (2012). The significant improvement effect of Erbium contents on the obtained nonlinear coefficients for the varistors was related to the microstructure uniformity and narrowed grain size distribution. Generally, the difference of the leakage currents was reverse to the variation on the nonlinear coefficients.

\subsection{Photocatalytic Degradation of $\mathrm{Er}_{2} \mathrm{O}_{3}-\mathrm{ZnO}$ Nanocomposites.}

\subsubsection{Photocatalytic activity.}

The use of rare-earth ions, as a metal doping, delivers electron traps that defeat recombination between electron and hole. Then, the holes will shift to the catalyst surface and oxidize the organic compounds that have been adsorbed by Dutta et al. (2005). The Er dopants over the $\mathrm{ZnO}$ catalyst nanomaterials led to increased fluorescence emissions and increased pair concentrations of electron-holes (Zhang 2012). Eropumam ions gave a strong potential of oxidation-reduction, leading to the photogeneration of electronic defects as well as the recombination rate of electron-hole. The surface favors the creation of positive holes, the dynamic reaction center will be considered. Thus, the outstanding production of holes has successfully removed phenolic compounds, such as the same case for MB by Ju-ka and Pivrikas (2008).
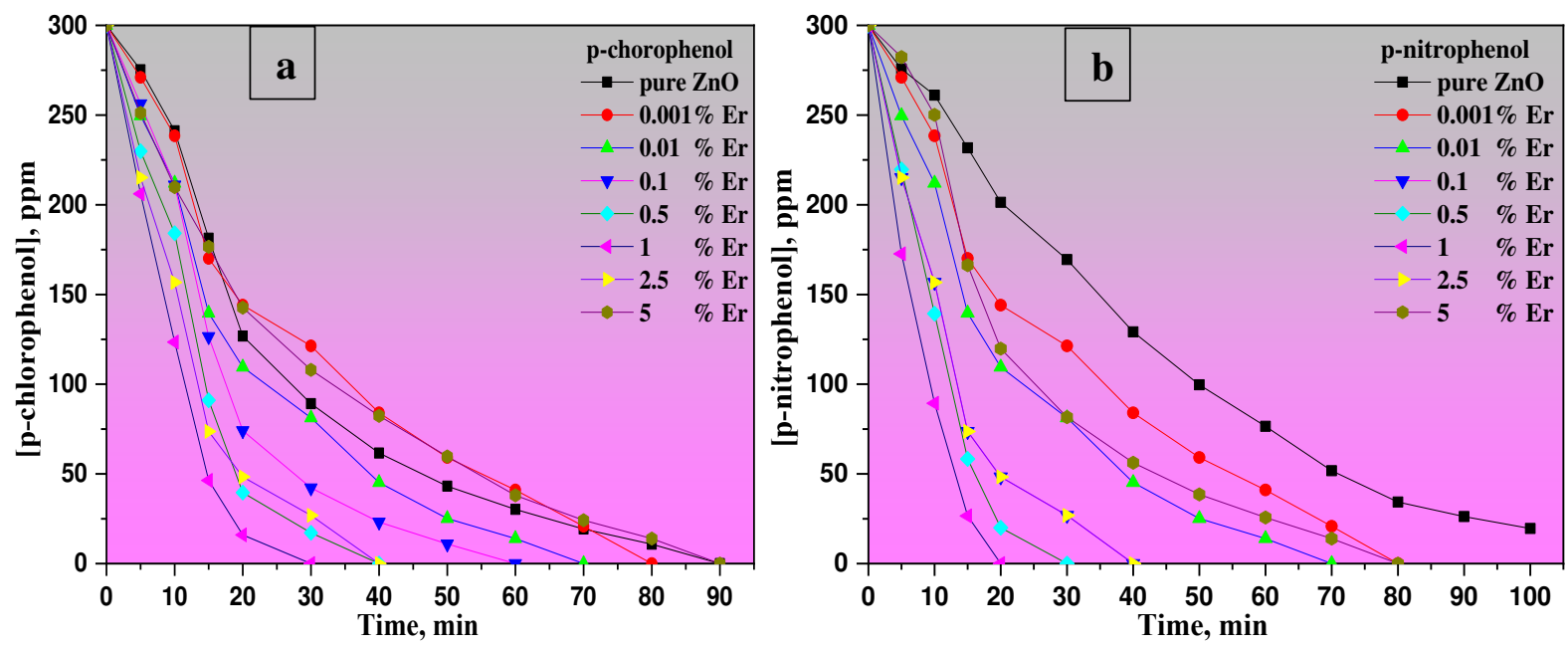

Fig. 16 (a,b). Concentration versus time for photodegradation using the as-prepared $\mathrm{Er}_{2} \mathrm{O}_{3}-\mathrm{ZnO}$ nanostructured with different Erbium doping concentrations: a) p-chlorophenol, b) p-nitrophenol.

Fig. $16(\mathrm{a}, \mathrm{b})$ showed a corresponding plot between p-chlorophenol concentration and pnitrophenol versus time of illumination through changing Er-concentration, respectively. Extensively, the percentage of $\mathrm{ZnO}$ doped with Er nanoparticles increases photocatalytic activity 
until $1 \mathrm{~g}$ of Er-doped $\mathrm{ZnO}$ (S5). The $1 \mathrm{~g}$ of Er-doped $\mathrm{ZnO}$ (S5) displays a remarkable drop in absorption as the irradiation duration increases. Fig.17(a,b) illustrates the photodegradation percentages as a function of irradiation time. The $\%$ of degradation was evaluated using equation (18).

$\%$ of degradation $=\left(C_{o}-C t / C_{o}\right) \times 100 \%$,

The $C_{o}$ is the initial methylene blue concentration; $C t$ is the concentration at the chosen time. As the degree of Er-doping increases by up to $1 \mathrm{~g}$ doped of $\mathrm{Er}$ (S5), the proportion of degradation increases significantly. However, the percentage of degradation (2.5 g, $5 \mathrm{~g}$ of Er (S5, and S6), respectively) declined as increasing the dopant concentration further.
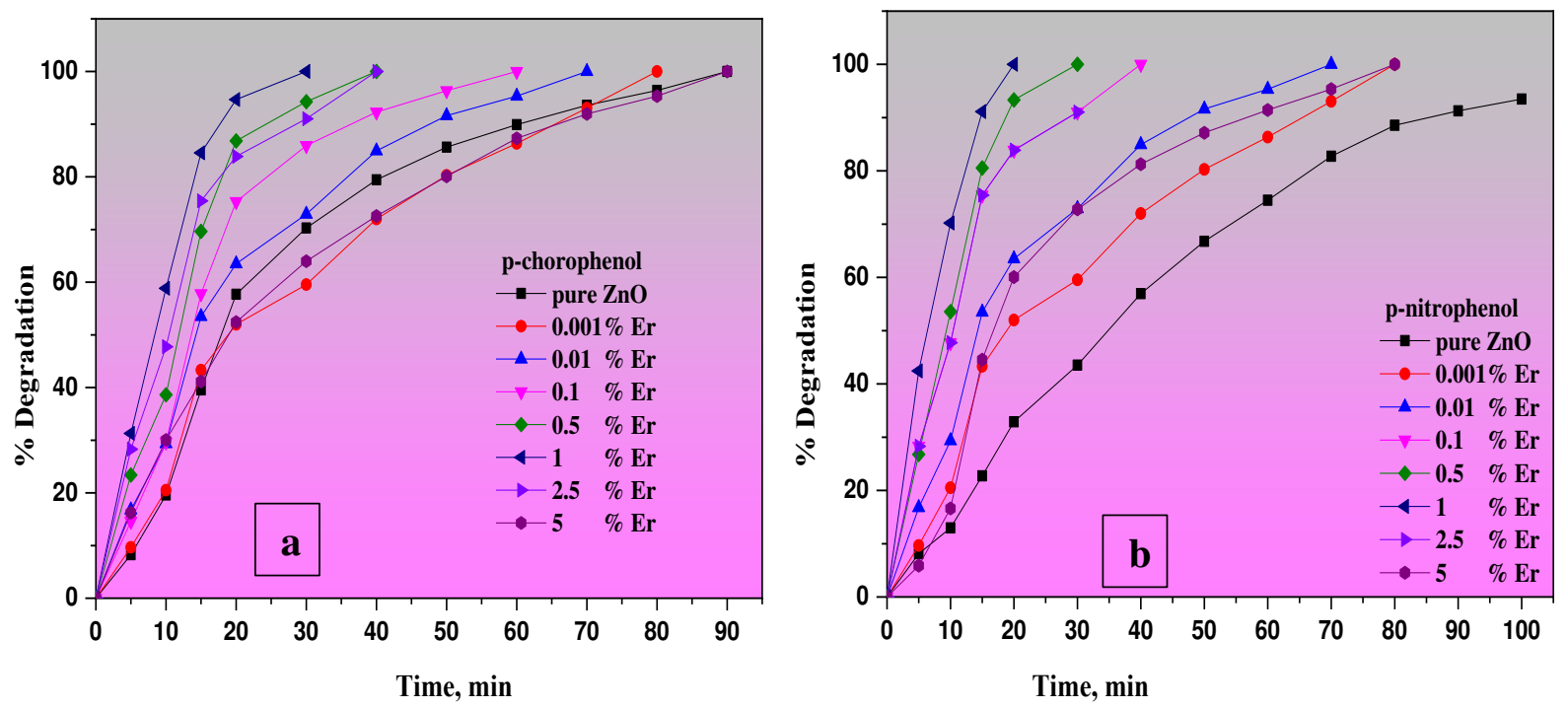

Fig. 17 (a,b). Degradation\% versus time for the as-prepared $\mathrm{Er}_{2} \mathrm{O}_{3}-\mathrm{ZnO}$ nanostructured with different Erbium doping concentrations: a) p-chlorophenol, b) p-nitrophenol.

The obtained results show that $1 \mathrm{~g}$ of Er-doped $\mathrm{ZnO}(\mathrm{S} 5)$ is essential for complete degradation (99.1\%) in 30 minutes of solution p-chlorophenol and 20 minutes for the p-nitrophenol solution. Thus, $1 \mathrm{~g}$ of Er-doped $\mathrm{ZnO}$ (S5) is the perfect photodegradation composition of $\mathrm{p}$ chlorophenol and p-nitrophenol. However, photocatalytic studies have shown that the increase has reduced the photocatalytic effects with doping separately and have decreased by an increase of $1 \mathrm{~g}$ of the Er- in the $\mathrm{ZnO}$ matrix (S5). This effect was attributed primarily to the fact that the light penetrated the $\mathrm{ZnO}$ suppress electron-hole pairs through the space-charge layer. It was decreased to a degree where the ratios of rare-earth ions were amplified to a certain amount (Wahl et al. 2003). Therefore, the dopant ion concentration is optimal; the thickness of the space-charge layer and the 
extent of the light dispersion at this concentration is comparable. Moreover, the pairs recombination of electron-hole has increased by too large several rare-earth ions in the surface of $\mathrm{ZnO}$, thereby the photocatalytic activity (Zhang and Zeng 2012).

\subsubsection{Kinetic study of the photocatalytic procedure.}

First-order kinetics is possible to exhibit heterogeneous photo-catalytic reactions amongst $\mathrm{ZnO}$ nanoparticles and organic compounds with water-solubility (Samoila et al. 2017). In this study, the authors, therefore, supposed that the concentration decay of p-chlorophenol and p-nitrophenol follow the pseudo-first-order kinetic model, $\mathrm{k}\left[\mathrm{min}^{-1}\right]$, calculated by nonlinear regression (Petrisor Samoila et al. 2017). For this kinetical analysis, the system's equilibrium has been achieved first via a 30-minute dark mixture of oxidic materials and phenolic solutions. The initial concentration of phenolic solutions $\left(C_{o}=300 \mathrm{ppm}\right)$ during the balance phase. After this phase, the UVillumination activated, and the photocatalysis reaction progressed with the decline of the phenol concentration. Fig. $18(\mathrm{a}, \mathrm{b})$ shows $\ln \left(C_{o} / C\right)$ versus the irradiation time. It was initiated that the pseudo-first reaction for each sample can be applied for the p-chlorophenol and p-nitrophenol degradations, respectively. The insertion in the $\mathrm{ZnO}$ matrix of Er-ions as rare-earth elements produced improved photocatalytic properties' studied materials.

Fig. 18 (a,b) using the nonlinear regression method was fit for the pseudo-first-order kinetic model in the presence of $\mathrm{ZnO}$-based materials. Table. 4 recapitulates the kinetic parameters for the p- chlorophenol and p-nitrophenol degradations. The most common expression used to define the kinetics of a heterogeneous procedure that includes aspects of both catalysis and adsorption phenomenon is the Langmuir-Hinshelwood model $(\mathrm{LH})$. The initial reaction rate of $k$ can be expressed according to the $\mathrm{LH}$ approach, according to $C_{o}$; the initial dye concentration, as indicated by Sobana and Thirumalai (2016):

$\ln \left(C_{t} / C_{o}\right) \rightarrow k t$

The first-order pseudo constants' values were higher according to the kinetic profiles, with an increase of the loading up to $1 \mathrm{~g}$ of Er- in the matrix. The fitted line reflects the LH model's prediction. K's maximum values were 0.147 and $0.158 \mathrm{~min}^{-1}$, respectively, for the p-chlorophenol and the p-nitrophenol. These studies confirmed the photodegradation of the waste materials by different concentrations of Er-doped $\mathrm{ZnO}$ nanostructured. The p-chlorophenol and p-nitrophenol molecules are physisorbed or chemisorbed on the ZnO-NPs surface during photocatalytic activity. The Er-doped $\mathrm{ZnO}$ nanocomposites are supposed to enhance the photocatalytic efficiency through 
surface defects. Also, the Er-ions can serve as an efficient electron scavenger for trapping electrons in the conductive band, leading to reduce the risk of recombining electron-hole (Khatamian et al. 2012). In this process, the responsive species are $\mathrm{H}_{2} \mathrm{O}_{2}, \mathrm{O}_{2}{ }^{-}$, and $\mathrm{HO}_{2}$, where this scavenger research was operated to identify responsible organisms for dye degradation. The Er-ions combined with $\mathrm{ZnO}$ are responsible for capturing exciting electrons from the $\mathrm{ZnO}$ conduction band to the Er-doped nanoparticles. The free electrons number declines at higher Er-concentrations, which causes photodegradation to decrease.
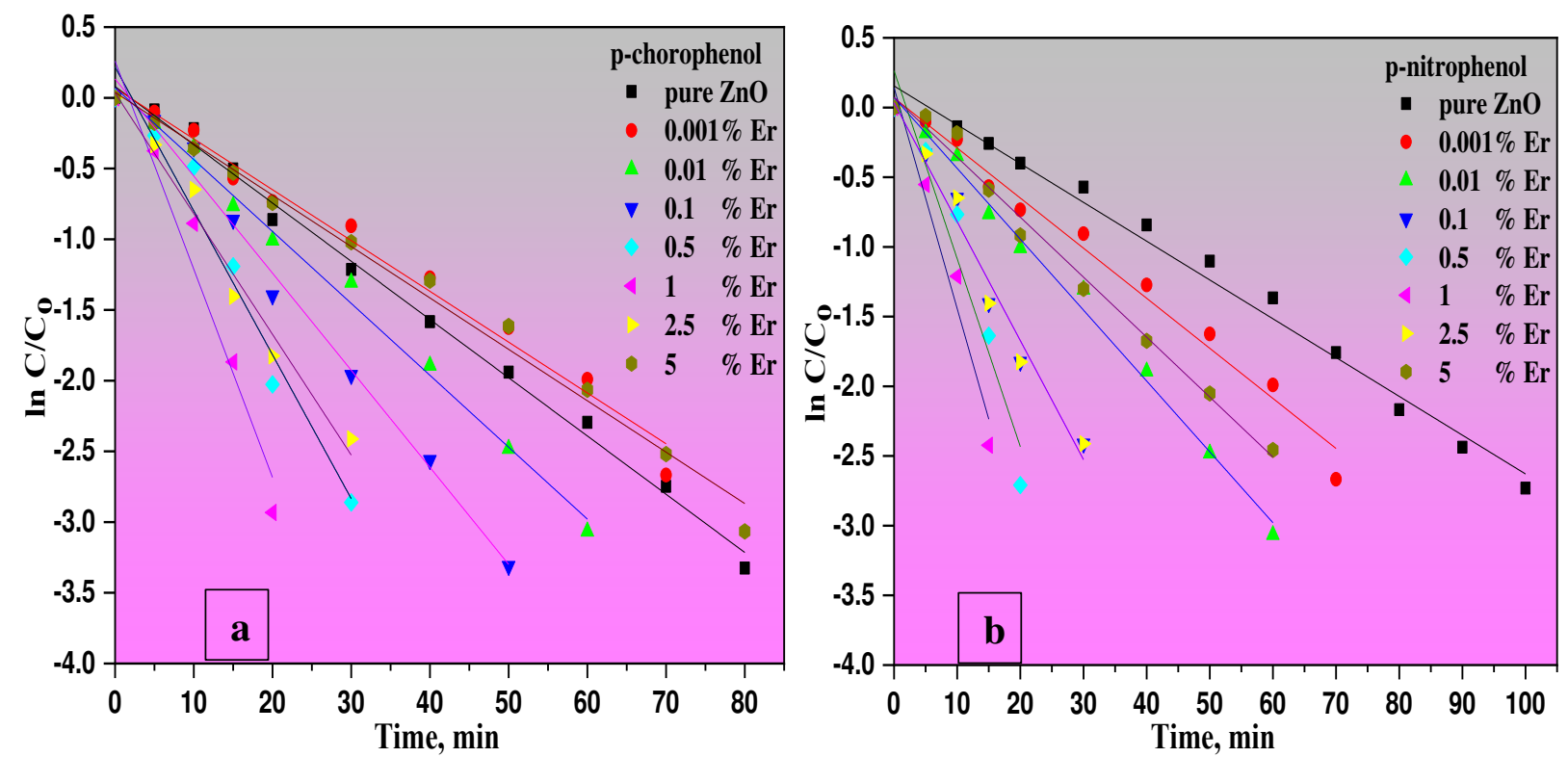

Fig. 18 (a,b). Kinetic data for photodegradation using for the as-prepared $\mathrm{Er}_{2} \mathrm{O}_{3}-\mathrm{ZnO}$ nanostructures with different Erbium doping concentrations: a) p-chlorophenol, b) p-nitrophenol.

Two mechanisms may explain the enhanced photocatalysis in the presence of Er ions. Based on the luminesce mechanism, the photocatalyst absorbance and bandgap significantly affect the photocatalysis performance, with the addition of the Er-dopant, the bandgap of ZnO shifts. Also, Er dopants can serve as the scavenger for superoxide ions to react and decrease the recombination rate of electron-hole pairs throughout the photocatalytic procedure (Khataee et al. 2013). Moreover, the Er: $\mathrm{ZnO}$ nanocomposites can generate an electron-hole pair surfacing barrier and a narrower zone of charging space in the $\mathrm{ZnO}$ lattice. However, an increase in the Er- material contributes to a rise in the spatial charge layer by growing the diffusion depth of ultrasonic irradiation into $\mathrm{ZnO}$ nanoparticles. The electron-hole recombination could be increased, and the efficiency of photocatalysis decreased. Furthermore, the excess Er dopant will cover the catalyst surface and 
increase electron-hole centers' recombination (Yan et al. 2005). Depending on the results, 1\% Erdoped $\mathrm{ZnO}$ is chosen for the next experiments as the best catalyst. Table. 5 shows that Er-doped $\mathrm{ZnO}$ has better photocatalytic performances than other nanoparticles that have been documented in the previous work. It was reported in recent studies that the performance of zinc oxide in visible photodegradation for some organic compounds in an aqueous solution is higher than $\mathrm{TiO}_{2}(\mathrm{Dindar}$ et al. 2001). Nearly all of the work was performed using artificially visible or microwave irradiation in the presence of zinc oxide (Parida and Parija 2006). This study aims to use the sun and ZnO's ability to degrade phenol by efficiently radiating solar light.

Table. 4. Reaction rate constants of 4-CP and 4-NP degradation for the as-prepared $\mathrm{Er}_{2} \mathrm{O}_{3}-\mathrm{ZnO}$ nanostructured with different Erbium doping concentrations.

\begin{tabular}{|l|c|c|c|c|}
\hline \multirow{2}{*}{ Samples } & \multicolumn{2}{|c|}{ p-chlorophenol } & \multicolumn{2}{c|}{ p-nitrophenol } \\
\cline { 2 - 5 } & K min m $^{-1}$ & $\begin{array}{c}\text { Adj. R- } \\
\text { Square }\end{array}$ & K min-1 & $\begin{array}{c}\text { Adj. R- } \\
\text { Square }\end{array}$ \\
\hline pure $\mathrm{ZnO}$ & 0.04118 & 0.99432 & 0.02784 & 0.98701 \\
\hline $0.001 \mathrm{wt} \% \mathrm{Er}: \mathrm{ZnO}$ & 0.03593 & 0.98143 & 0.03593 & 0.98143 \\
\hline $0.01 \mathrm{wt} \% \mathrm{Er}: \mathrm{ZnO}$ & 0.05084 & 0.99281 & 0.05084 & 0.99281 \\
\hline $0.1 \mathrm{wt} \% \mathrm{Er}: \mathrm{ZnO}$ & 0.06865 & 0.98953 & 0.08533 & 0.97262 \\
\hline $0.5 \mathrm{wt} \% \mathrm{Er}: \mathrm{ZnO}$ & 0.10172 & 0.95929 & 0.13487 & 0.92498 \\
\hline $1 \mathrm{wt} \% \mathrm{Er}: \mathrm{ZnO}$ & 0.14714 & 0.94093 & 0.15856 & 0.94533 \\
\hline $2.5 \mathrm{wt} \% \mathrm{Er}: \mathrm{ZnO}$ & 0.08533 & 0.97262 & 0.08533 & 0.97262 \\
\hline $5 \mathrm{wt} \% \mathrm{Er}: \mathrm{ZnO}$ & 0.03634 & 0.98944 & 0.04301 & 0.98752 \\
\hline
\end{tabular}

R. Kuma et al. found that the $\mathrm{Ce}: \mathrm{ZnO}$ nanoparticles displayed significant photocatalytic behavior (2015). The degradation percentage improved to $99.5 \%$ as increasing the Ceconcentration; however, photocatalytic degradation decreased further when Ce concentration increased. Therefore, the prepared Ce-doped $\mathrm{ZnO}$ particles exhibit significant photocatalytic degradation at an optimum Ce- $(3.28 \%)$ as an optimum concentration in 70 minutes only. K. Yu et al. reveals the XRD spectrum's characteristic peaks in the Er-doped $\mathrm{ZnO}$ nanostructures (2013). Under ultraviolet, the Er-doped $\mathrm{ZnO}$ absorbed more light, and the fluorescence emission intensity increased by the Er doping in the $\mathrm{ZnO}$. The degradation of the solution methylene blue (MB) showed that $\mathrm{ZnO}$ has significantly improved its photocatalytic activity through doping. 
Table. 5. Photocatalytic performance of several nanostructured materials incomparable with the studied ones.

\begin{tabular}{|c|c|c|c|c|c|c|c|c|c|}
\hline Photocatalyst & $\begin{array}{c}\text { Doping } \\
\%\end{array}$ & $\begin{array}{l}\text { Method of } \\
\text { preparation }\end{array}$ & $\begin{array}{l}\text { Organic } \\
\text { solution }\end{array}$ & $\begin{array}{l}\text { Dye } \\
\text { Conc. }\end{array}$ & $\begin{array}{c}\text { Catalyst } \\
\text { load, } \\
\text { (g/l) }\end{array}$ & $\begin{array}{c}\text { Irradiati } \\
\text { on time }\end{array}$ & $\begin{array}{l}\text { Energy } \\
\text { Source }\end{array}$ & $\begin{array}{c}\% \text { of } \\
\text { Degrada } \\
\text { tion }\end{array}$ & Refs. \\
\hline $\begin{array}{c}\text { Ce- doped } \\
\mathrm{ZnO}\end{array}$ & $\begin{array}{c}3.28 \\
\%\end{array}$ & $\begin{array}{c}\text { Solution } \\
\text { combustion }\end{array}$ & DR-26 & $\begin{array}{c}40 \\
\text { ppm }\end{array}$ & 0.07 & $70 \mathrm{~min}$ & $\begin{array}{l}\text { UV- } \\
\text { light }\end{array}$ & $99.5 \%$ & $\begin{array}{r}\text { (Yu et } \\
\text { al.2013) }\end{array}$ \\
\hline Er-doped $\mathrm{ZnO}$ & $4.8 \%$ & $\begin{array}{l}\text { Homogeneous } \\
\text { precipitation }\end{array}$ & MB & $\begin{array}{c}10 \\
\mathrm{mg} / \mathrm{L}\end{array}$ & 0.05 & $60 \mathrm{~min}$ & $\begin{array}{l}\text { UV- } \\
\text { light }\end{array}$ & $97.7 \%$ & $\begin{array}{c}\text { (Khataee et } \\
\text { al. 2015) }\end{array}$ \\
\hline Er-doped $\mathrm{ZnO}$ & $4 \%$ & $\begin{array}{c}\text { Sonochemical } \\
\text { synthesis }\end{array}$ & RO 29 & $1 \mathrm{ppm}$ & 0.1 & $180 \mathrm{~min}$ & $\begin{array}{l}\text { Ultrason } \\
\text { ic bath }\end{array}$ & $92.2 \%$ & $\begin{array}{c}\text { (Kumar et } \\
\text { a.1.2018) }\end{array}$ \\
\hline Er-doped $\mathrm{ZnO}$ & $2.5 \%$ & $\begin{array}{c}\text { Simple } \\
\text { combustion }\end{array}$ & DR -31 & $\begin{array}{c}35 \\
\mathrm{ppm}\end{array}$ & 0.08 & $60 \mathrm{~min}$ & $\begin{array}{l}\text { UV- } \\
\text { light }\end{array}$ & $99.1 \%$ & $\begin{array}{c}\text { (Khataee et } \\
\text { al. 2013) }\end{array}$ \\
\hline $\begin{array}{l}\text { Sm-doped } \\
\mathrm{ZnO}\end{array}$ & $6 \%$ & $\begin{array}{c}\text { DC magnetron } \\
\text { reactive } \\
\text { sputtering } \\
\text { deposition }\end{array}$ & MB & $\begin{array}{c}15 \\
\mathrm{ppm}\end{array}$ & $\begin{array}{c}10 \times 10 \\
\mathrm{~mm}\end{array}$ & $120 \mathrm{~min}$ & $\begin{array}{l}\text { Sun } \\
\text { light }\end{array}$ & $96.57 \%$ & $\begin{array}{l}\text { (Mengstu et } \\
\text { al. 2018) }\end{array}$ \\
\hline Ag-doped $\mathrm{ZnO}$ & & Coprecipitation & M-violet & $\begin{array}{c}4.5 \times \\
10^{-4} \mathrm{M}\end{array}$ & 1 & $3 \mathrm{~h}$ & $\begin{array}{l}\text { Sun } \\
\text { light }\end{array}$ & $83 \%$ & $\begin{array}{c}\text { (Yu et al. } \\
\text { 2013) }\end{array}$ \\
\hline $\begin{array}{c}\text { Eu- doped } \\
\text { ZnO }\end{array}$ & $1 \%$ & $\begin{array}{c}\mathrm{Co}- \\
\text { precipitation }\end{array}$ & MB & $\begin{array}{l}100 \\
\mathrm{ppm}\end{array}$ & 1 & $180 \mathrm{~min}$ & $\begin{array}{l}\text { UV- } \\
\text { light }\end{array}$ & $95.3 \%$ & $\begin{array}{c}\text { (Zong et al. } \\
\text { 2014) }\end{array}$ \\
\hline Nd-doped $\mathrm{ZnO}$ & $3 \%$ & $\begin{array}{c}\text { Microwave- } \\
\text { assisted } \\
\text { solution }\end{array}$ & MB & $\begin{array}{c}1 \times \\
10^{-5} \mathrm{M}\end{array}$ & 0.02 & $300 \mathrm{~min}$ & $\begin{array}{l}\text { UV- } \\
\text { light }\end{array}$ & $71.0 \%$ & $\begin{array}{c}\text { (Phuruangrat } \\
\text { et al. 2018) }\end{array}$ \\
\hline Nd-doped ZnO & $1 \%$ & Sol-gel & MB & $\begin{array}{c}10 \\
\mathrm{ppm}\end{array}$ & 2 & $25 \mathrm{~min}$ & $\begin{array}{l}\text { UV- } \\
\text { light }\end{array}$ & $98.0 \%$ & $\begin{array}{c}\text { (Alam et al. } \\
\text { 2018) }\end{array}$ \\
\hline $\mathrm{ZnO}$ & ----- & Microwave & $\begin{array}{l}\text { P- } \\
\text { Nitrophe } \\
\text { nol }\end{array}$ & $\begin{array}{l}300 \\
\mathrm{ppm}\end{array}$ & 0.6 & $4 \mathrm{~h}$ & $\begin{array}{l}\text { Sun } \\
\text { light }\end{array}$ & $98 \%$ & $\begin{array}{c}\text { (Parida et al. } \\
\text { 2006) }\end{array}$ \\
\hline $\mathrm{ZnO}$ & ----- & Microwave & $\begin{array}{c}\text { P- } \\
\text { chloroph } \\
\text { enol }\end{array}$ & $\begin{array}{c}50 \\
\mathrm{ppm}\end{array}$ & 0.2 & $20 \mathrm{~min}$ & $\begin{array}{c}\text { Visible } \\
\text { light }\end{array}$ & $98.5 \%$ & $\begin{array}{c}\text { (Rajar et al. } \\
\text { 2018) }\end{array}$ \\
\hline Er-doped $\mathrm{ZnO}$ & $1 \%$ & Combustion & $\begin{array}{l}\text { P- } \\
\text { chloroph } \\
\text { enol }\end{array}$ & $\begin{array}{c}300 \mathrm{pp} \\
\mathrm{m}\end{array}$ & 0.1 & $30 \mathrm{~min}$ & $\begin{array}{c}\text { Visible } \\
\text { light }\end{array}$ & $99.5 \%$ & Present work \\
\hline Er-doped $\mathrm{ZnO}$ & $1 \%$ & Combustion & $\begin{array}{l}\text { P- } \\
\text { Nitrophe } \\
\text { nol }\end{array}$ & $\begin{array}{l}300 \\
\mathrm{ppm}\end{array}$ & 0.1 & $20 \mathrm{~min}$ & $\begin{array}{c}\text { Visible } \\
\text { light }\end{array}$ & $99.5 \%$ & Present work \\
\hline
\end{tabular}


Alireza Khataee et al. used the sonochemical method for Er-doped $\mathrm{ZnO}$ synthesis and found the sono-degradation efficiency of doped $\mathrm{ZnO}$ for all doping content greater than undoped $\mathrm{ZnO}$ (2015). A 4\% Er-doped $\mathrm{ZnO}$ demonstrated 88\% of reactive Orange 29 (RO29) of best sonoCatalytic performance with decoloration efficiency. The RO29 degradation was performed in the existence of synthesized catalytic systems utilizing an ultrasound bath (Ultra 8060, England) with $150 \mathrm{~W}$ output power and $36 \mathrm{kHz}$ frequency. Sonik Bhatia et al. found that the percentage of degradation rise at $2.5 \mathrm{wt} \%$ increased with Er concentration (2016). Thus, there is almost total degradation in only 60 minutes under UV light. The Kinetic study showed that all the ER: $\mathrm{ZnO}$ samples obey a constant rate of the first-order. Photocatalytic efficiency improvement was demonstrated by D. Ranjith Kumar et al., which for Sm: ZnO samples were from 83.02\% to 97.3\% and was reduced by $95.72 \%$ at higher concentration to $8 \%$ for Sm-ions (2018). Mengstu Etay Ashebir et al. utilized a co-precipitation approach to preparing Ag-doped $\mathrm{ZnO}$ samples (2018).

Considering the main energy source is the sunlight, photocatalytic activities were assessed in the samples by evaluating the photocatalytic decolorization of the methyl violet dye. For the synthesized sample, a catalyst dose of one gram per letter $(1 \mathrm{~g} / \mathrm{L})$ with a starting concentration of $4.5 \times 10^{-4} \mathrm{~g} / \mathrm{L}$, the photocatalytic decolorization for methyl violet dye was illustrated the beneficial $\mathrm{pH}$ of 9.0. The photocatalytic decolorization efficiency of $\mathrm{Mn}$ : $\mathrm{ZnO}$ as well as $\mathrm{Ag}$ : $\mathrm{ZnO}$ was substantially larger than that of the pure $\mathrm{ZnO}$ matrix. In visible light, the addition of $\mathrm{Mn}$ and $\mathrm{Ag}$ metals improved the $\mathrm{ZnO}$ photocatalytic activities because of their ability to raise the defects in the $\mathrm{ZnO}$ surface. In effect, the transfer of optical absorption to the visible wavelength region. Yanqing Zong et al. reported that $11.0 \mathrm{~mol} \%$ of Eu: $\mathrm{ZnO}$ nanoparticles had the maximum photocatalytic performance of Methylene Blue (MB) through the effective separation of photogenerated carriers (2014). The photocatalytic performance of $\mathrm{Nd}$-doped $\mathrm{ZnO}$ was investigated by A Phuruangrat through the decomposition of the UV-activated methylene blue (MB) (2018). The best photocatalytic activity for $\mathrm{MB}$ dye degradation was the improved $3 \mathrm{wt} \% \mathrm{Nd}$-doped $\mathrm{ZnO}$ by $3.95 \times 10^{-3} \mathrm{~min}^{-1}$. The photocatalysis was also discussed of the UV-activated $\mathrm{Nd}$ : $\mathrm{ZnO}$ samples. The greatest activity with $98 \%$ degradation efficiency for $10 \mathrm{ppm}$ MB degradation was found by U. Alam (2018). K.M. Parida et al. was prepared $\mathrm{ZnO}$ with different precipitating agents using different methods. The solar light in set reactors toward the 4-nitrophenol oxidation was used to perform photocatalytic reactions (2006). He concluded that the 15 minutes photodegradation using microwave radiated samples in $0.6 \mathrm{~g} / \mathrm{L}$ showed $92 \%$ and $98 \%$ of 4-nitrophenol, which keeps 3 and 4 hours under the sun. Thus, the $\mathrm{ZnO}$ irradiated microwave is effectively used to oxidize and reduce 
organic and inorganic pollutants. In the case of stability and activity, irradiated microwave samples are better than commercial ZnO. Kausar Rajar et al. showed a simplistic approach to synthesizing zinc oxide nanoparticles by microwaves that assisted chemical precipitation (2018). It has been proven that in the absence of initiators such as $\mathrm{H}_{2} \mathrm{O}_{2}, 98.5 \%$ of 4-CP was degraded in 20 minutes, reflecting a good prospective use as photocatalyst for the $\mathrm{ZnO} \mathrm{NP}$. Four times, the $\mathrm{ZnO}$ nanocatalysts were recycled, which displayed an efficiency of up to $95.5 \%$ for $4-\mathrm{CP}$ catalytic degradation in the definite time of 20 minutes.

\subsubsection{Photocatalytic degradation mechanism}

The excited electrons are transferred to the conduction band (CB) when solar light is irradiated on the valence band (VB). The load pairs resulted in regulating the performance of the $\mathrm{ZnO}$ photocatalytic. Fast recombination of the photo charges, however, will reduce photocatalytic performance. Besides, the high energy level of the $\mathrm{ZnO}$ surface, which reduces the photocatalytic activity, could easily be packed into large aggregates. Therefore, removing the recombination of electron-hole is significantly high to enhance the photocatalytic efficiency of the $\mathrm{ZnO}$ matrix. Superoxide anion radicals $\left[\mathrm{O}_{2}^{-}\right]$are produced due to the reaction between the $\mathrm{CB}$ electrons and oxygen $\left(\mathrm{O}_{2}\right)$, while $[\cdot \mathrm{OH}]$ are obtained when the VB holes react with $\mathrm{H}_{2} \mathrm{O}$. Scheme. 1 illustrates the two mechanisms that can produce $[\cdot \mathrm{OH}]$. The holes of the valence band (VB) first oxidize molecules of water to $[\cdot \mathrm{OH}]$.

Optically, the formed electrons react with oxygen besides decrease $[\cdot \mathrm{OH}]$ radical (Szabó-Bárdoset al. 2003). It is usually assumed that the electrons transferred from the $\mathrm{ZnO}$ surface and absorbed $\mathrm{O}_{2}$ molecules limit the photocatalytic mechanism of electron-hole pair rate for semiconductors (Haruta 1997; $\mathrm{Xu}$ et al. 2010). Suppose the $\mathrm{ZnO}$ is modified through Er- dopants. In that case, this can attract the excited electrons in the $\mathrm{CB}$, which perform as an electron capture center and defeats the rate of recombination of the electron-hole significantly. Using consecutive reactions as the final product, the doping electrons react to $\mathrm{O}_{2}$ in the form of [·OH]. During doping on the Er-doped $\mathrm{ZnO}$ valence bands, the charge transport would be facilitated to the $\mathrm{H}_{2} \mathrm{O}$ molecule, or $[\cdot \mathrm{OH}]$ absorbed $[\cdot \mathrm{OH}]$ to form on the photocatalyst surface. During photocatalysis, $[\cdot \mathrm{OH}]$ was developed to react to surface-adsorbed MO molecules to be degraded pollutants (Sun et al. 2008). The [·OH] can, therefore, be understood in the nanoparticles existence of Er-doped $\mathrm{ZnO}$ as follows:

$$
\begin{aligned}
& \mathrm{ZnO}+\mathrm{Er}^{+3} \rightarrow \mathrm{ZnO}\left(\mathrm{h}^{+}\right)+\mathrm{Er}^{+2} \\
& \mathrm{Er}^{+2}+\mathrm{O}_{2} \rightarrow \mathrm{O}_{2}{ }^{*}+\mathrm{Er}^{+3}
\end{aligned}
$$




$$
\begin{aligned}
& \mathrm{O}_{2}{ }^{*}+\mathrm{H}^{+} \rightarrow \mathrm{HOO}, \\
& \mathrm{HOO}+\mathrm{H}^{+}+\mathrm{Er}^{+2} \rightarrow \mathrm{H}_{2} \mathrm{O}_{2}+\mathrm{Er}^{+3}, \\
& \mathrm{H}_{2} \mathrm{O}_{2}+\mathrm{Er}^{+2} \rightarrow{ }^{*} \mathrm{OH}+{ }^{-} \mathrm{OH}+\mathrm{Er}^{+3}, \\
& \mathrm{ZnO}\left(\mathrm{h}^{+}\right)+\mathrm{H}_{2} \mathrm{O} \rightarrow{ }^{*} \mathrm{OH}+\mathrm{H}^{+}, \\
& { }^{*} \mathrm{OH}+4-\mathrm{CP} \rightarrow \mathrm{CO}_{2}+\mathrm{H}_{2} \mathrm{O}, \\
& { }^{*} \mathrm{OH}+4-\mathrm{NP} \rightarrow \mathrm{CO}_{2}+\mathrm{H}_{2} \mathrm{O},
\end{aligned}
$$

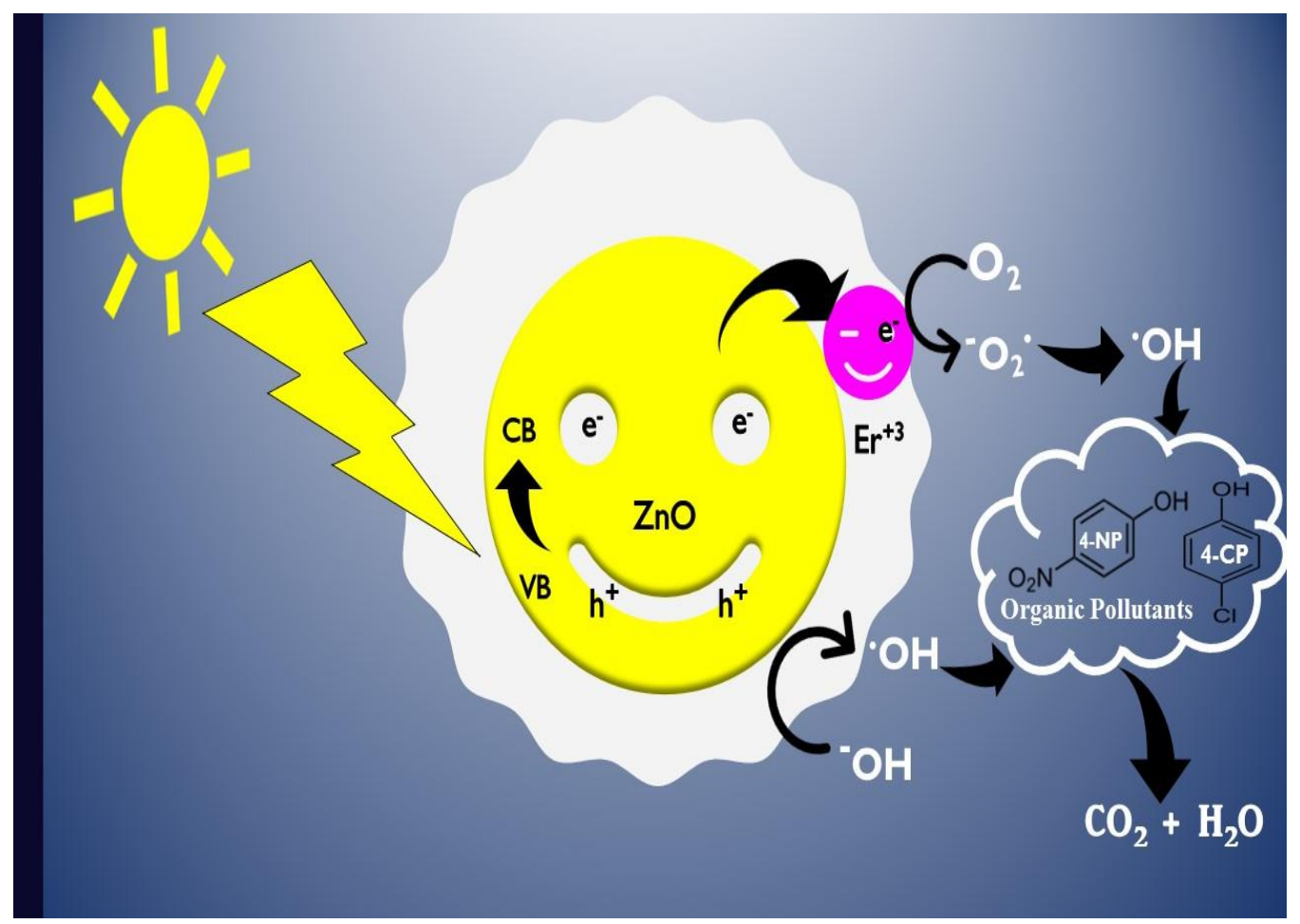

Scheme. 1. Schematic illustration of proposed photodegradation mechanism of 4CP and 4NP using for the as-prepared $\mathrm{Er}_{2} \mathrm{O}_{3}-\mathrm{ZnO}$ nanostructures with different Erbium doping concentrations under visible light.

\subsubsection{The proposed products of photocatalytic degradation}

The photocatalytic oxidation of phenolic compounds as the commonly reported organic compounds included three processes as regular steps. Firstly, Er-doped ZnO's uptake of the phenolic solution molecules occurred to attract them close to the catalytic sites. The second process involved the effective absorption of visible light photons by the composite grains to achieve multiple electron excitation. This is followed by the charge transfer interactions among the composite and the organic molecules, resulting in the oxidizing species' degrade the organic contaminants (Rana et al. 2013). The oxidative mineralization of phenolic compounds took place 
through several steps through either chromatographic or spectroscopic findings. First, it involves creating extremely toxic quinones, followed by the perfumed ring's opening, which leads to aliphatic acid creation and lastly to carbon dioxide (Borras et al. 2007; Liu et al. 2008). As seen in Scheme. 2, the major pathways of oxidation reaction (perceived intermediates) are demonstrated during the 4-CP oxidation following the consecutive attack on the hydroxyl radicals.

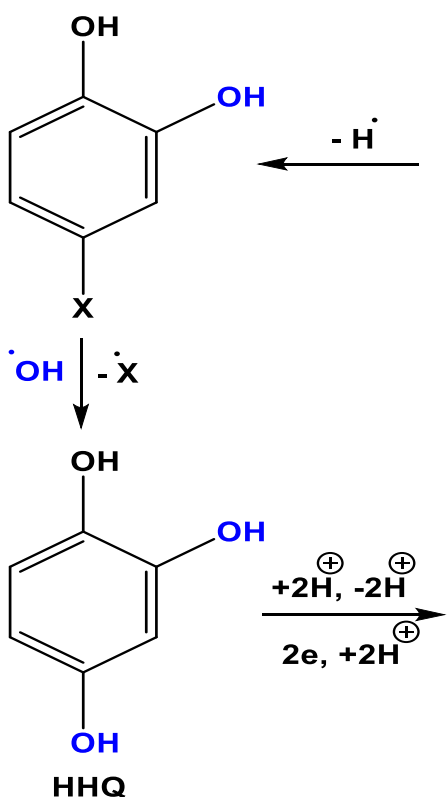<smiles>[X]c1ccc(O)c(O)c1O</smiles><smiles>[X]c1ccc(O)cc1</smiles><smiles>[X]C1(O)C=CC(O)=CC1</smiles><smiles>[C]=[N+][O-]</smiles><smiles>[Y][V]</smiles><smiles>O=C1C=CC(=O)C(O)=C1</smiles><smiles>CC=CC(=O)C=CCC</smiles>

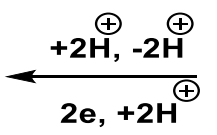<smiles>Oc1ccc(O)cc1</smiles>

Further oxidation and then small aliphatic compounds

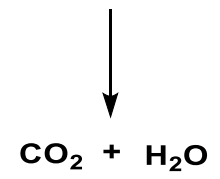

Scheme. 2. Photocatalytic degradation pathway of 4-CP and 4-NP for the as-prepared $\mathrm{Er}_{2} \mathrm{O}_{3}-\mathrm{ZnO}$ nanostructured with different Erbium doping concentrations.

Chemical analysis has illustrated that this intermediate is not accumulated during the long irradiation period centralizing the mineralization of the original solution of 4-CP. In 4-chlorophenol and 4-nitrophenol, the hydroxyl radical may attack the para position results hydroquinone (HQ). It is subjected to oxidation-reduction to produce benzoquinone (BQ). Similarly, if the hydroxyl radical attacks the ortho position, 4-chloro/nitrocatechol will be formed. The latter product has been transformed into hydroxy hydroquinone (HHQ) via oxidation through another hydroxyl radical, leading to chlorine or nitro radical removal. The hydroxybenzoquinone (HHQ) undergoes oxidation 
and reduction to form hydroxybenzoquinone (HBQ). The hydroxyl radicals' attack on BQ and HBQ results in aliphatic compounds that are also oxidized into aliphatic compounds with smaller molecular weight and then finally degraded into $\mathrm{CO}_{2}$ and $\mathrm{H}_{2} \mathrm{O}$.

\subsubsection{Photocatalyst recyclability and stability}

Finally, we performed the one percent Er-doped $\mathrm{ZnO}$ test to reuse catalytic material in ideal conditions. A contrast was carried out between fresh material and reused material (with optimum conditions). The photodegradation outcomes are illustrated in Fig. 19 (a,b); the reused photocatalyst's stability was verified by the results showing a positive recovery of the $1 \%$ Er-doped $\mathrm{ZnO}$ (S5) used catalyst. The observed efficiency of degradation with the reused catalyst $1 \% \mathrm{Er}-$ doped $\mathrm{ZnO}$ (S5) exceeded the estimated level of $96.5 \%$.
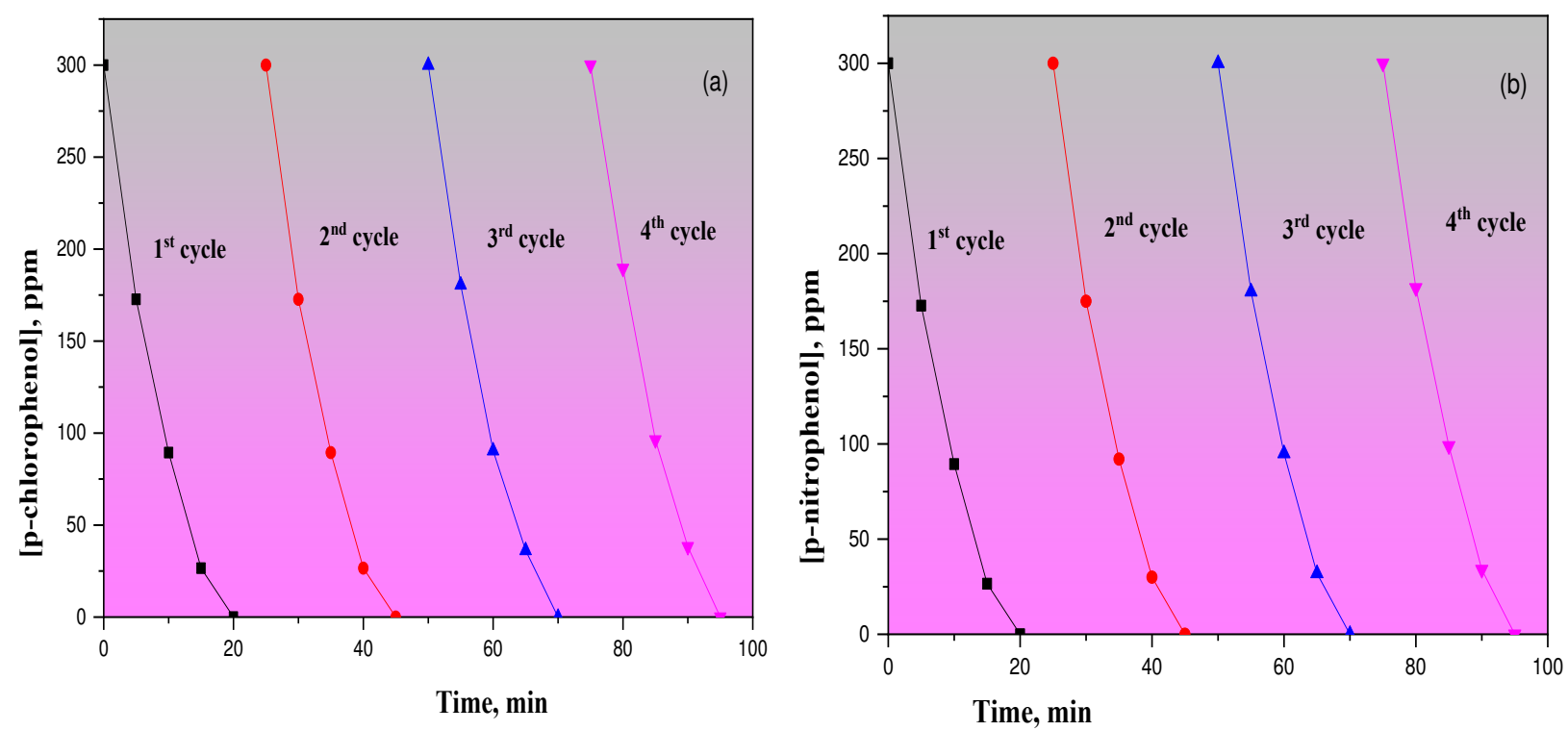

Fig. 19. The recycling data for the photodegradation using $1 \%$ Er-doped $\mathrm{ZnO}$ (S1) of

a) p-chlorophenol, b) p-nitrophenol

\section{Conclusion}

In this proposed work, Erbium (Er-) effects as a dopant in the host $\mathrm{ZnO}$ matrix, combined efficiently in nanostructured powder, were successfully synthesized using the combustion technique. Compared to the conventional techniques, the combustion-friendly chemical approach has the uniqueness of the high yield, low price, simple and effective procedures, and the ability to accomplish high purity in synthesizing oxide nano-powders. The produced $\mathrm{Er}_{2} \mathrm{O}_{3}-\mathrm{ZnO}$ nanostructured materials displayed excellent structural morphology, optical, electrical, dielectric, 
and photocatalytic characteristics compared to the pure $\mathrm{ZnO}$ nanoparticles. The XRD data and SEM analysis prove the prepared $\mathrm{Er}_{2} \mathrm{O}_{3}-\mathrm{ZnO}$ nanocomposites' polycrystalline structure and the nanoscale surface morphology, respectively. Noticeably, the surface morphology of Er-doped ZnO nanopowder has a practically uniform distribution. The optical absorption characterization discloses that the $\mathrm{Er}_{2} \mathrm{O}_{3}: \mathrm{ZnO}$ nanostructures have a direct bandgap. The direct optical bandgaps for the $\mathrm{Er}_{2} \mathrm{O}_{3}-$ $\mathrm{ZnO}$ nanocomposites ranged between $2.88 \mathrm{eV}$ and $3.19 \mathrm{eV}$, and on the other hand, the indirect optical transitions evaluated to be from $3.2 \mathrm{eV}$ to $3.35 \mathrm{eV}$. From the electrical characterization, the $\mathrm{ZnO}$ electrical conductivity decreased as the concentrations of the dopants increased. Also, the leakage current is decreased with increasing the Erbium contents. The increase of Erbium contents leads to an increase in the mean required energy for the homogeneous distribution in the ceramic varistor samples and electrons overcoming the Schottky barrier. The significant improvement of Er-dopants on the obtained nonlinear coefficients for the varistors was related to the microstructure uniformity and narrowed grain size distribution.

The successful visible photocatalytic activity was demonstrated in $\mathrm{ZnO}$ doped with different concentrations of Er nanoparticles. The Er-dopants played a vital role in improving the mineralization of transparent phenolic compounds via photocatalysis. The effective carrier transport through Er- functionality enhances the impact on responsible photodegradation activities. The process of charge transformation, which enhances their catalytic efficiency besides finds its part in catalytic applications, was demonstrated by designing the defect of the catalyst's band function through rare-earth impurities. Doping of Er- to $\mathrm{ZnO}$ has been shown to modify the ZnO's optical characteristics and greatly improve the photocatalytic activity. The Er-doped $\mathrm{ZnO}$ nanocomposites have attracted great consideration, taking advantage of their excellent potential for practical nano-technological applications in electronic varistor devices and environmental applications.

\section{Acknowledgment}

The authors extend their appreciation to the Deanship of Scientific Research at King Khalid University for funding this work through research groups program under grant number R.G.P. $2 / 64 / 40$

\section{-Ethical Approval}

Dr. Ibrahim Yahia has approved the ethics of this study. 


\section{-Competing Interests}

The authors declare that they have no known competing financial interests or personal relationships that could have appeared to influence the work reported in this paper.

\section{-Authors Contributions}

\section{Thekrayat AlAbdulaal}

Formal analysis-Equal, Investigation-Equal, Methodology-Equal, Visualization-Equal, Writingoriginal draft-Equal, Writing-review \& editing-Equal

\section{Manal AlShadidi}

Data curation-Lead, Formal analysis-Equal, Investigation-Equal, Visualization-Equal, Writingoriginal draft-Equal

\section{Mai Hussien}

Investigation-Equal, Methodology-Equal, Visualization-Equal, Writing-original draft-Equal

Ganesh Vanga

Methodology-Equal, Validation-Equal

\section{Abdel-Fatah Bouzidi}

Methodology-Equal, Visualization-Equal, Writing-original draft-Equal

Saqib Rafique

Investigation-Equal, Software-Equal

Hamed Algarni

Project administration-Equal, Validation-Equal

Heba Zahran

Methodology-Equal, Software-Equal

Mohamed Abdel-wahab

Methodology-Equal, Software-Equal

Ibrahim Yahia

Funding acquisition-Lead, Project administration-Lead, Resources-Lead, Writing-review \& editing-Lead

\section{-Consent to Participate}

Not applicable

\section{-Consent to Publish}

All authors are agreed to publish this work in the journal of Environmental Science and Pollution Research.

\section{-Availability of data and materials}

In this current research, the datasets obtained and analyzed are available with the corresponding author "Dr.Thekrayat AlAbdulaal". 


\section{REFERENCES}

A.B. Djurisic, A.M.C. Ng, X.Y. Chen, Prog. Quantum Electron. 2010,34,191.

Afsal, M., Wang, C. Y., Chu, L. W., Ouyang, H., \& Chen, L. J. (2012). Highly sensitive metalinsulator-semiconductor UV photodetectors based on $\mathrm{ZnO} / \mathrm{SiO} 2$ core-shell nanowires. Journal of Materials Chemistry, 22(17), 8420-8425.

A. Khataee, S. Saadi, M. Safarpour, S. Woo, Ultrasonics Sonochemistry Sonocatalytic performance of Er-doped $\mathrm{ZnO}$ for degradation of a textile dye, Ultrason. Sonochem 27 (2015) 379e388, http://dx.doi.org/10.1016/ j.ultsonch.2015.06.010.

A. Khataee, S. Saadi, M. Safarpour, S. Woo, Ultrasonics Sonochemistry Sonocatalytic performance of Er-doped $\mathrm{ZnO}$ for degradation of a textile dye, Ultrason. Sonochem 27 (2015) 379e388, http://dx.doi.org/10.1016/ j.ultsonch.2015.06.010.

A. Ortiz, C. Falcony, M. Garcia and A. Sanchez, J. Phys. D 20, 670 (1987). http://dx.doi.org/10.1088/ 0022-3727/20/5/019

Aydın, C., Abd El-sadek, M. S., Zheng, K., Yahia, I. S., \& Yakuphanoglu, F. (2013). Synthesis, diffused reflectance, and electrical properties of nanocrystalline Fe-doped $\mathrm{ZnO}$ via sol-gel calcination technique. Optics \& Laser Technology, 48, 447-452.

AlAbdulaal, T. H., \& Yahia, I. S. Optical linearity and nonlinearity, structural morphology of $\mathrm{TiO}_{2}-$ doped PMMA/FTO polymeric nanocomposite films: Laser power attenuation. (2021). Optik, 227, 166036.

A.K. Jonscher. The 'universal' dielectric response. Nature 1977;267, 673-679.

A.K. Jonscher, Dielectric relaxation in solids (Chelsea Dielectrics, London, 1993)

A.R. Khataee, Y. Hanifehpour, M. Safarpour, M. Hosseini, S.W. Joo, Synthesis and characterization of ErxZn1Se nanoparticles: a novel visible light responsive photocatalyst, Sci. Adv. Mater. 5 (2013) 1074-1082.

A. Khataee, S. Saadi, M. Safarpour, S. Woo, Ultrasonics Sonochemistry Sonocatalytic performance of Er-doped $\mathrm{ZnO}$ for degradation of a textile dye, Ultrason. Sonochem 27 (2015) 379e388, http://dx.doi.org/10.1016/ j.ultsonch.2015.06.010. 
A. Phuruangrat, T. Thongtem, S. Satchawan, S. Thongtem, H. Yai, M. Science, Photocatalytic activity of rugby-like Nd-doped $\mathrm{ZnO}$ particles activated by ultraviolet, J. Nanomater. Biostructures 13 (2018) 625-630.

B. Chavillon, L. Cario, A. Renaud, F. Tessier, F. Chevire, M. Boujtita, Y. Pellegrin, E. Blart, A.Smeigh, L.Hammarstrom, F.Odobel, S.Jobic, J. Am. Chem. Soc. 2012,134, 464.

B. Julian, R. Corberan, E. Cordoncillo, P. Esoribano, B. Viana and C. Sanchez, Nanotechnol. 16, 2707 (2005). http://dx.doi.org/10.1088/0957-4484/16/ 11/040

Bircan Dindar, Siddik Icli. Unusual photoreactivity of zinc oxide irradiated by concentrated sunlight, Journal of Photochemistry and Photobiology A: Chemistry. Volume 140, Issue 3, 31 May 2001, Pages 263-268. https://doi.org/10.1016/S1010-6030(01)00414-2

B. Knecht, A. Meith, “Surge Arresters: Zinc Oxide Based Non-Linear Resistances”, Brown Boveri Review, (1979) 739-742.

Gomez, Thin Solid Films 293, 117 (1997).

C. Pacholski, A. Kornowski, H. Weller, Angew. Chem.-Int. Edit. 2002,41,1188.

C.X. Xu, X.W. Sun, B.J. Chen, Appl. Phys. Lett. 2004,84,1540.

C.H. Chen, S.J. Chang, S.P. Chang, M.J. Li , I.C. Chen , T.J. Hsueh , A.D. Hsu, C.L. Hsu , J.Phys.Chem.C2010,114,12422.

C. Falcony, A. Ortiz, M. Garcia, and J. S. Helman, J. Appl. Phys. 63, 2378 (1988). http://dx.doi.org/10. 1063/1.341055

C. Aydın, M.S. Abd El-sadek, Kaibo Zheng, I.S. Yahia, F. Yakuphanoglu, Synthesis, diffused reflectance and electrical properties of nanocrystalline Fe-doped $\mathrm{ZnO}$ via sol-gel calcination technique, Optics \& Laser Technology, 2013, 48, 447-452. [23] D.W. Chu, Y.P. Zeng, D.L. Jiang, J. Phys. Chem. C 2007,111,5893 .

C. Aydın, M.S. Abd El-Sadek, Kaibo Zheng, I.S. Yahia, F. Yakuphanoglu, Synthesis, diffused reflectance and electrical properties of nanocrystalline $\mathrm{Fe}$-doped $\mathrm{ZnO}$ via sol-gel calcination technique, Optics \& Laser Technology, 2013, 48, 447-452. 
C. W. Nahm, Effect of $\mathrm{MnO}_{2}$ addition on microstructure and electrical properties of $\mathrm{ZnO}-\mathrm{V} 2 \mathrm{O} 5$ based varistor ceramics, Ceramics International 35 (2) (2009) 541-546.

C. Xu, L. Cao, G. Su, W. Liu, X. Qu, Y. Yu, Preparation, characterization and photocatalytic activity of Co-doped ZnO powders, J. Alloy. Compd. 497 (1-2) (2010) 373-376.

C. Borras, C. Berzoy, J. Mostany, J. C. Herrera, and B. R. Scharifker, "A comparison of the electrooxidation kinetics of pmethoxyphenol and p-nitrophenol on $\mathrm{Sb}$-doped $\mathrm{SnO}_{2}$ surfaces: Concentration and temperature effects," Applied Catalysis B Environmental, vol. 72, no. 1-2, pp. 98-104, 2007.

D. Lin , H. Wu, W. Pan , Adv. Mater. 2007,19,3968; b) R.R. Piticescu, R.M. Piticescu, C.J. Monty, J. Eur. Ceram. Soc. 2006,26,2979.

D. D. Wang, G.Z. Xing, M. Gao, L.L. Yang, J.H. Yang, T. Wu, J. Phys. Chem. C 2011,115,22729. D. V. Voort, A. Imbof and G. J. Blasse, Solid State Chem. 96, 311 (1992). http://dx.doi.org/10.1016/ S0022-4596(05)80264-6

D. Pathinettam Padiyan, A. Marikini, K.R. Murli, Influence of thickness and substrate temperature on electrical and photoelectrical properties of vacuum-deposited CdSe thin films, Mater. Chem. Phys. 78 (2002) 51-58.

D. Zhang and F. Zeng, "Visible light-activated cadmium-doped $\mathrm{ZnO}$ nanostructured photocatalyst for the treatment of methylene blue dye," Journal of Materials Science, vol. 47, no. 5, pp. 2155 2161, 2012. https://doi.org/10.1007/s10853-011-6016-4.

D.R. Kumar, K.S. Ranjith, R.T.R. Kumar, Structural, optical, photocurrent and solar-driven photocatalytic properties of vertically aligned samarium doped $\mathrm{ZnO}$ nanorod arrays, Opt. Int. J. Light Electron Opt. 154 (2018) 115-125, https://doi.org/10. 1016/j.ijleo.2017.10.004.

E. Pelizzetti and N. Serpone, Homogeneous and Heterogeneous Photo-Catalysis, Reidel, Dordrecht, The Netherlands, 1986. https://doi.org/10.1007/978-94-009-4642-2

E. R. Carraway, A. J. Huffman, and M. R. Hoffmann, "Photocatalytic oxidation of organic acids on quantum-sized semiconductor colloids," Environmental Science and Technology, vol. 28, no. 5, pp. 786-793, 2004 
E. P. Zironi, J. Cañetas-Ortega, H. Gómez, A. Maldonado, R. Asomoza, and J. Palacios-[94] ElMallah, H. M. (2012). AC electrical conductivity and dielectric properties of perovskite (Pb, $\mathrm{Ca})$ $\mathrm{TiO}_{3}$ ceramic. Acta Physica Polonica-Series A General Physics, 122(1), 174.

E.A. Davis, N.F. Mott, Conduction in non-crystalline systems V. Conductivity, optical absorption and photoconductivity in amorphous semiconductors, Philos. Mag. 22 (1970) 903-922.

E. Szabó-Bárdos, H. Czili, A. Horváth, Photocatalytic oxidation of oxalic acid enhanced by silver deposition on $\mathrm{T}_{\mathrm{TiO}}$ surface, J. Photochem. Photobiol., A 154 (2-3) (2003) 195-201.

F. Gu, S. F. Wang, M. K. Lu, G. J. Zhou, D. Xu and D. R. Yuan, Langmuir, 20, 3528 (2004). http://dx. doi.org/10.1021/la049874f.

F. Paraguay-Delgado, W. Estrada-Lopez and E. Andrade, Thin Solid Films 366, 16 (2000).

F. El-Kabbany, S. Taha, M. Hafez, A study of the phase transition of reheated diphenyl carbazide (DPC) by using UV spectroscopy, Spectrochimica Acta Part A: Molecular and Biomolecular Spectroscopy, 128 (2014) 481-488.

G. K. Mor, K. Shankar, M. Paulose, O.K. Varghese, C.A. Grimes, Nano Lett.2006,6,215.

G.D. Yuan, W.J. Zhang, J.S. Jie, X. Fan, J.X. Tang, I. Shafiq, Z.Z. Ye, C.S. Lee, S.T. Lee, Adv. Mater. 2008,20,168.

G. Z. Xing, J.B. Yi, J.G. Tao, T. Liu, L.M. Wong, Z.Zhang, G. P. Li, S. J. Wang, J. Ding, T.C. Sum, C.H. A. Huan, T. Wu, Adv.Mater. 2008,20,3521.

G.S. Wu, Y.L. Zhuang, Z.Q. Lin, X.Y. Yuan, T. Xie, L.D. Zhang, Physica E 2006,31,5.

G. Ju-ka and Pivrikas, Private Communications, (2008).

H.B. Zeng, G.T. Duan, Y. Li, S.K. Yang, X.X. Xu, W.P. Cai, Adv. Funct. Mater.2010,20,561.

H.B. Wang, F. Ma, Q.Q. Li, C.Z. Dong, D.Y. Ma, H.T. Wang, K.W. Xu, Nanoscale 2013, 5,2857.

H.N. Zhang, Z.Y. Li, W. Wang, C. Wang, L. Liu, J. Am. Ceram. Soc.2010,93,142.

Hsu, C. L., \& Lu, Y. C. (2012). Fabrication of a transparent ultraviolet detector by using n-type $\mathrm{Ga}_{2} \mathrm{O}_{3}$ and p-type Ga-doped $\mathrm{SnO}_{2}$ core-shell nanowires. Nanoscale, 4(18), 5710-5717. 
H. Ishizumi and Y. Kanemitsu, Appl. Phys. Lett. 86, 253106 (2005). http://dx.doi.org/10.1063/1. $\underline{1952576}$

I.S. Yahia, H.Y. Zahran, F.H. Alamri, Pyronin Y as new organic semiconductors: Structure, optical spectroscopy, and electrical/dielectric properties, Synthetic Metals, 218, (2016)19-26.

J. B. Lee, M. H. Lee, C. K. Park, and J. S. Park, Thin Solid Films 447—448, 2962004.

J.W. Lo, W.C. Lien, C.A. Lin, J.H. He, ACS Appl. Mater. Interfaces 2011,3,1009.

J. Gao, X. Luan, J. Wang, B. Wang, K. Li, Y. Li, P. Kang, G. Han, Preparation of Er3 p: YAlO 3/Fe-doped $\mathrm{TiO}_{2}$ e $\mathrm{ZnO}$ and its application in photocatalytic degradation of dyes under solar light irradiation, DES 268 (2011) 68e75, http://dx.doi.org/10.1016/j.desal.2010.09.052.

K. Yu, J. Shi, Z. Zhang, Y. Liang, W. Liu, ZnO, and Er-doped ZnO, 2013, pp. 1e6. 10.1109/ArgoGeoinformatics.2013.6621868

K.-S. Yu, J.-Y. Shi, Z.-L. Zhang, Y.-M. Liang, and W. Liu, Synthesis, characterization, and photocatalysis of ZnO and Er-doped ZnO. J. Nanomater. 2013, 372951 (2013).

K. SowriBabun, A. Ramachandra Reddy, Ch. Sujatha, K. Venugopal Reddy, Effects of precursor, temperature, surface area and excitation wavelength on photoluminescence of $\mathrm{ZnO} /$ mesoporous silica nanocomposite, Ceramics International, 2013, 39, 3055-3064.

Kai-sheng Yu,Jian-ying Shi, Zai-li Zhang, Yong-mei Liang,and Wei Liu. Synthesis, Characterization, and Photocatalysis of ZnO and Er-Doped ZnO. Volume 2013 |Article ID 372951 | 5 pages | https://doi.org/10.1155/2013/372951

K.M. Parida, S. Parija. Photocatalytic degradation of phenol under solar radiation using microwave $\begin{array}{lllllll}\text { irradiated zinc } & \text { oxide. Solar } & \text { Energy } & 80 & \text { (2006) }\end{array}$ https://doi.org/10.1016/j.solener.2005.04.025

K. Yu, J. Shi, Z. Zhang, Y. Liang, W. Liu, Synthesis, Characterization, and Photocatalysis of ZnO and Er-doped ZnO, Journal of Nanomaterials Volume 2013, Article ID 372951, 5 pages http://dx.doi.org/10.1155/2013/372951. 
K.M. Parida, S.S. Dash, D.P. Das, Physico-chemical characterization and photocatalytic activity of zinc oxide presented by various methods, Journal of Colloid and Interface Science 298 (2006) 787793.

Kausar Rajar, Sira Juddin, Aamna Blouch, M.I. Bhanger, Tufail H. Sherazi, Raj Kumar. Degradation of 4-Chlorophenol Under Sunlight Using ZnO Nanoparticles as Catalysts. Journal of ELECTRONIC MATERIALS, Vol. 47, No. 3, 2018. https://doi.org/10.1007/s11664-017-6029-0

L. Vayssieres, Adv. Mater. 2003,15, 464.

L.W. Chang, Y.C. Sung, J.W. Yeh, H.C. Shih, J. Appl. Phys. 2011,109,074318.

L.J. Luo, W.Tao, X.Y.Hu, T. Xiao, B.J. Heng, W.Huang, H.Wang, H.W. Han, Q.Jiang, J.B. Wang, Y.W. Tang, J. Power Sources 2011,196,10518.

L. Murowski, and R.J. Barczynski, Dielectric Properties of Transition Metal Oxide Glasses, Journal of Non-Crystalline Solids, Vol. 185, 1995, p. 84.

L. Zhang and Y. Zhu, "A review of controllable synthesis and enhancement of performances of bismuth tungstate visible-light-driven photocatalysts," Catalysis Science and Technology, vol. 2, no. 4, pp. 694-706, 2012. https://doi.org/10.1039/c2cy00411a.

M. Willander, O. Nur, Q.X. Zhao, L.L. Yang, M. Lorenz, B.Q. Cao, J.Z. Perez, C. Czekalla, G. Zimmermann, M. Grundmann, A. Bakin, A. Behrends, M. Al-Suleiman, A. El-Shaer, A.C. Mofor, B. Postels, A. Waag, N. Boukos, A. Travlos, H.S. Kwack, J. Guinard, D.L. Dang, Nanotechnology 2009,20,332001.

M. Law, L.E. Greene, J.C. Johnson, R. Saykally, P.D. Yang, Nat. Mater. 2005,4,455

Michalowicz J, Duda W. Phenols-sources and toxicity. Pol. J. Environ. Stud. 2007;16: 347-362.

M.T. Chen, M.P. Lu, Y. J. Wu, J.H. Song, C.Y. Lee, M.Y. Lu, Y.C. Chang, L.J. Chou, Z.L. Wang, L.J. Chen, Nano Lett. 2010,10,4387.

M. de L. Olvera and A. Maldonado, Phys. Stat. Sol. (a) 196, 410 (2003).

Mai. SA Hussien, Mervat I. Mohammed, and Ibrahim S. Yahia. "Flexible photocatalytic membrane based on CdS/PMMA polymeric nanocomposite films: multifunctional materials." Environmental Science and Pollution Research 27.36 (2020): 45225-45237. 
Maji, P., Pande, P. P., \& Choudhary, R. B. (2015). Effect of Zn (NO3)2 filler on the dielectric permittivity and electrical modulus of PMMA. Bulletin of Materials Science, 38(2), 417-424.

M. Kobayashi, M. Mizuno, T. Aizawa, M. Hayashi, K. Mirani, "Development of Zinc Oxide NonLinear Resistors and their Applications to gapless Surge Arrester", Transactions on Power Apparatus and System, 97 (4), (1978) 1149-1158.

M.Khatamian, A.A.Khandar, B.Divband, M.Haghighi, S.Ebrahimiasl. Heterogeneous photocatalytic degradation of 4-nitrophenol in aqueous suspension by $\mathrm{Ln}\left(\mathrm{La}^{3+}, \mathrm{Nd}^{3+}\right.$ or $\left.\mathrm{Sm}^{3+}\right)$ doped $\mathrm{ZnO}$ nanoparticles. Journal of Molecular Catalysis A: Chemical. Volume 365, December 2012, Pages 120-127

Mengstu Etay Ashebir, Gebrekidan Mebrahtu Tesfamariam, Gebretinsae Yeabyo Nigussie, Tesfakiros Woldu Gebreab, Structural, Optical, and Photocatalytic Activities of Ag-doped and Mndoped ZnO Nanoparticles, Journal of Nanomaterials Volume 2018, Article ID 9425938, 9 pages https://doi.org/10.1155/2018/9425938

M. Haruta, Size-and support-dependency in the catalysis of gold, Catal. Today 36 (1) (1997) 153166.

Nie, B., Hu, J. G., Luo, L. B., Xie, C., Zeng, L. H., Lv, P., ... \& Yu, Y. Q. (2013). Monolayer Graphene Film on ZnO Nanorod Array for High-Performance Schottky Junction Ultraviolet Photodetectors. Small, 9(17), 2872-2879.

N. Rakov, F. E. Ramos, G. Hirata, and M. Xiao, Appl. Phys. Lett. 83, 272 (2003). http://dx.doi.org/10. 1063/1.1592636

N.K. Divya, P.U. Aparna, P.P. Pradyumnan, Dielectric Properties of Er 3 p Doped ZnO Nanocrystals, 2015, pp. 287e294.

N. Sobana, K. Thirumalai, Kinetics of solar light assisted degradation of direct red 23 on activated carbon-loaded zinc oxide and influence of operational parameters, Can. Chem. Trans. 4 (2016) 77e89, http://dx.doi.org/10.13179/ canchemtrans.2016.04.01.0258.

O.D. Jayakumar, I.K. Gopalakrishnan, S.K. Kulshreshtha, Adv. Mater.2006,18,1857.

P. V. Kamat, "Photochemistry on nonreactive and reactive (semiconductor) surfaces," Chemical Reviews, vol. 93, no. 1, pp. 267-300, 1993. https://doi.org/10.1021/cr00017a013 
P. Ruankham, T. Sagawa, H. Sakaguchi, S. Yoshikawa, J. Mater. Chem.2011,21,9710. [53] P. Alivisatos, Science 271, 933 (1996). http://dx.doi. org/10.1126/science.271.5251.933

P. K. Dutta, S. O. Pehkonen, V. K. Sharma, and A. K. Ray, "Photocatalytic oxidation of arsenic (III): evidence of hydroxyl radicals," Environmental Science and Technology, vol. 39, no. 6, pp. 1827-1834, 2005. https://doi.org/10.1021/es0489238

Petrisor Samoila, Corneliu Cojocaru, Liviu Sacarescu, Petronela Pascariu Dorneanu, AndreiAdrian Domocos, Aurelian Rotaru. Remarkable catalytic properties of rare-earth-doped nickel ferrites synthesized by sol-gel auto-combustion with maleic acid as fuel for CWPO of dyes Applied Catalysis B: Environmental. Volume 202, March 2017, Pages 21-32. https://doi.org/10.1016/j.apcatb.2016.09.012

Q.C. Li, V. Kumar, Y. Li, H.T. Zhang, T.J. Marks, R.P.H. Chang, Chem. Mat. 2005,17,1001.

Q. Yang, X. Guo, W.H. Wang, Y. Zhang, S. Xu, D.H. Lien, Z.L. Wang, ACS Nano 2010,4,6285.

R. Calarco, M. Marso, T. Richter, A.I. Aykanat, R. Meijers, A.V. Hart, T. Stoica, H. Luth, Nano Lett. 2005, 5, 981 .

R. Kumar, A. Umar, G. Kumar, M.S. Akhtar, Y. Wang, S.H. Kim, Ce-doped ZnO nanoparticles for efficient photocatalytic degradation of direct red-23 dye, Ceram. Int. 41 (2015) 7773-7782, http://dx.doi.org/10.1016/ j.ceramint.2015.02.110.

S. Iijima, T. Ichihashi, Nature 1993,363,603.

S.H. Dalal, D.L. Baptista, K.B. K. Teo, R.G. Lacerda, D.A. Jefferson, W.I. Milne, Nanotechnology $2006,17,4811$.

S.M. Hatch, J. Briscoe, A. Sapelkin, W.P. Gillin, J.B. Gilchrist, M.P. Ryan, S. Heutz, S. Dunn, J. Appl. Phys. 2013,113,204501.

S. Kim, H. Park, G. Nam, H. Yoon, B. Kim, I. Ji, Y. Kim, I. Kim, Y. Park, D. Kang, J.Y. Leem, Electron.Mater.Lett.2014,10,81.

S.Y. Bae, C.W. Na, J.H. Kang, J. Park, J. Phys. Chem. B 2005,109,2526. Available from: https://www.epa.gov/wqc/national-recommended-water-quality-criteria-table [Accessed: 2016-0820]. 
Sonik Bhatia, Neha Verma, R.K. Bedi. Optical application of Er-doped ZnO nanoparticles for photodegradation of direct red - 31 dye. Optical Materials 62 (2016) 392-398. http://dx.doi.org/10.1016/j.optmat.2016.10.013

Sh.A. Mansour, I.S. Yahia, F. Yakuphanoglu, The electrical conductivity and dielectric properties of C.I. Basic Violet 10, Dyes Pigm. 2010, 87, 144-148.

S. Bhattacharyya, S.K. Saha, M. Chakravorty, B.M. Mandal, D. Chakravorty, K. Goswami., Frequency-dependent conductivity of interpenetrating polymer network composites of polypyrrole-poly(vinyl acetate), Journal of Polymer Science Part B: Polymer Physics. 2001, 39, 1935-1941.

Saengnapa Kakarndee, Suwat Nanan. SDS capped and PVA capped ZnO nanostructures with high photocatalytic performance toward photodegradation of reactive red (RR141) azo dye. Journal of Environmental Chemical Engineering. Volume 6, Issue 1, 2018,74-94.

S.B. Rana, A. Singh, S. Singh, Characterization and Optical Studies of Pure and Sb Doped ZnO Nanoparticles, vol. 6, 2013, pp. 45-57.

T.K. Jia, W.M. Wang, F. Long, Z.Y. Fu, H. Wang, Q. J.Zhang, J. Alloy. Compd. 2009,484,410.

Tsonos, C. (2019). Comments on frequency-dependent AC conductivity in polymeric materials at low-frequency regime. Current Applied Physics, 19(4), 491-497.

US EPA. National Recommended Water Quality Criteria-Human Health Criteria Table. 2016.

U. Wahl, E. Rita, J. G. Correia, E. Alves, and J. P. Araújo, "Implantation site of rare earth in singlecrystalline ZnO," Applied Physics Letters, vol. 82, no. 8, pp. 1173-1175, 2003. https://doi.org/10.1063/1.1555283

U. Alam, Azam Khan, Danish Ali, Detlef Bahnemann, M. Muneer. Comparative photocatalytic activity of sol-gel derived rare earth metal ( $\mathrm{La}, \mathrm{Nd}, \mathrm{Sm}$, and $\mathrm{Dy}$ )-doped $\mathrm{ZnO}$ photocatalysts for degradation of dyes, RSC Adv. 8 (2018) 17582-17594, https://doi.org/10.1039/C8RA01638K

Venkatesan, D., Deepan, D., Velavan, M., Sankar, R., Jayavel, R., \& Dhanasekaran, R. (2010, February). Preparation and characterization of rare-earth (Pr, Nd) doped $\mathrm{ZnO}$ nanoparticles. In 2010 International Conference on Nanoscience and Nanotechnology (pp. 343-347). IEEE. 
V. Kumar, R.G. Singh, N. Singh, A. Kapoor, R.M. Mehra, L.P. Purohit, Synthesis and characterization of aluminum-boron co-doped $\mathrm{ZnO}$ nanostructures, Mater. Res. Bull. 48 (2013) 362-366.

V. Kumar, R.G. Singh, N. Singh, A. Kapoor, R.M. Mehra, L.P. Purohit, Synthesis and characterization of aluminum-boron co-doped $\mathrm{ZnO}$ nanostructures, Mater. Res. Bull. 48 (2013) 362-366.

V.M. Jali, S. Aparna, Sanjeev Ganesh, S.B. Krupanidhi. AC conductivity studies on the electron irradiated BaZrO3 ceramic. Nucl Instruments Methods Phys Res B 2007,257,505.

V. Bobnar, A. Levstik, C. Huang and Q.M. Zhang; Distinctive Contributions from organic filler and relaxorlike polymer matrix to dielectric response of CuPc-P(VDF-TrFE-CFE) composite, Phys. Rev. Lett. 92, 047604 (2004).

W. Lee, M.C. Jeong, J.M. Myoung, Appl. Phys. Lett. 2004,85,6167.

W.R. Chang, Y.K. Fang, S.F. Ting, Y.S. Tsair, C.N. Chang, C.Y. Lin, S.F. Chen, IEEE Electron Device Lett.2003,24,565.

W.D. Callister, Materials science and engineering: An introduction, force ed., John Wiley \& Sons, New York, 1997.

W.C. Zhang, X.L. Wu, H.T. Chen, J. Zhu, G.S. Huang, the Excitation wavelength dependence of the visible photoluminescence from amorphous $\mathrm{ZnO}$ granular films, J. Appl. Phys. 2008, 103, 093718.

W. Brütting, ed., Physics of Organic Semiconductors, WILEY-VCH Verlag, 2006.

X. Michalet, F.F. Pinaud, L.A. Bentolila, J.M. Tsay, S. Doose, J.J. Li, G. Sundaresan, A.M. Wu, S.S. Gambhir and S. Weiss, Science 307, 538 (2005). http://dx.doi.org/10.1126/science.1104274

X.H. Huang, Z.Y. Zhan, K.P. Pramoda, C.Zhang, L.X. Zheng, S.J. Chua, Cryst Eng Comm $2012,14,5163$.

XU Dong, JIANG Bin, JIAO Lei, CUI Feng-dan, XU Hong-xing, YANG Yong-tao, YU Ren-hong, and CHENG Xiao-nong, Transactions of Nonferrous Metals Society of China, Vol. 22, Supplement 1, 2012, p. s110-s114. 
Xu, D., Tang, D., Jiao, L., Yuan, H., Zhao, G., \& Cheng, X. (2012). Comparative characteristics of yttrium oxide and yttrium nitric acid doping in $\mathrm{ZnO}$ varistor ceramics. Journal of Central South University, 19(8), 2094-2100. doi:10.1007/s11771-012-1250-8

X. Yan, J. He, D.G. Evans, X. Duan, Y. Zhu, Preparation, characterization and photocatalytic activity of Si-doped and rare-earth-doped $\mathrm{TiO}_{2}$ from mesoporous precursors, Appl. Catal. B: Environ. 55 (2005) 243-252.

Y.K. Tseng, C.J. Huang, H.M. Cheng, I.N. Lin, K.S. Liu, IC. Chen, Adv. Funct. Mater. 2003, 13, 811.

Y.L. Li, X.A. Zhao, W.L. Fan, J. Phys. Chem. C 2011,115,3552.

Yanqing Zong, Zhe Li, Xingmin Wang Jiantao Ma, Yi Men. Synthesis and high photocatalytic activity of Eu-doped $\mathrm{ZnO}$ nanoparticles. Ceramics International, Volume 40, Issue 7, Part B, August 2014, Pages 10375-10382. https://doi.org/10.1016/j.ceramint.2014.02.123

Y. Liu, H. Liu, and Y. Li, "Comparative study of the electrocatalytic oxidation and mechanism of nitrophenols at Bi-doped lead dioxide anodes," Applied Catalysis B: Environmental, vol. 84, no. 12, pp. 297-302, 2008.

Y. Sun, Y. Chen, L. Tian, Y. Yu, X. Kong, Q. Zeng, Y. Zhang, H. Zhang, Morphology dependent upconversion luminescence of ZnO: Er3+ nanocrystals, J. Lumin. 128 (1)m(2008) 15-21.

Z. Sofiani, S. Dabos-Seignon, B. Derkowska, P.Dalasinski, M. Wo jdyla, A.M. Lamrani, L. Dghoughi, M. Addou, W. Bala and B. Sahraoui, Optics Communications, vol. 267, pp. 433-439, (2006).

Zhang, X. H., Chen, J., Wu, Y., Xie, Z., Kang, J., \& Zheng, L. (2011). A simple route to fabricate high sensibility gas sensors based on erbium-doped $\mathrm{ZnO}$ nanocrystals. Colloids and Surfaces A: Physicochemical and Engineering Aspects, 384(1-3), 580-584. 
Figures

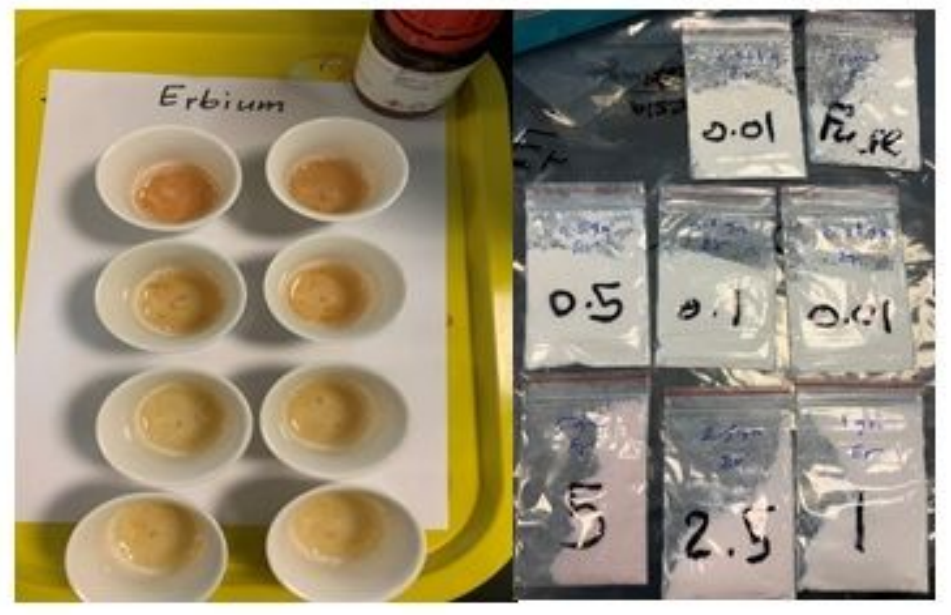

Figure 1

The as-prepared Er2O3-ZnO nanocomposites with a different Erbium doping concentration.

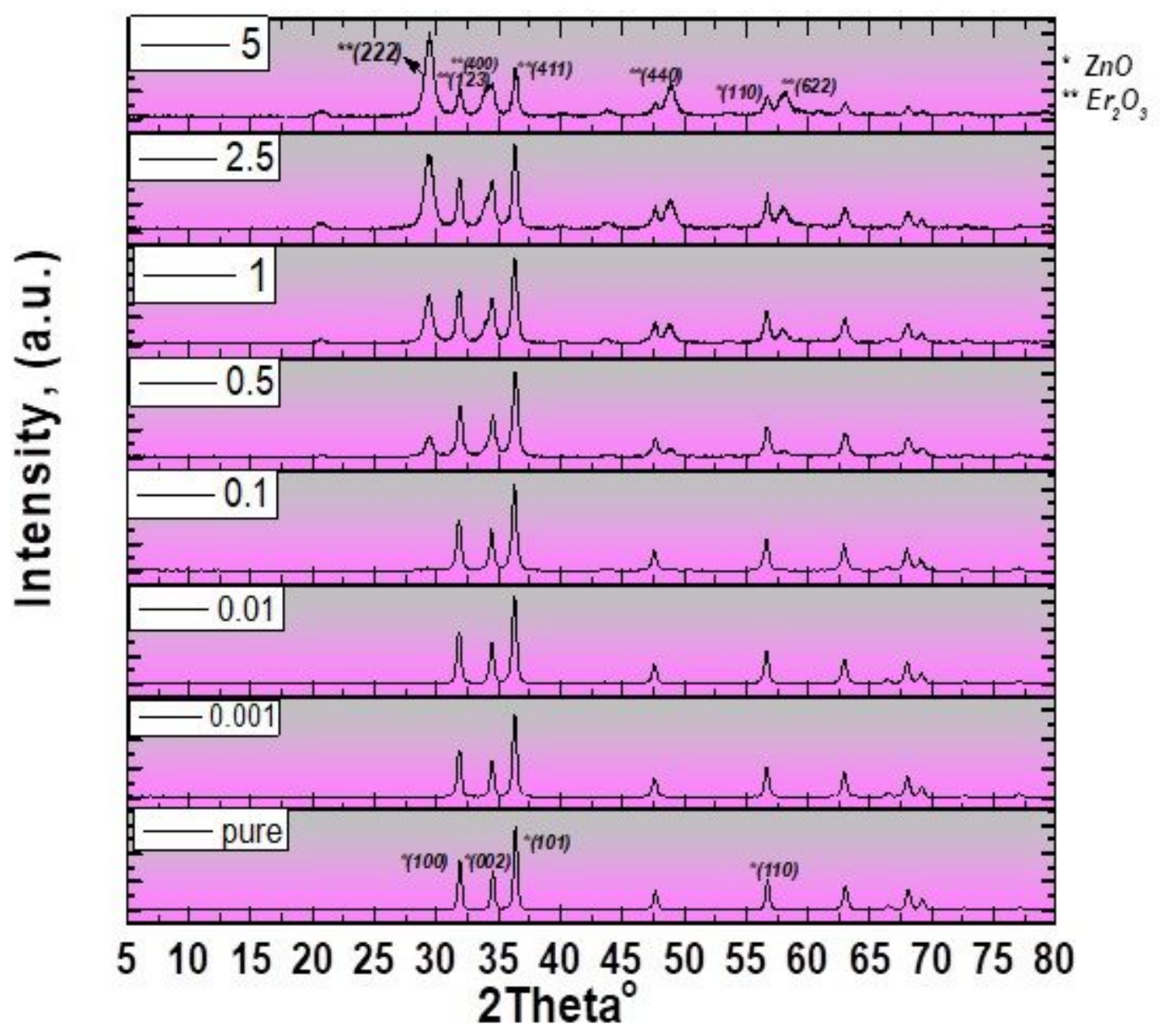


Figure 2

XRD patterns of the prepared Er2O3-ZnO nanostructures with various Erbium concentrations.

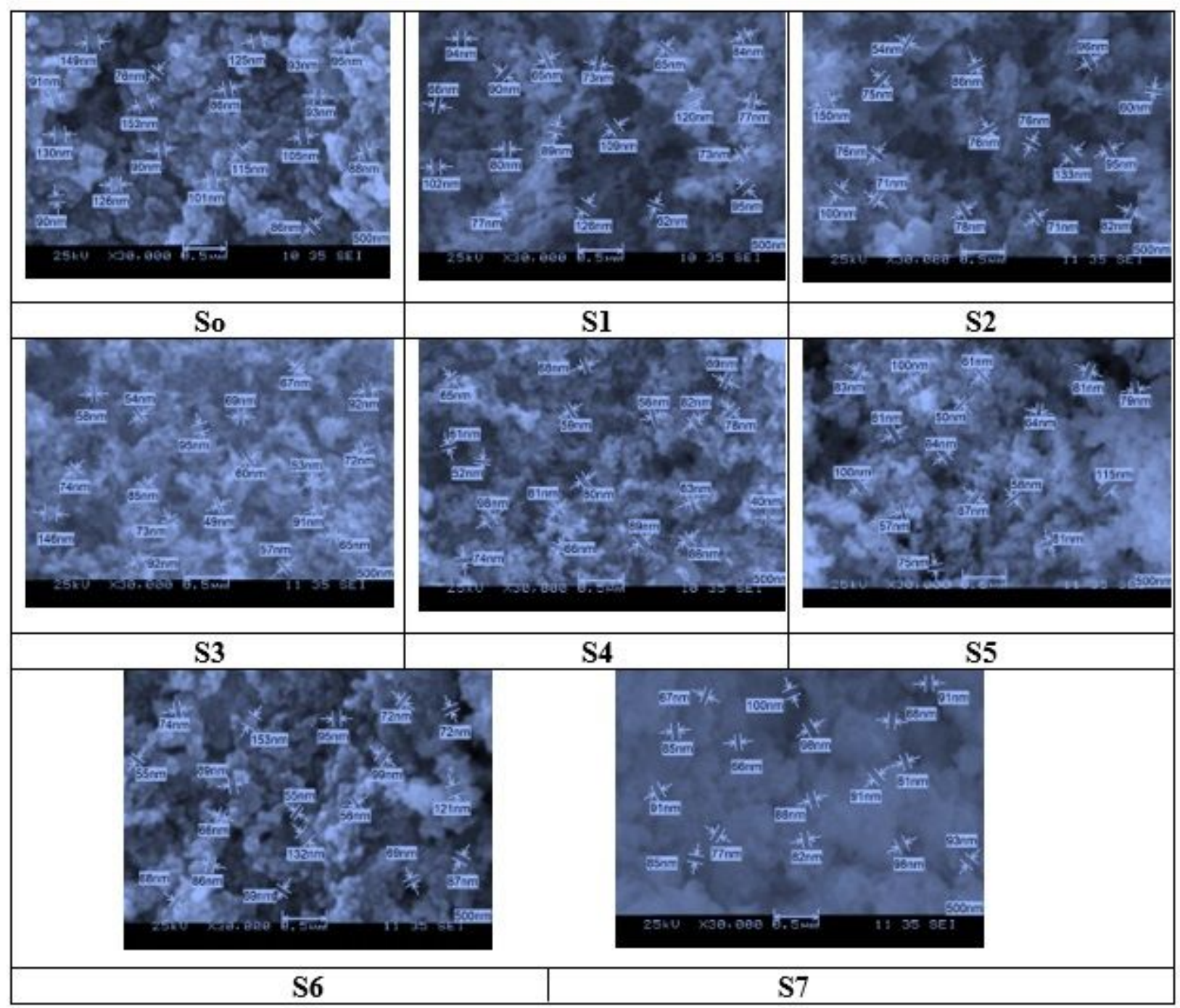

Figure 3

SEM images of the as-prepared Er2O3-ZnO nanostructures, with different Erbium doping concentrations. 


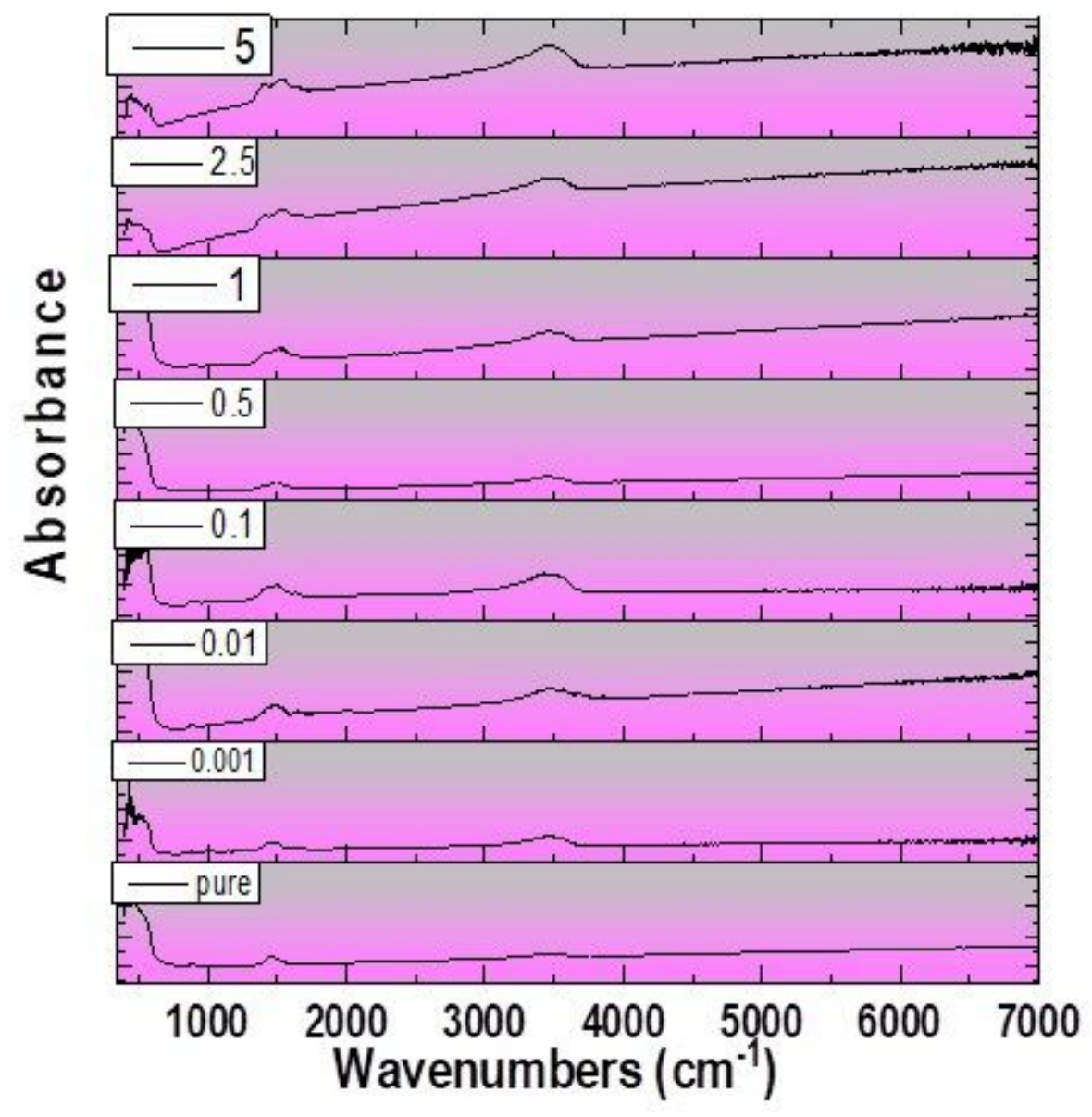

Figure 4

FT-IR spectra of the synthesized Er2O3-ZnO nanostructures at various Erbium doping concentrations.

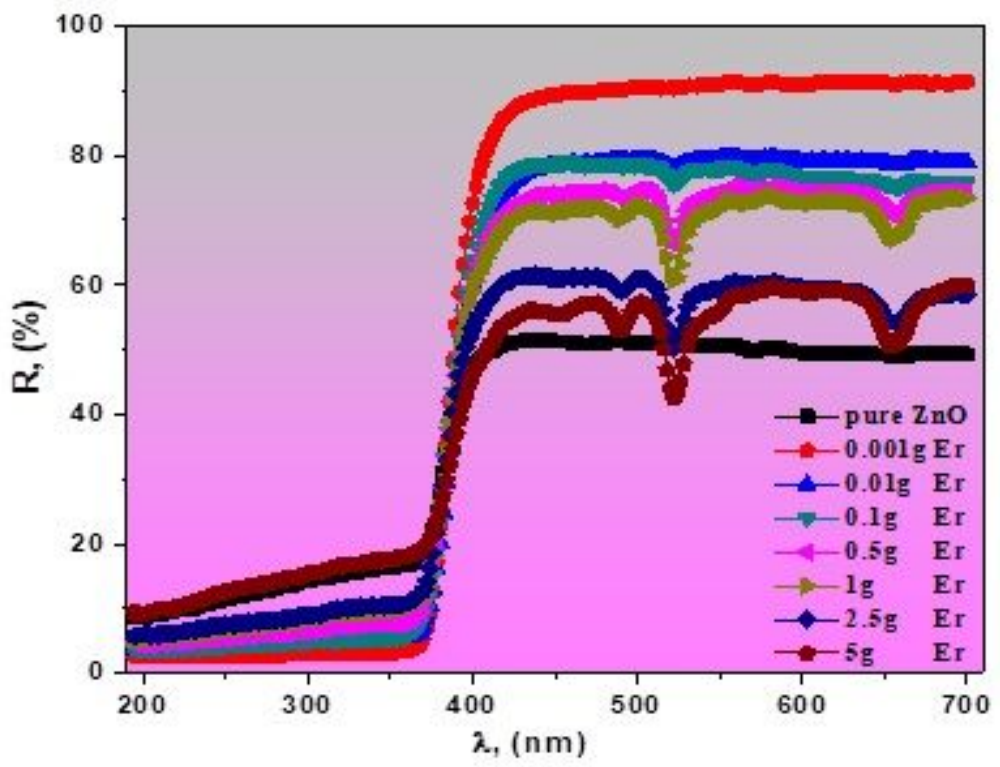

Figure 5 
Optical diffused reflectance (ODR) versus the light wavelength of the as-prepared Er2O3-ZnO nanostructured with different Erbium doping concentrations.

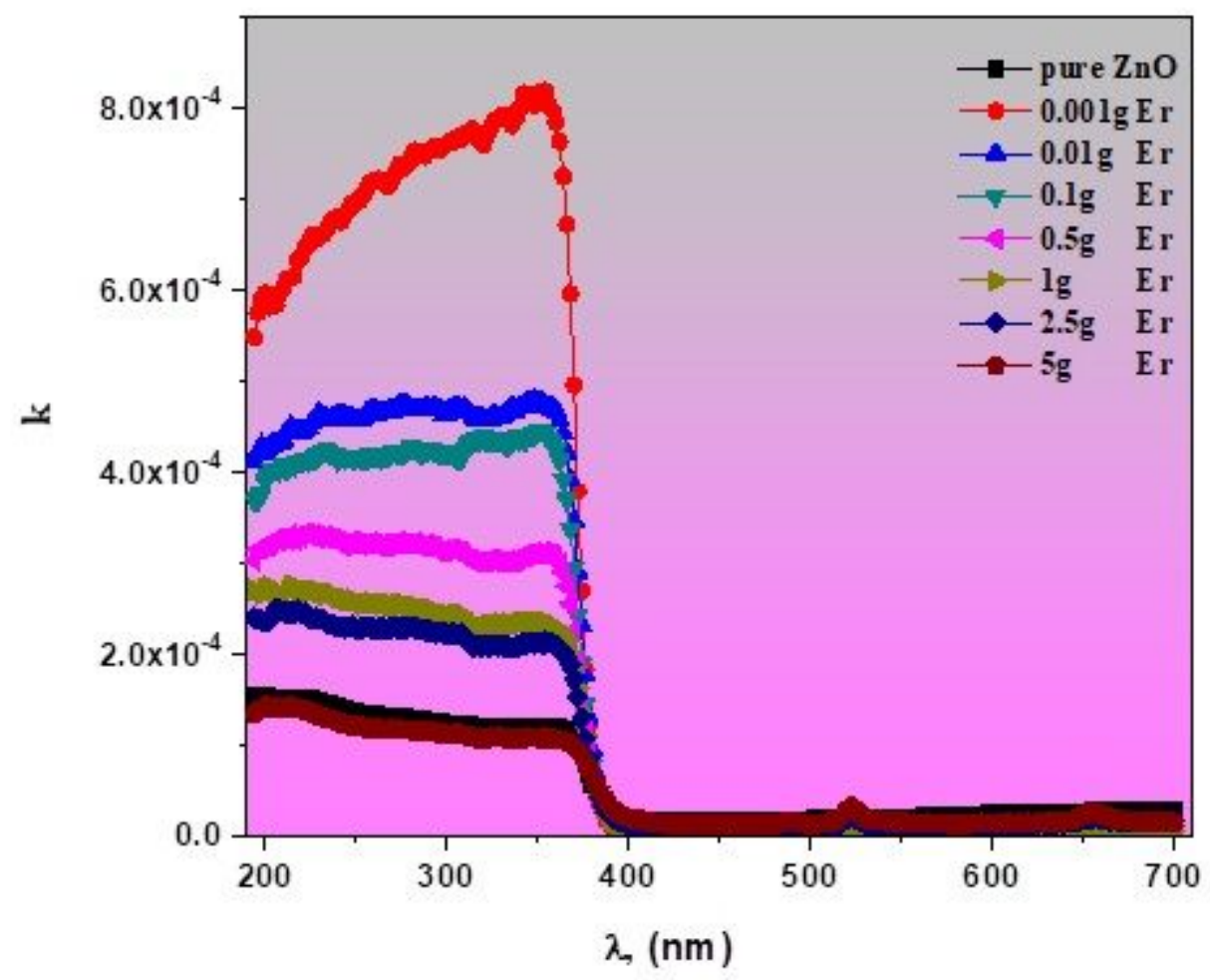

\section{Figure 6}

Absorption coefficient $(\mathrm{k})$ as a function of the wavelength of all prepared Er2O3-ZnO nanostructured with different Erbium doping concentrations.

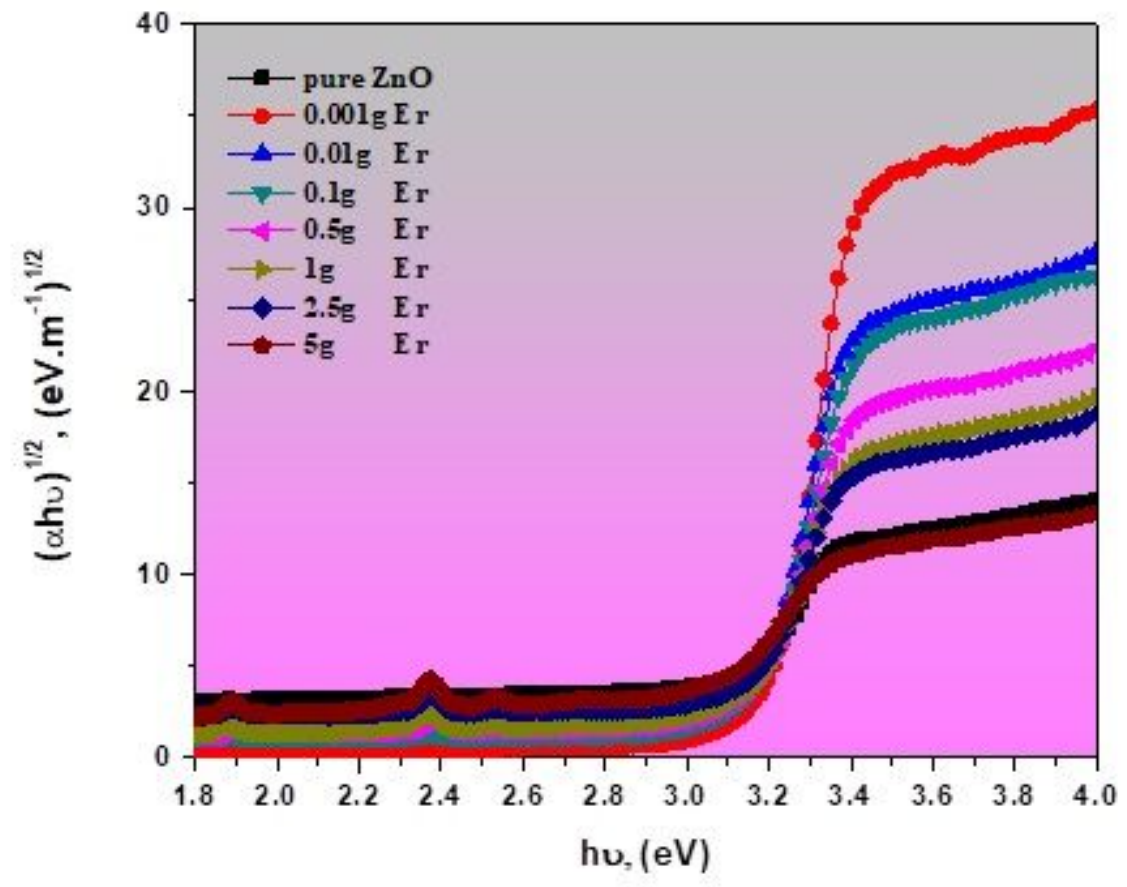

Figure 7 
Relationship between the optical allowed direct transition (ahv) $1 / 2$ and the photon energy (hv) of all Er203-ZnO nanostructures with different doping ratios.

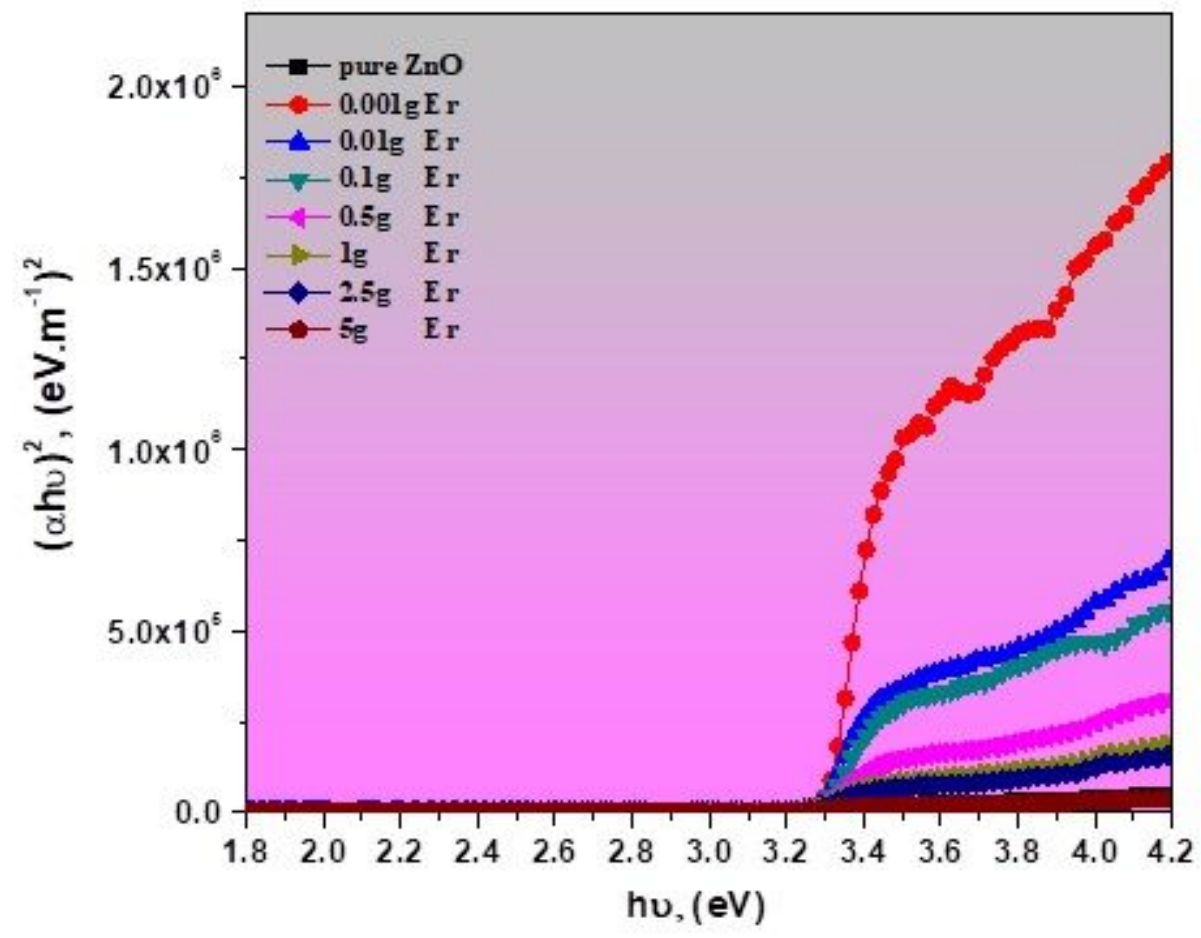

Figure 8

Optical allowed indirect transition (ahv)2 versus the photon energy (hv) of the as-prepared Er2O3-ZnO nanostructures at various doping ratios.

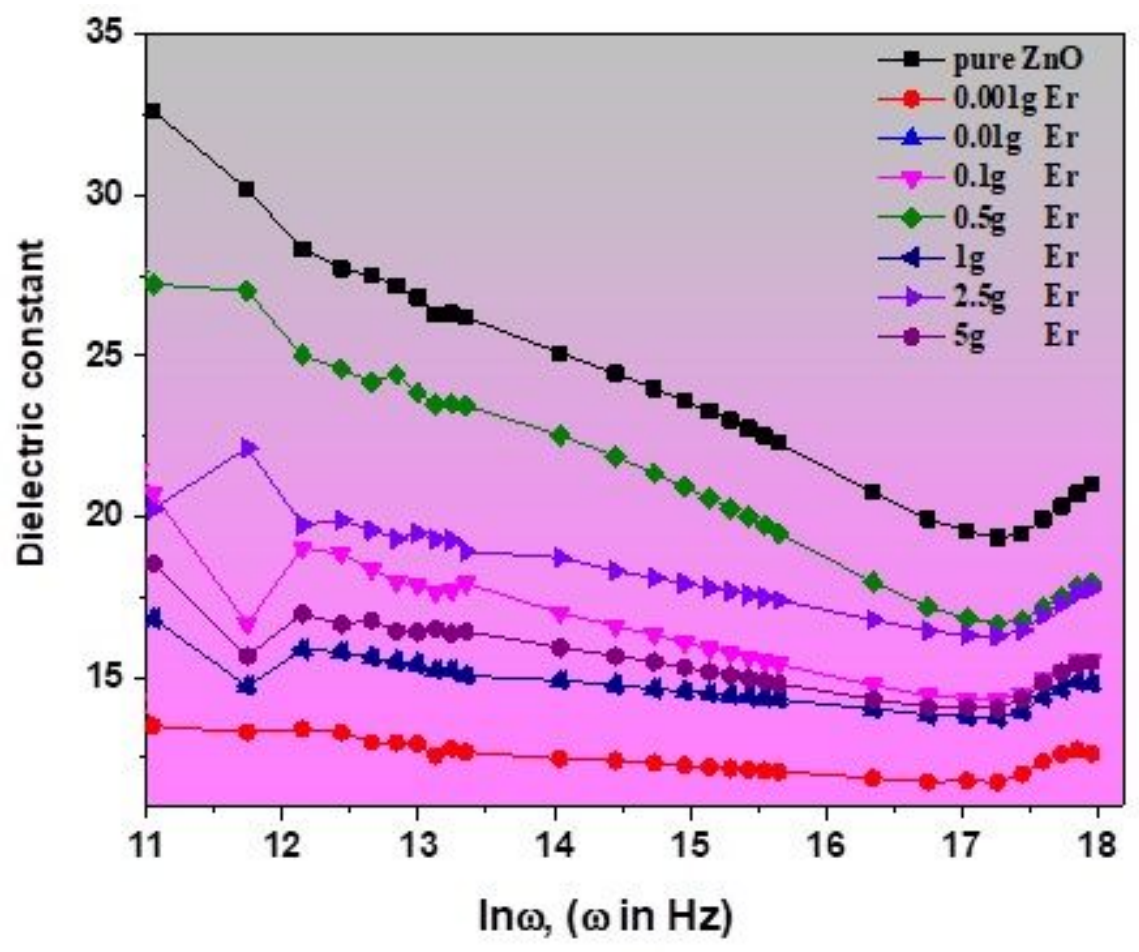

Figure 9 
Dielectric constant versus the applied frequency of the as-prepared Er203-ZnO nanostructured with different Erbium doping concentrations.

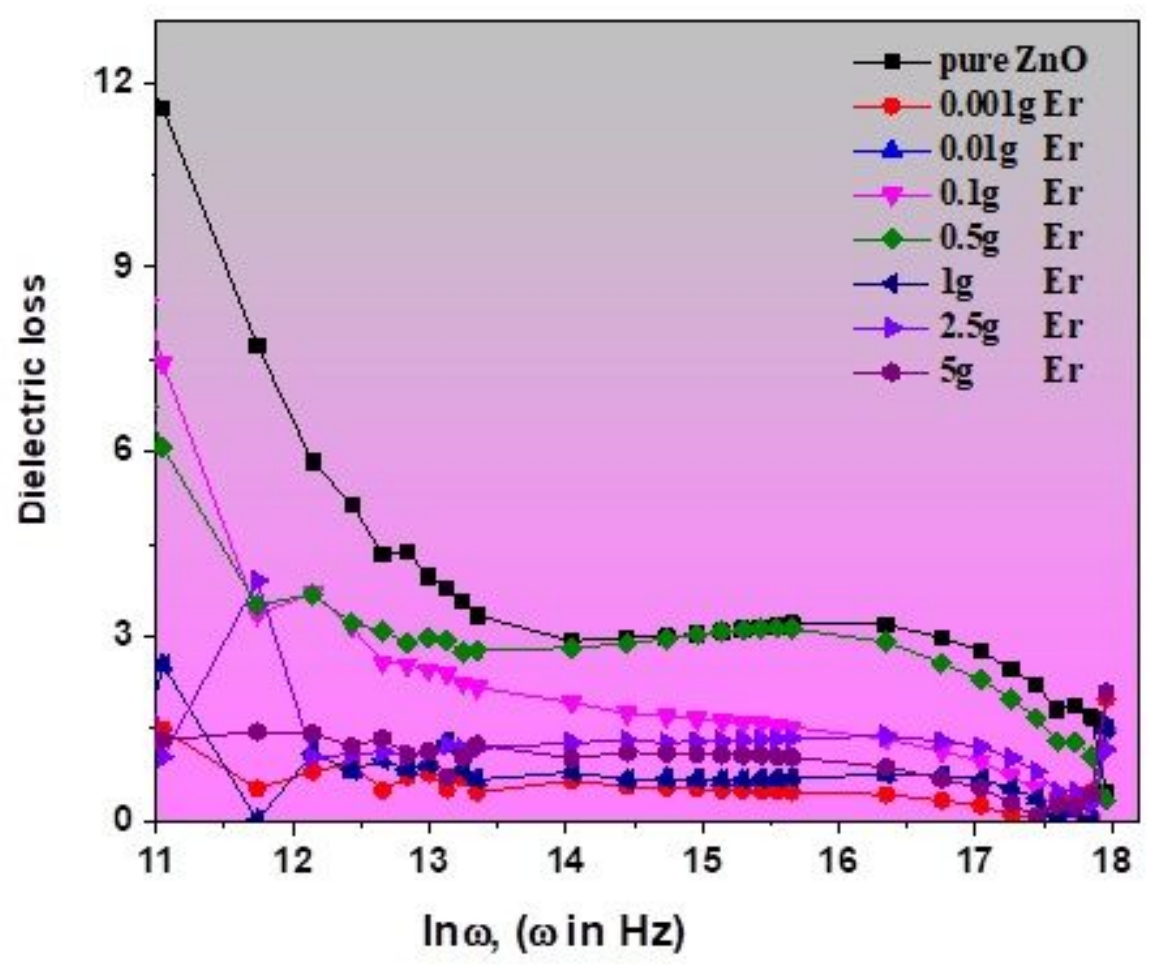

Figure 10

Dielectric loss as a function of the applied frequency of the as-prepared Er203-ZnO nanostructured with different Erbium doping concentrations. 


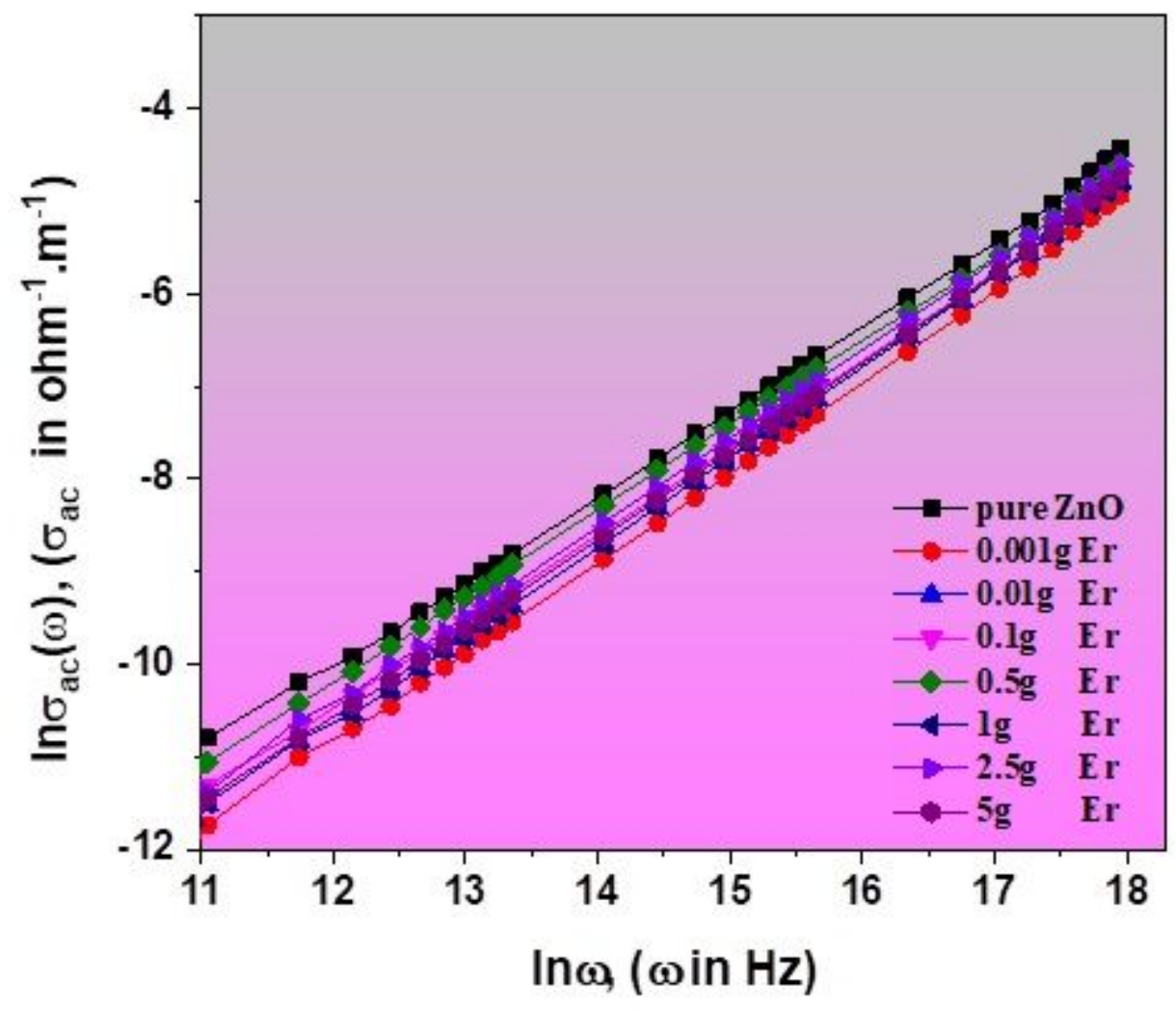

Figure 11

AC electrical conductivities as a function of the as-prepared Er2O3-ZnO nanostructured with different Erbium doping concentrations. 

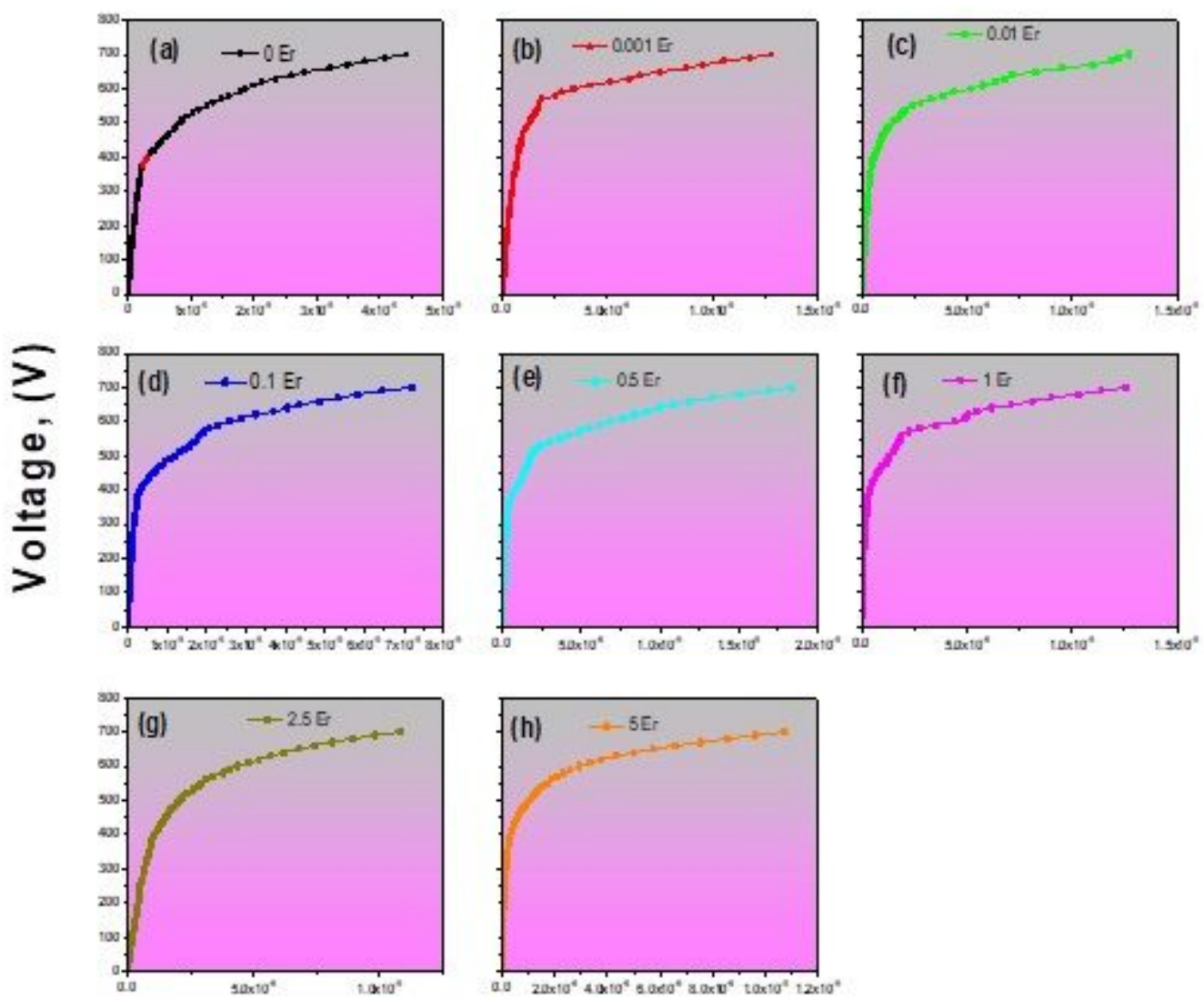

Current $\times 10^{-12}$,(A)

Figure 12

(a-h). V-I characteristics of ZnO varistor ceramics versus the as-prepared Er2O3-ZnO nanostructured with different Erbium doping concentrations. 


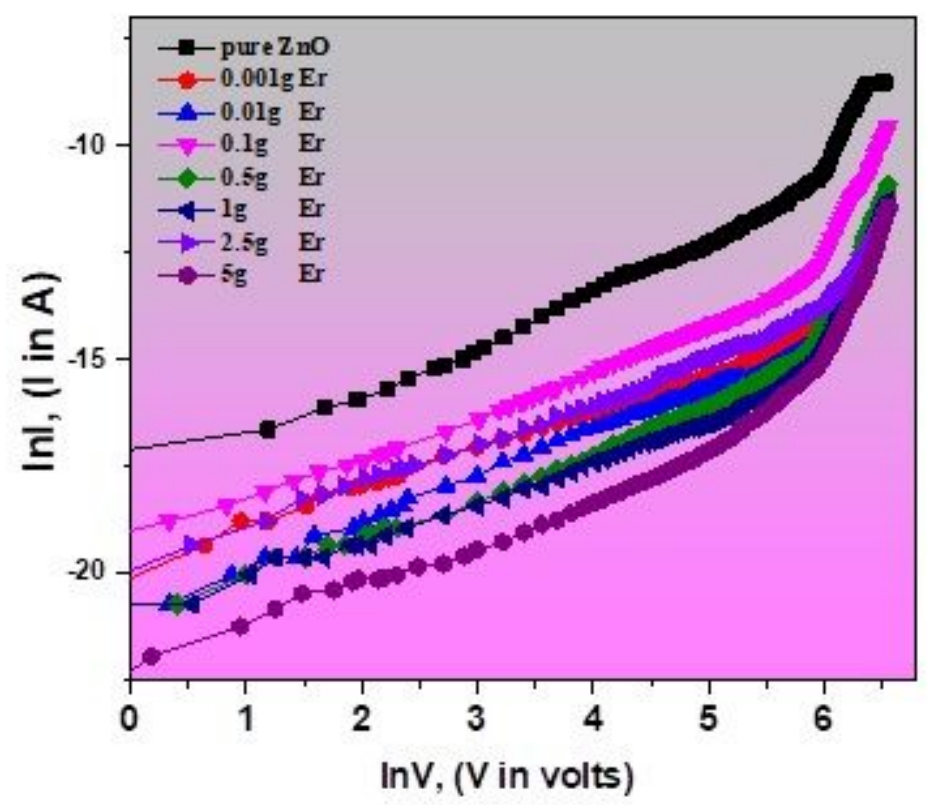

Figure 13

The linear relation between Inl and InV of the as-prepared Er2O3-ZnO nanostructured at various Erbium ratios. 

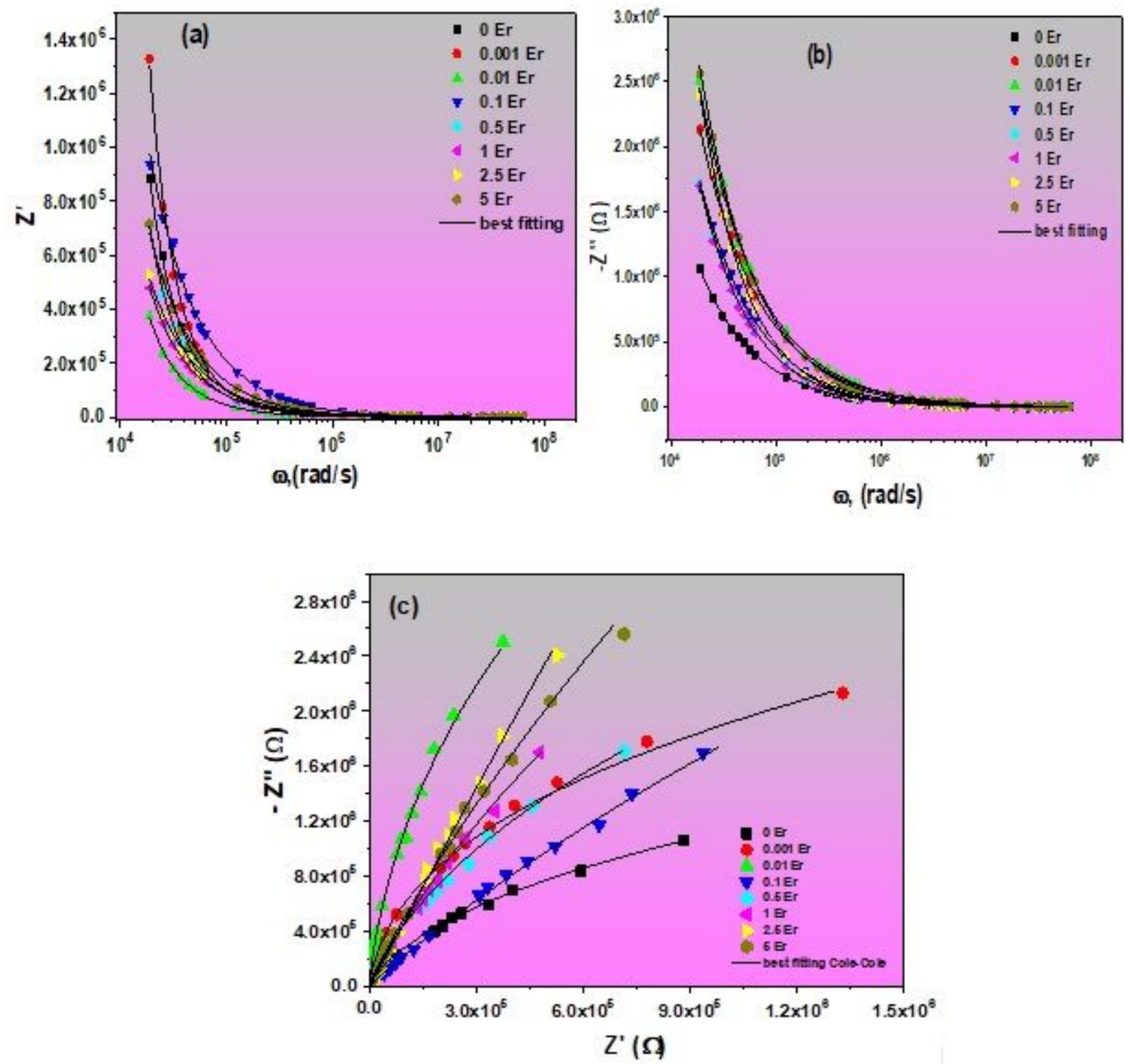

Figure 14

(a) Real, (b) imaginary parts, and (c) Cole-Cole plots (the line represents the theoretical Cole-Cole fitting) of the as-prepared Er2O3-ZnO nanostructures with different Erbium doping concentrations. 

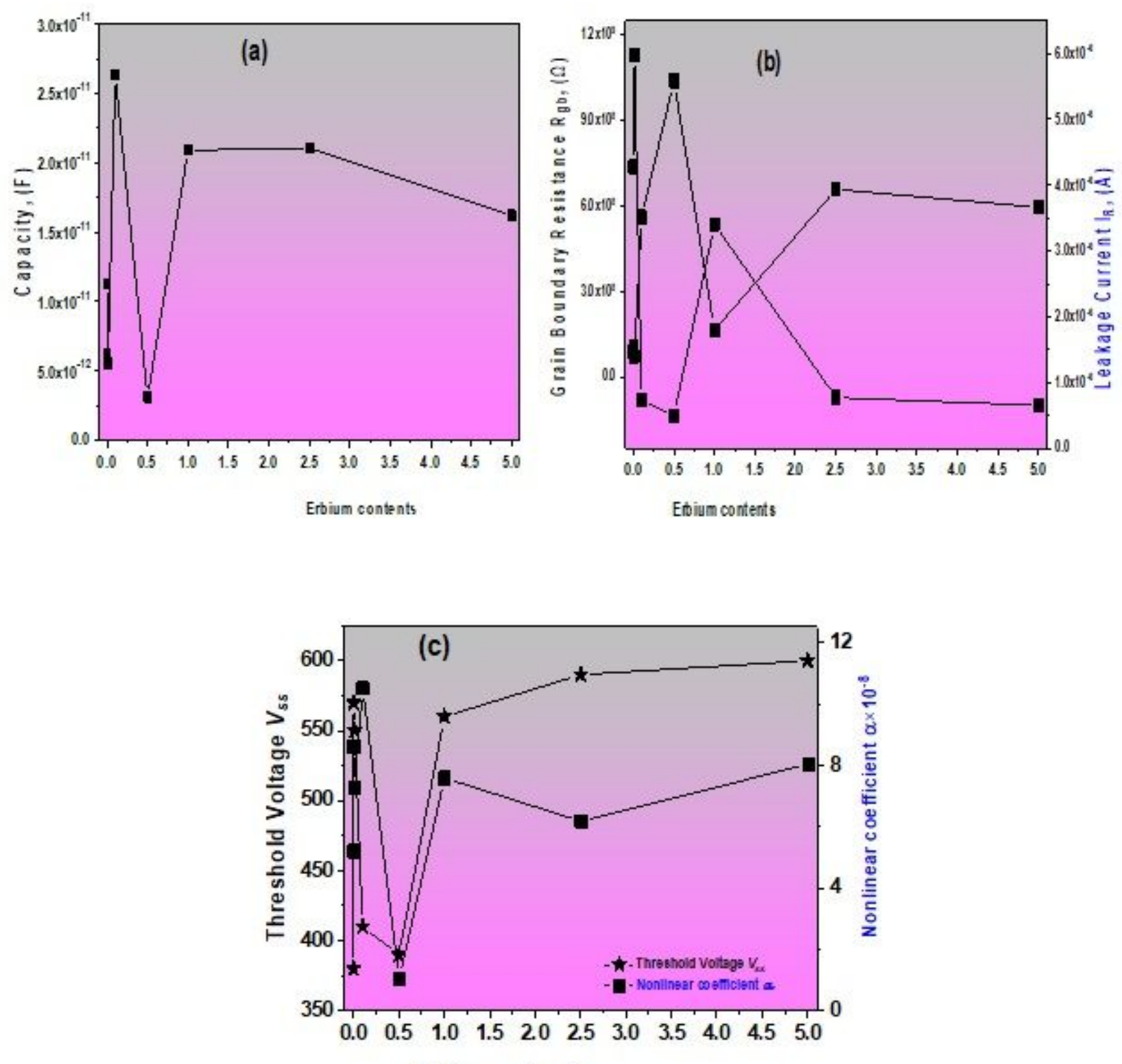

Erbium contents

Figure 15

( $\mathrm{a}, \mathrm{b}$ \& c). Influence of Erbium contents on V-I fitted parameters of the as-prepared Er203-ZnO nanostructures with different Erbium doping concentrations. 

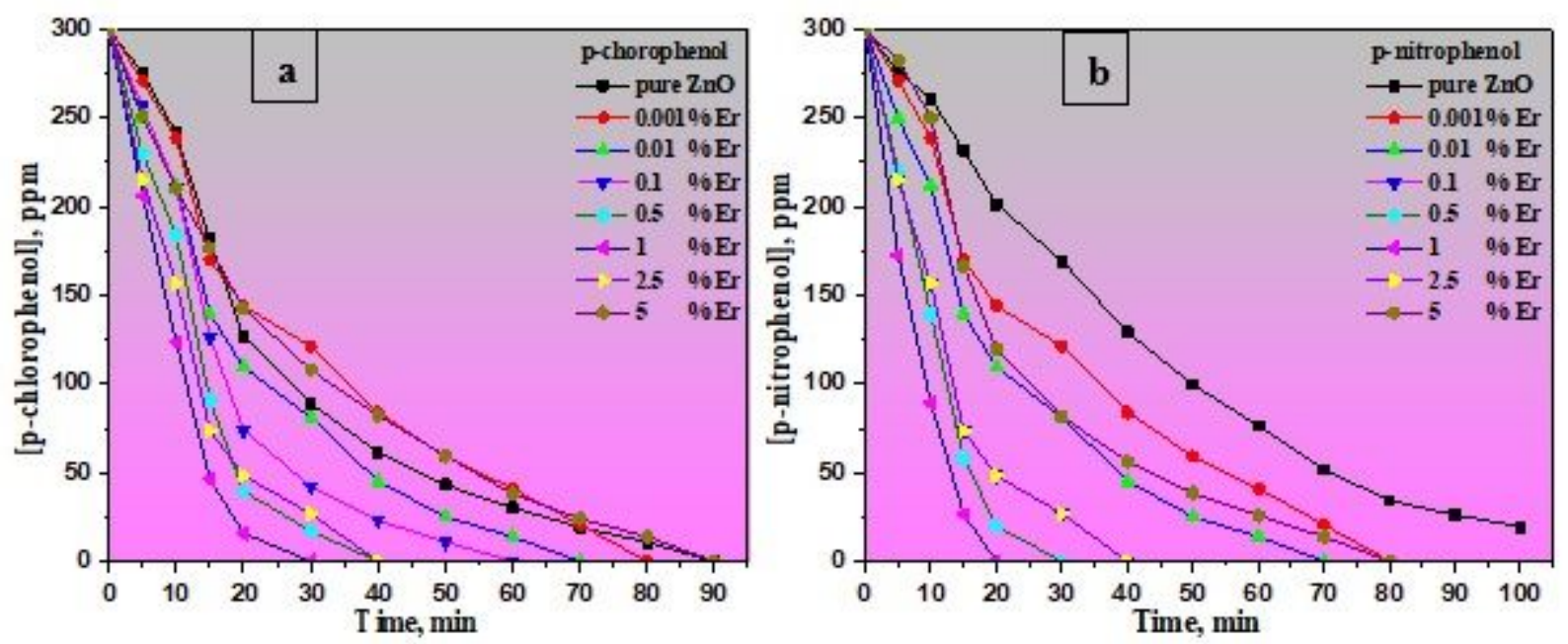

Figure 16

$(\mathrm{a}, \mathrm{b})$. Concentration versus time for photodegradation using the as-prepared Er2O3-ZnO nanostructured with different Erbium doping concentrations: a) p-chlorophenol, b) p-nitrophenol.
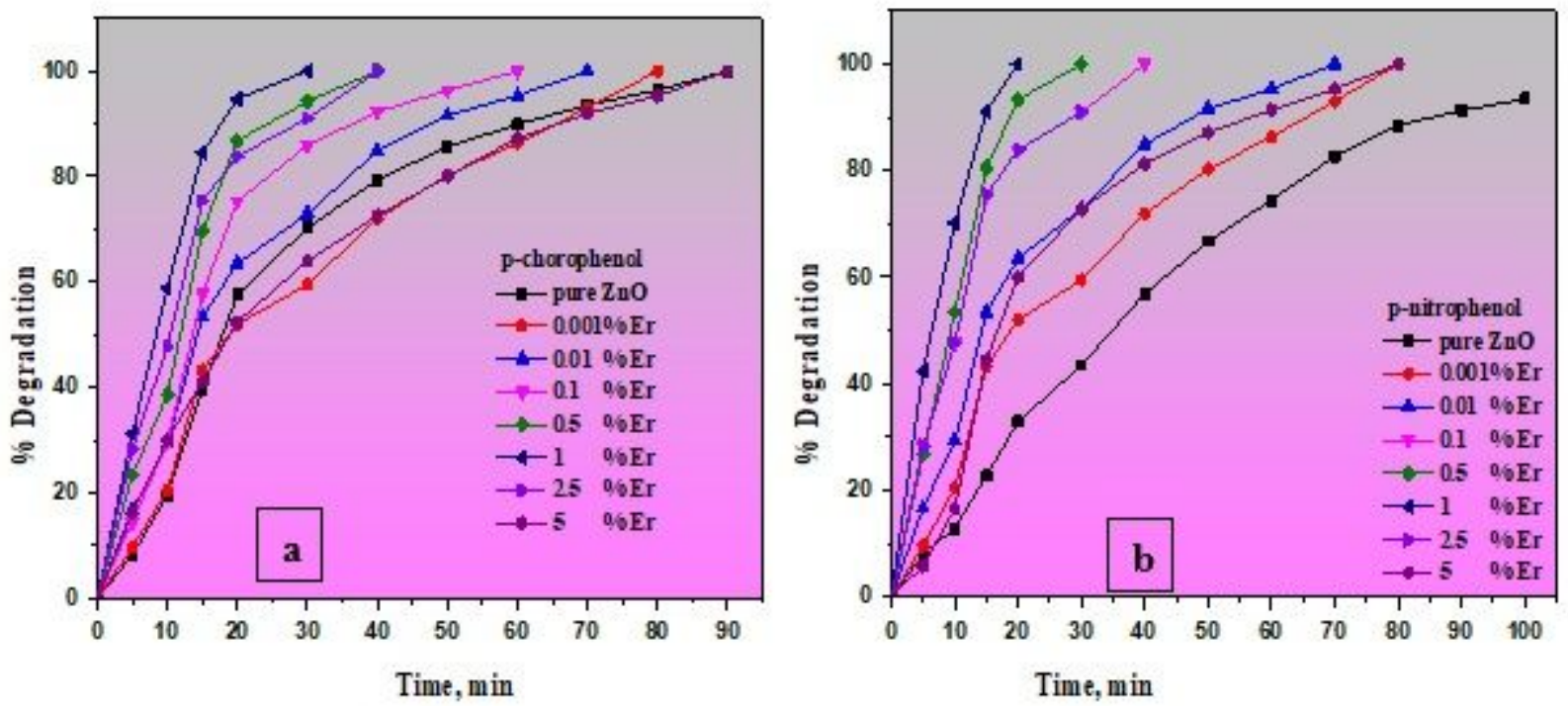

Figure 17

$(a, b)$. Degradation\% versus time for the as-prepared Er203-ZnO nanostructured with different Erbium doping concentrations: a) p-chlorophenol, b) p-nitrophenol. 

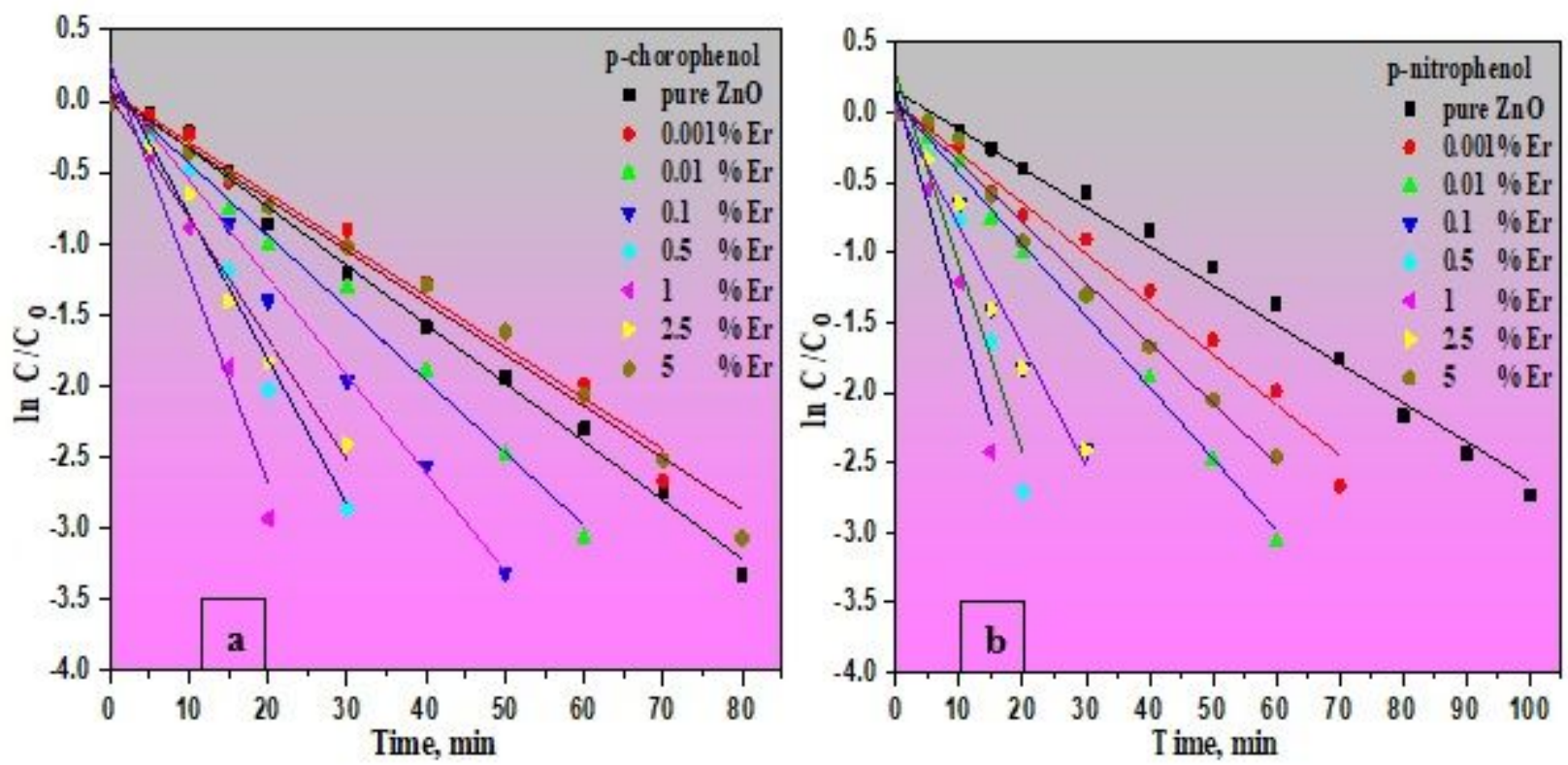

Figure 18

$(a, b)$. Kinetic data for photodegradation using for the as-prepared Er2O3-ZnO nanostructures with different Erbium doping concentrations: a) p-chlorophenol, b) p-nitrophenol.
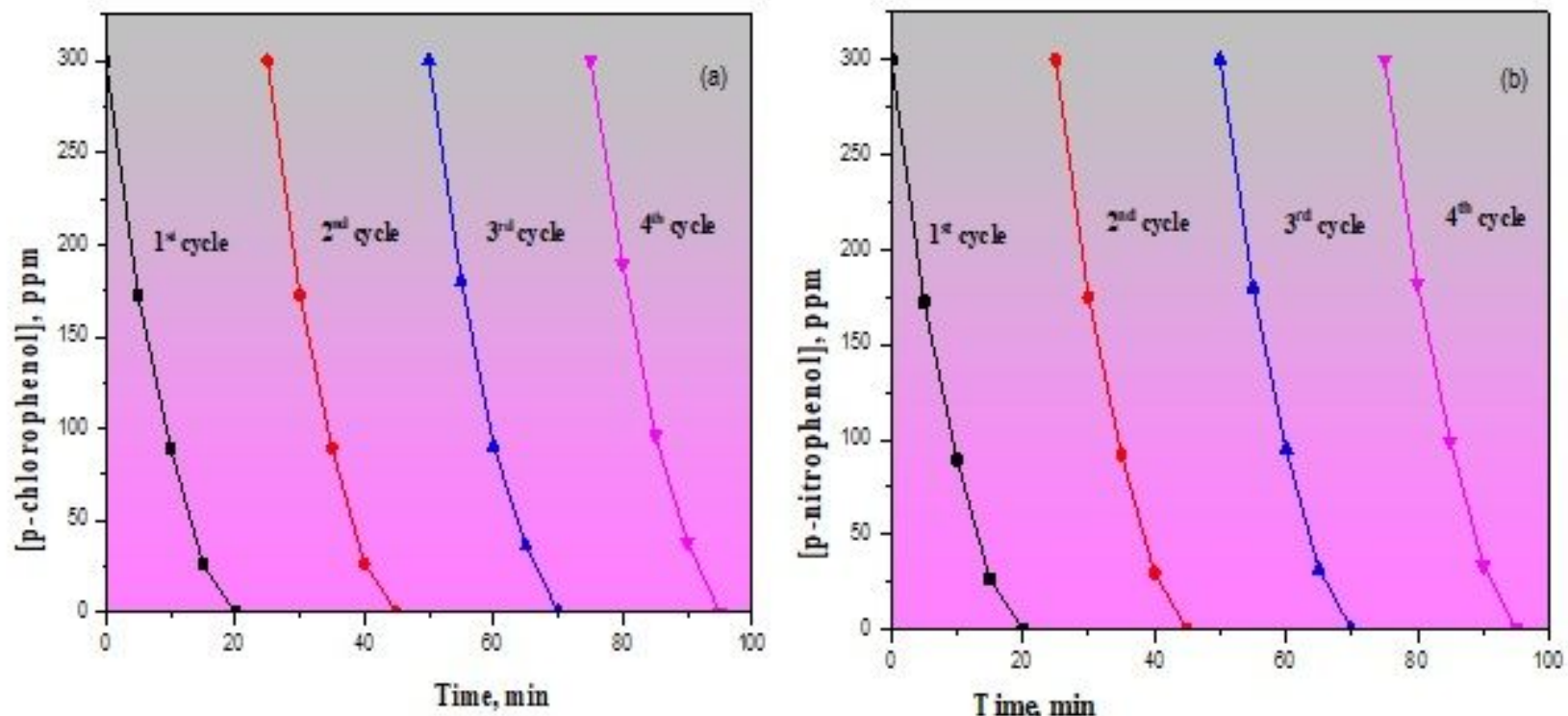

Figure 19

The recycling data for the photodegradation using 1\% Er-doped $\mathrm{ZnO}(\mathrm{S} 1$ ) of a) p-chlorophenol, b) pnitrophenol 